UNIVERSIDADE DE SÃO PAULO
FACULDADE DE ODONTOLOGIA DE RIBEIRÃO PRETO

ESTUDO IN VITRO DA ESTABILIDADE DE COR E OPACIDADE DE CINCO SISTEMAS CERÂMICOS SOB INFLUÊNCIA DO ENVELHECIMENTO ARTIFICIAL ACELERADO

LUCIANA DE PAULA RIBEIRO DOS SANTOS PORTO

Ribeirão Preto 


\section{ESTUDO IN VITRO DA ESTABILIDADE DE COR E OPACIDADE DE CINCO SISTEMAS CERÂMICOS SOB INFLUÊNCIA DO ENVELHECIMENTO ARTIFICIAL ACELERADO}

Tese apresentada à Comissão de PósGraduação da área de Reabilitação Oral da Faculdade de Odontologia de Ribeirão Preto da Universidade de São Paulo para a obtenção do título de doutor em Odontologia.

Orientadora: Prof $^{\mathrm{a}}$. Dr ${ }^{\mathrm{a}}$. REGINA MAURA FERNANDES

Ribeirão Preto 


\section{FICHA CATALOGRÁFICA}

Porto, Luciana de Paula Ribeiro dos Santos.

Estudo in vitro da estabilidade de cor e opacidade de cinco sistemas cerâmicos sob influência do envelhecimento artificial acelerado. Ribeirão Preto, 2007.

140p. il., 30cm.

Tese de Doutorado, apresentada à Faculdade de Odontologia de Ribeirão Preto/USP - Área de concentração: Reabilitação Oral.

Orientadora: Fernandes, Regina Maura.

1. Porcelana dental. 2. Envelhecimento artificial.

3. Espectrofotometria. 


\section{FOLHA DE APROVAÇÃO}

\section{Luciana de Paula Ribeiro dos Santos Porto}

ESTUDO IN VITRO DA ESTABILIDADE DE COR E OPACIDADE DE CINCO SISTEMAS CERÂMICOS SOB INFLUÊNCIA DO ENVELHECIMENTO ARTIFICIAL ACELERADO.

Tese apresentada à Comissão de PósGraduação da área de Reabilitação Oral da Faculdade de Odontologia de Ribeirão Preto da Universidade de São Paulo para a obtenção do título de doutor em Odontologia.

Ribeirão Preto /

Banca Examinadora

Prof. Dr.

Instituição

Assinatura

Prof. Dr.

Instituição

Assinatura

Prof. Dr.

Instituição

Assinatura

Prof. Dr. Instituição

Assinatura

Prof. Dr. 
Aos meus pais, Ulisses e Darci, pessoas que tanto admiro por me darem as mãos em qualquer caminho que eu percorra, pelo amor e estímulo fundamentais para atingir este objetivo.

Ao Manoel, meu amado marido e companheiro de lutas e aventuras. Sei que muitos foram os momentos difíceis pelos quais passamos nestes anos, mas o seu amor sempre me manteve forte e me tornou capaz de superar mais esta etapa de minha vida. Obrigado por estar ao meu lado.

Aos meus irmãos, Cristina e Guilherme, que mesmo fisicamente distantes, sempre me apoiaram durante todo este percurso.

Dedico este trabalho a vocês. 
AGRADECIMENTO ESPECIAL

À prof. Dra. Regina Maura Fernandes, orientadora e amiga, que me ensinou os caminhos da pesquisa científica e, pacientemente, me guiou durante o processo de confecção desta tese. Minha eterna gratidão. 


\section{AGRADECIMENTOS}

À Faculdade de Odontologia de Ribeirão Preto - USP, instituição que proporcionou todo meu aprendizado durante os cursos de graduação, especialização e pós-graduação.

Aos professores da pós-graduação da Faculdade de Odontologia de Ribeirão Preto - USP, pelos ensinamentos que tornaram possível este trabalho.

Ao coordenador da comissão de pós-graduação, prof. Dr. Osvaldo Luiz Bezzon, pelo apoio científico.

Ao prof. Dr. Osvaldo Zaniquelli, pela paciência e preciosa orientação na realização da análise estatística dos resultados obtidos neste estudo.

À prof. Dra. lara Augusta Orsi, pela orientação na técnica de redação desta tese.

À empresa Angelus, por disponibilizar o material Vitro-Ceram para esta pesquisa.

Ao Sr. Edson Volta, engenheiro e técnico do Laboratório Integrado de Pesquisa de Biocompatibilidade de Materiais (LIPEM), pela sempre disponibilidade de 
tempo, pelo apoio e auxílio durante o processo de envelhecimento e leitura dos corpos de prova.

Ao Sr. Paulo Sérgio Ferreira, técnico do Departamento de Materiais Dentários e Prótese da FORP - USP, pelos ensinamentos que me capacitaram à confecção dos corpos de prova.

Ao Sr. José de Godoi, técnico do Departamento de Materiais Dentários e Prótese da FORP - USP, pela fundição da infra-estrutura metálica utilizada nos corpos de prova metalocerâmicos.

Ao técnico do laboratório Odonto Prótese, Sr. Helci Ferreira Gilaverte, por esclarecer, pacientemente, todas as minhas dúvidas durante o processo de confecção dos corpos de prova.

Ao Sr. Domingos Faccioli, pela gentileza em ceder o aparelho Easyshade, utilizado neste trabalho.

Ao consultor técnico da Angelus em Ribeirão Preto, Sr. Paulo Eduardo Pereira Christóforo, pela confecção dos corpos de prova ceramo-cerâmicos.

À empresa Adexim-Comexim, pelo pronto esclarecimento de dúvidas com relação à máquina de ensaio de envelhecimento artificial acelerado. 
Ao consultor técnico da Vita, Sr. Marc Lindner, por disponibilizar os conhecimentos técnicos sobre o aparelho Easyshade.

Às funcionárias da pós-graduação Regiane de Cássia Tirado Damasceno, Isabel Cristina Galino Sola e Regiane Cristina Moi Saciloto, pelo auxílio e dedicação.

À Oficina de Precisão Mecânica do campus da USP - Ribeirão Preto, pela confecção da matriz de teflon utilizada neste trabalho.

A todos os professores, técnicos, funcionários, colegas e amigos, que de alguma forma contribuíram com a elaboração deste trabalho. Que a omissão de nomes não atenue meus agradecimentos. 
"Aprender é mudar"

Sidharta (Primeiro Buda)

"De tudo ficaram três coisas: a certeza de que estamos sempre a começar, a certeza de que é preciso continuar,

e a certeza de que seremos interrompidos antes de terminar.

Portanto devemos fazer da interrupção um caminho novo, da queda um passo de dança,

do medo uma escada,

do sonho uma ponte,

da procura um encontro."

Fernando Sabino. 


\section{RESUMO}

O objetivo deste estudo foi avaliar a estabilidade de cor e opacidade de cinco sistemas cerâmicos glazeados naturalmente e com pintura extrínseca, utilizando os espectrofotômetros Color Guide 45/0 (BYK-Gardner) e Easyshade (Vita), sob influência do envelhecimento artificial acelerado. Foram confeccionados 14 corpos de prova para cada grupo testado de cerâmica metalocerâmica Ceramco 3 (Dentsply) (grupo 1), cerâmica pura Ceramco 3 (grupo 2), cerâmica pura EX -3 (Noritake) (grupo 3), Vitroceram (Angelus) recoberta com Allceram (Degudent) (grupo 4) e Vitroceram recoberta com Cerabien (Noritake) (grupo 5). Sete corpos de prova de cada grupo cerâmico foram glazeados naturalmente e sete foram submetidos à pintura extrínseca com pigmento Vita Chrom 712. Uma leitura inicial foi realizada em todos os corpos de prova utilizando o espectrofotômetro Color Guide, obtendo valores de opacidade e das coordenadas $L^{*}, a^{*}, b^{*}$ e $\Delta E^{*} ;$ e utilizando o espectrofotômetro Easyshade, obtendo valores de $\Delta \mathrm{L}^{*}, \Delta \mathrm{C}^{*}, \Delta \mathrm{h}^{*} \mathrm{e} \Delta \mathrm{E}^{*}$. Após o envelhecimento artificial de $500 \mathrm{~h}$, foram realizadas novas leituras nos espectrofotômetros.

Os resultados encontrados foram submetidos à análise estatística e concluiu-se que os grupos 2, 3 e 4 foram influenciados estatisticamente pelo envelhecimento artificial acelerado quanto à opacidade; e que o grupo 5 foi o que obteve o pior desempenho de estabilidade de cor $\left(\Delta \mathrm{E}^{*}=3,32-\right.$ VTCE e $\Delta \mathrm{E}^{*}=2,68$ - VTCEPE) para o espectrofotômetro Color Guide. Com o espectrofotômetro Easyshade os grupos 4 e 5 e as cerâmicas MC, CER, EX foram considerados ineficazes quanto à estabilidade de cor $(p<0,05)$. 


\section{ABSTRACT}

The aim of this study was to evaluate the color stability and opacity of five ceramic systems naturally glazed and with extrinsic porcelain colorant, under influence of accelerated aging, using two spectrophotometers Color Guide 45/0 (BYK-Gardner) and Easyshade (Vita) as a tool for color and opacity measurement. Fourteen samples were provided for each tested group of ceramics: metal-ceramic Ceramco3 (Dentsply) (Group 1), Ceramco3 (Group 2), EX3 (Noritake) (Group 3), Vitroceram (Angelus) with Allceram (Degudent) (Group 4) and Vitroceram with Cerabien (Noritake) (Group 5). Seven samples of each group were submitted to extrinsic colorant (Vita Chrom 712) and the other seven were naturally glazed. An initial measurement was performed and the values of opacity, $L^{*}, a^{*}, b^{*}$ and $\Delta E^{*}$ were obtained using the Color Guide spectrophotometer, and using Easyshade the values of $\Delta \mathrm{L}^{*}, \Delta \mathrm{C}^{*}, \Delta \mathrm{h}^{*}$ and $\Delta \mathrm{E}^{*}$ were obtained. After the process of $500 \mathrm{~h}$ accelerated aging a new measurement was performed for all samples.

The results were statistically analyzed and the conclusion was that the opacity of groups 2, 3 and 4 were statistically influenced by the accelerated aging and the group 5 had the worst assessment in color stability $\left(\Delta \mathrm{E}^{*}=3,32-\right.$ VTCE e $\Delta E^{*}=2,68-$ VTCEPE) with the Color Guide spectrophotometer. With Easyshade, groups 4 and 5 and MC, CER and EX ceramics were considered ineffective as for color stability $(p<0,05)$. 


\section{SUMÁRIO}

RESUMO

ABSTRACT

1. INTRODUÇÃo.

2. REVISÃO DE LITERATURA ...................................................................5

2.1. Cerâmica..................................................................................6

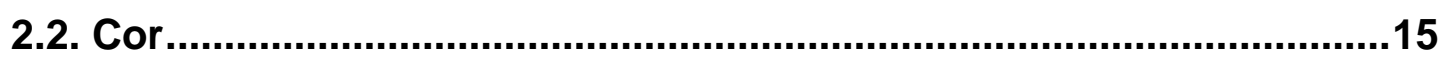

2.2.1. Definição e Teorias ........................................................... 15

2.2.2. Sistemas de Classificação ................................................ 19

2.2.3. Equipamentos para medição de cor .....................................24

2.3. Cerâmica x Cor.................................................................................28

2.3.1. Espectrofotometria em Odontologia ....................................28

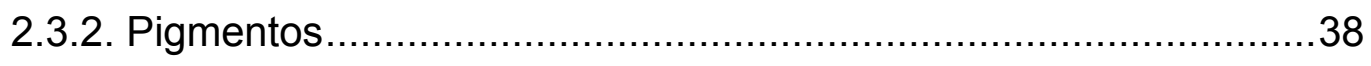

3. PROPOSIÇÃO ........................................................................................44

4. MATERIAL E MÉTODO........................................................................46

4.1. Obtenção dos corpos de prova ........................................................47

4.1.1. Técnica de obtenção dos corpos de prova metalocerâmicos em cerâmica Ceramco 3 - Grupo 1 ...................................49

4.1.2. Técnica de obtenção dos corpos de prova totalmente cerâmicos em cerâmica Ceramco 3 - Grupo 2 .........................54

4.1.3. Técnica de obtenção dos corpos de prova totalmente cerâmicos em cerâmica EX-3 - Grupo 3.

4.1.4. Técnica de obtenção dos corpos de prova sistema ceramocerâmico Vitroceram recobertos com Allceram - Grupo 4.

4.1.5. Técnica de obtenção dos corpos de prova sistema ceramocerâmico Vitroceram recobertos com Cerabien - Grupo 5. 
4.2. Leitura dos corpos de prova com espectrofotômetro Color Guide 45/0 (BYK Gardner). .........................................................66

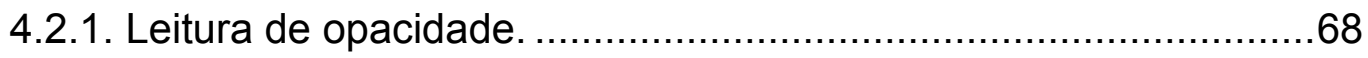

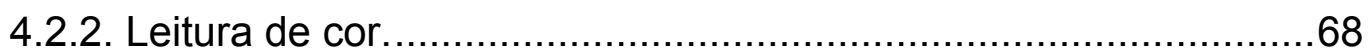

4.3. Leitura dos corpos de prova com espectrofotômetro Easyshade

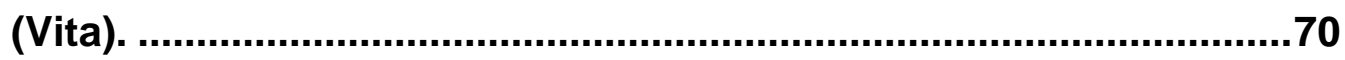

4.4. Ensaio de envelhecimento artificial acelerado...................................74

5. RESULTADOS E DISCUSSÃO

5.1. Espectrofotômetro Color Guide 45/0 (BYK Gardner)........................78

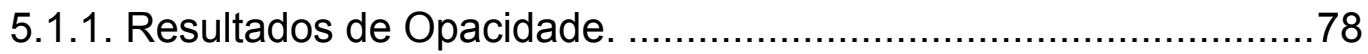

5.1.2. Resultados de leitura da coordenada $L^{*}$...................................... 83

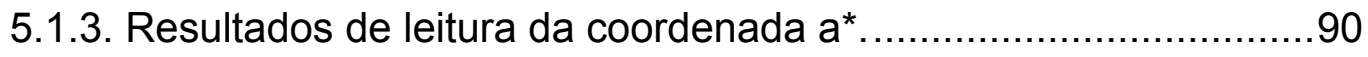

5.1.4. Resultados de leitura da coordenada $b^{*}$.....................................95

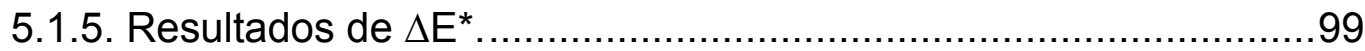

5.2. Espectrofotômetro Easyshade (Vita). ...........................................106

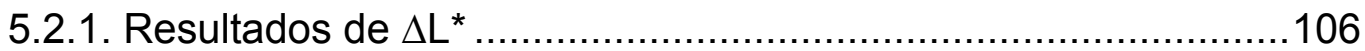

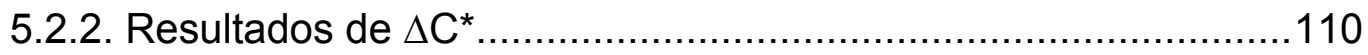

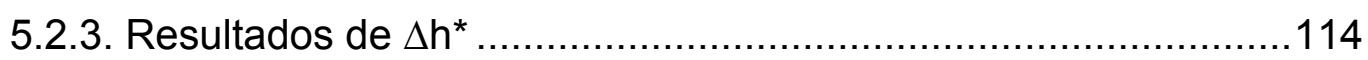

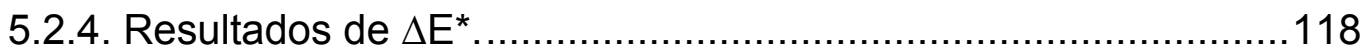

6. CONCLUSÕES

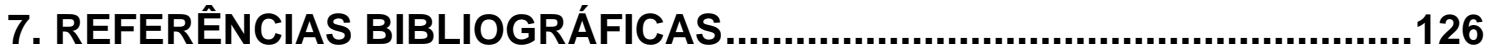

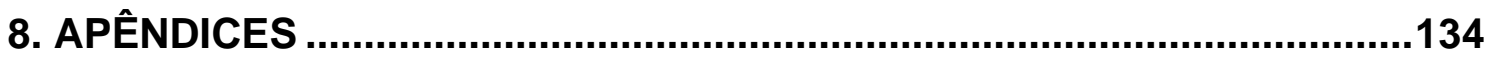


1. INTRODUÇÃO 
Os profissionais em Odontologia preocupam-se, há tempos, em assemelhar a aparência das restaurações com os dentes naturais dos pacientes. O diagnóstico da cor de um elemento dentário e a correta escolha da cor do material utilizado em uma restauração estética vem sendo uma das maiores dificuldades encontrada pelos profissionais da odontologia, pois a cor é a mais subjetiva das características de um procedimento restaurador. Diferentemente da forma, tamanho, proporção e textura, a cor depende não apenas da técnica do profissional, mas de uma série de fatores. É comum até os mais conceituados profissionais do mundo errarem na escolha ou na finalização estética da cor de uma restauração odontológica.

Dentre os materiais restauradores odontológicos, a cerâmica é aquele que melhor reproduz as propriedades ópticas do esmalte e da dentina, como fluorescência, opalescência e translucidez (MENDES et al., 2007).

As cerâmicas são altamente estéticas e capazes de reproduzir a maior parte das características dos dentes naturais. Ao longo das últimas décadas as cerâmicas odontológicas foram sendo modificadas com o objetivo de melhorar suas propriedades físicas e ópticas como diminuir o ponto de fusão, modificar os coeficientes de expansão e contração, e propiciar cor, opacidade, opalescência e translucidez mais semelhantes aos dentes naturais (KELLY, 2004).

Surgiu assim uma grande diversidade de sistemas cerâmicos, tanto metalocerâmicos como, mais recentemente, os ceramo-cerâmicos, ou seja, sistemas cerâmicos livres de metal. Estes últimos representam uma ótima alternativa para a execução de restaurações tanto em dentes anteriores como posteriores. No entanto, a escolha por um destes sistemas é difícil e deve-se a 
uma criteriosa análise de vários aspectos como resistência, grau de adaptação marginal entre dente e restauração e estabilidade de cor (PORTO, 2003).

As restaurações totalmente cerâmicas, sem substrato metálico, permitem uma maior transmissão de luz, melhorando a cor e a translucidez da restauração, mas ainda assim a perfeição estética não pode ser assegurada, já que apesar da maior translucidez do copping cerâmico, o alto conteúdo cristalino necessário para dar resistência geralmente resulta em grande opacidade (BARATH et al. 2003).

Mesmo nos sistemas ceramo-cerâmicos, a estética das restaurações protéticas é considerada satisfatória por apenas 59\% dos dentistas que as confeccionaram e por $92 \%$ dos usuários, ou seja, mesmo utilizando um sistema considerado altamente estético, as limitações do próprio profissional, do técnico de laboratório e do caso em si, são capazes de se sobrepor ao objetivo inicial (ODMAN, ANDERSSON, 2001).

Como é difícil alcançar um resultado estético excelente, muitas vezes os técnicos em prótese lançam mão de pigmentos para pintura extrínseca de restaurações cerâmicas, na tentativa de se corrigir a cor destas restaurações. Os pigmentos para pintura extrínseca são também muito utilizados nos sistemas metalocerâmicos com o mesmo propósito.

A tecnologia é outro fator que pode ajudar na obtenção da cor mais exata de uma cerâmica quando comparada ao dente natural, através do uso de espectrofotômetros desenvolvidos para descrever matematicamente a percepção de uma determinada cor, ajudando a padronizar a reprodução desta, mesmo com os desvios previstos entre cada observador humano. 
Este estudo tem como objetivo avaliar, por meio de dois diferentes espectrofotômetros a opacidade e a estabilidade de cor de cerâmicas odontológicas feldspáticas reforçada por metal, pura e aplicada sobre infraestrutura reforçada por alumina, glazeadas naturalmente e com pintura extrínseca, submetidas ao envelhecimento artificial acelerado. 
2. REVISÃO DE LITERATURA 


\subsection{Cerâmica}

Historicamente a cerâmica é o material estético mais utilizado para repor dentes perdidos ou parte dele. Já em 1886, Land (1903) introduziu a primeira coroa totalmente estética, que foi confeccionada com um tipo de cerâmica feldspática sobre uma lâmina de platina e possuía baixa resistência e uso clínico limitado. Mas, apesar destas limitações, foi durante décadas a restauração mais estética que a odontologia podia oferecer.

Em 1932, Felcher descreveu a composição básica da porcelana odontológica usada até então (sílica, caulim e feldspato), suas propriedades, assim como as dificuldades técnicas encontradas, que iam desde porosidade excessiva até problemas durante a sinterização destas cerâmicas e comparouas com as usadas industrialmente para manufatura de outros materiais como pratos, copos, vasos entre outros.

Até 1938 as cerâmicas dentais eram relativamente opacas e brancas. Nesta época, Elias Wildeman formulou um material mais translúcido com cores que se aproximavam mais dos dentes naturais (CLARK, 1939).

Através dos anos, houve um desenvolvimento continuado deste material, e em 1956 buscou-se uma associação das cerâmicas com certas ligas de ouro, combinando a resistência dessas ligas com a estética da porcelana, dando origem às restaurações metalocerâmicas (BRECKER, 1956).

A fragilidade das cerâmicas usadas em odontologia foi responsável por vários estudos, entre eles o de Hodson (1959), que relatou que os materiais com boa resistência mecânica são geralmente cristalinos na sua estrutura e opacos. As cerâmicas dentais, que por sua vez são translúcidas o suficiente 
para simular o esmalte dental, são constituídas basicamente por vidro em sua estrutura e conseqüentemente possuem as propriedades físicas mais compatíveis com o vidro, explicando a dificuldade para encontrar um material com boas propriedades físicas e estéticas.

Ainda nos anos 50, Vines e Semmelman (1957) idealizaram uma técnica para sinterização de cerâmica sob vácuo, que foi um marco no aprimoramento das cerâmicas tanto na estética quanto na resistência, pois o processo de sinterização a vácuo reduz o número e o tamanho das bolhas de ar existentes entre as partículas de cerâmica.

$\mathrm{Na}$ década de 60 , percebeu-se que a base de metal das metalocerâmicas afetava a estética pela diminuição da transmissão de luz através da porcelana e Mc Lean (1965), procurando então desenvolver uma cerâmica mais resistente sem prejudicar a estética, incluiu alumina ( $\left.\mathrm{Al}_{2} \mathrm{O}_{3}\right)$ em sua composição. A cerâmica assim obtida, embora $80 \%$ mais resistente, ainda tinha o inconveniente de ser acentuadamente antiestética e por isso foi empregada para a confecção de núcleo cerâmico, sendo posteriormente recoberto com uma cerâmica feldspática, melhorando a estética do trabalho (Mc LEAN, 1996).

Apesar dos fatores desfavoráveis, como a necessidade de desgaste dental acentuado e estética diminuída, as restaurações metalocerâmicas tornaram-se mais populares, embora o emprego das coroas de cerâmica pura tenha continuado. Segundo Jones (1971), o renascimento do uso da cerâmica em odontologia a partir de 1950 se deve a alguns fatores como: a melhora nos preparos cavitários devido ao uso de alta rotação para corte com brocas de diamante e carbide, a introdução de melhores materiais de moldagens como 
polissulfetos e siliconas, o desenvolvimento e uso de vácuo durante a sinterização, o desenvolvimento de novas ligas para técnica de fusão porcelana-metal, e o desenvolvimento de uma nova cerâmica reforçada por alumina.

É importante salientar também que o primeiro tipo de cerâmica encontrada data aproximadamente de 5.000 anos a.C. e era uma louça de argila crua. Com o tempo, elas passaram a ser queimadas no fogo e outros materiais foram adicionados. Mais tarde foram encontradas na China, em 100 a.C. peças queimadas até altas temperaturas e que se apresentavam mais fortes e impermeáveis. Em 1000 d.C., também na China, encontrou-se porcelanas desenvolvidas de argila branca sob altas temperaturas que resultavam em finas louças. A sua utilização como material odontológico se iniciou a cerca de trezentos anos, sendo a primeira tentativa de utilização na odontologia atribuída a Fauchard em 1728, porém há um desacordo de pesquisadores sobre este fato. Em 1774, o farmacêutico francês Aléxis Duchateu percebeu que os dentes de hipopótamo de sua prótese total apresentavam porosidades que absorviam facilmente os fluidos bucais, gerando odor, manchas, gosto e desconforto. Ele observou que os utensílios que usava para moer materiais químicos resistiam ao manchamento, e iniciou então a confecção de várias dentaduras com porcelana. As primeiras tentativas foram desapontadoras, assim associou-se ao dentista Nicholas Dubois de Chemant para juntos modificarem a composição da porcelana de alta fusão, baixando apreciavelmente sua temperatura de queima, obtendo sucesso na confecção da prótese total. De Chemant recebeu a patente de inventor da cerâmica odontológica, sendo acusado de usar a invenção de Duchateu. Entre 
1800 e 1900, as cerâmicas foram bastante estudadas e empregadas em odontologia, principalmente na manufatura de dentes artificiais para próteses totais, e alterações na sua composição foram realizadas com o intuito de diminuir seu ponto de fusão (SPROULL, 1978).

A translucidez, a transmissão de luz e a biocompatibilidade proporcionam às cerâmicas dentais uma excelente propriedade estética e biológica, por outro lado, devido à sua composição, basicamente vidros não cristalinos compostos de unidades estruturais de sílica e oxigênio (SiO4), a friabilidade torna-se uma propriedade inerente ao material. Assim são adicionados óxidos de potássio, sódio, e cálcio à sua estrutura, para se tentar obter as propriedades necessárias para seu uso em odontologia: baixa temperatura de fusão, alta viscosidade e resistência a desvitrificação (SHILLINGBURG et al., 1998).

Entretanto, a adição dessas substâncias está limitada a uma porcentagem de $22 \%$ a $25 \%$, acima disto, as cerâmicas perdem sua resistência química, sendo desintegradas pela água. Nesta porcentagem o material fica com uma expansão térmica de $11-12 \mu \mathrm{m} / \mathrm{mm} /{ }^{\circ} \mathrm{C}$ e temperatura de fusão em $800^{\circ} \mathrm{C}(\mathrm{KOMMA}, 1993)$

O aumento na procura de restaurações mais estéticas estimulou o desenvolvimento de restaurações não metálicas para dentes posteriores e restaurações cerâmicas mais resistentes para dentes anteriores. Com isto, nos últimos anos, foi introduzida no mercado, uma grande variedade de cerâmicas dentais, com melhores qualidades de adaptação, resistência física e estética livre de metal (TIDEHAG; GUNNE, 1995). 
Segundo Baratieri et al. (2001) e Chaim et al. (2002), os sistemas cerâmicos atuais podem ser classificados da seguinte maneira:

-Cerâmicas feldspáticas

A cerâmica feldspática foi a primeira a ser utilizada na confecção de peças protéticas, constituindo-se basicamente de: feldspato (78 a 85\%), quartzo (12 a 22\%), e caulim (3 a 4\%). O feldspato é um mineral existente na natureza, composto de potassa (K2O), alumina (AI2O3) e sílica (SiO4). Uma propriedade importante do feldspato é sua tendência de formar, quando fundido, um mineral cristalino conhecido por leucita e a presença desta é mais importante na fabricação da cerâmica para serem fundidas sobre o metal. $\mathrm{O}$ processo de obtenção de uma cerâmica feldspática ou convencional ocorre da seguinte maneira: os componentes selecionados pelos fabricantes são homogeneizados por um processo de fundição em fornos especiais, em altas temperaturas, de $1200^{\circ} \mathrm{C}$ a $1250^{\circ} \mathrm{C}$, quando a condição de equilíbrio ocorre pela fusão dos componentes. A fim de facilitar a pulverização da massa obtida, esta é introduzida em água fria, ainda aquecida, para provocar o seu desequilíbrio térmico e conseqüente fragmentação. Este tratamento é identificado como pré-fusão, tecnicamente denominado fritted, e apresenta a vantagem da diminuição da temperatura de trabalho subseqüente, uma vez que a maior parte das reações térmicas já ocorreu durante a fundição dos componentes (PHILLIPS, 1984).

O pó de porcelana obtido é aglutinado por um líquido especial ou mesmo água destilada, e então, esculpido em camadas sobre um troquel refratário, uma lâmina de platina ou uma liga metálica e durante a sinterização 
de cada incremento forma-se um vidro e a leucita. Esta matriz vítrea engloba os cristais de quartzo, que permanecem praticamente inalterados. O caulim tem a função de conferir opacidade à porcelana e ligar seus componentes, ou seja, servir de aglutinante, principalmente antes de a cerâmica ser levada ao forno. Estruturalmente, este processo produz duas fases distintas: a cristalina e a vítrea. A fase cristalina é composta por quartzo, leucita e pigmentos corantes, que são adicionados à cerâmica com o objetivo de reproduzir as cores originais dos dentes naturais e a fase vítrea é formada basicamente pelo feldspato e traduz as características de um vidro. As cerâmicas feldspáticas podem ser empregadas para confeccionar coroas metalocerâmicas, facetas de porcelana, coroas puras de porcelana, inlays e onlays. Assim sendo, elas podem ser utilizadas isoladamente ou associadas a outros sistemas, nos quais a porcelana feldspática recobre um copping metálico - exemplos de marcas comerciais: Ceramco 3 (Dentsply) e EX3 (Noritake), ou recobre uma porcelana aluminizada infiltrada por vidro como os sistemas In-Ceram (Vita) ou Vitroceram (Angelus) - exemplos de marcas comerciais: Cerabien (Noritake) e Allceram (Degudent), o que lhe confere maior resistência à fratura. As principais vantagens da porcelana feldspática são: excelente resultado estético, não necessita equipamento especial, custo, possibilidade de usar camadas delgadas, bom embasamento científico. Como desvantagens podem-se citar: friabilidade, baixa resistência e grande poder abrasivo sobre dentes antagonistas (BARATIERI et al., 2001). 
-Vidros ceramizados fundidos

Representado pelo sistema Dicor, emprega a técnica da cera perdida. Sobre um troquel procede-se o enceramento, com a posterior escultura e inclusão do padrão. A cera é removida e um vidro na forma de lingote é fundido no revestimento por uma centrífuga especial. A peça é então desincluída e novamente incluída para sofrer o processo de ceramização, sendo a cristalização dirigida por aumento térmico, aumentando a resistência do material por esses cristais formados. São empregados para confecção de facetas, coroas totais unitárias, inlays e onlays (BARATIERI et al., 2001).

\section{-Vidros ceramizados injetados}

Representado pelo sistema IPS Empress (com leucita) e IPS Empress 2 (dissilicato de lítio) (Ivoclar), emprega a técnica da cera perdida onde pastilhas de vidro pré-ceramizados da cor desejada, são fundidas e injetadas a vácuo, sob pressão hidrostática, permitindo uma ótima adaptação marginal e uma cerâmica menos dura, desgastando menos o dente antagonista. A técnica tem a limitação de confeccionar restaurações monocromáticas, pois as pastilhas possuem uma só cor. Este sistema permite a confecção de inlays, onlays, overlays, coroas unitárias e próteses fixas de três elementos (BARATIERI et al., 2001).

-Vidros ceramizados usinados sistemas CAD-CAM (computer assisted design, computer assisted machine)

Este sistema utiliza pequenos blocos de vidro ceramizados e préprensados, desgastados por discos ou outros instrumentos, até as dimensões 
obtidas por uma imagem escaneada do preparo. As desvantagens das restaurações CAD-CAM incluem a necessidade de um equipamento de alto custo, estética pobre devido à falha na cor, adaptação e escultura. Como vantagens, o sistema dispensa o uso de material de moldagem, técnico de laboratório e reduzido número de sessões clínicas (BARATIERI et al., 2001).

-Cerâmica aluminizada infiltrada com vidro Sistema Procera Allceram (Nobel Biocare)

Consiste em um copping cerâmico com aproximadamente 99\% de óxido de alumínio. A peça protética é fabricada a partir do sistema CAD-CAM. O troquel de gesso é escaneado, sendo essa apresentação numérica do modelo transmitida via modem para um laboratório especializado na Suíça e o copping é usinado com excelente ajuste marginal. O sistema oferece excelente estética, resistência e durabilidade. As indicações são coroas unitárias anteriores e posteriores, prótese fixa de três elementos e facetas laminadas (BARATIERI et al., 2001).

-Cerâmica aluminizada infiltrada com vidro Sistema In-Ceram (Vita)

Desenvolvido pelo Dr. Mickail Sadoun em 1989, este sistema está disponível em três formas diferentes: In-Ceram Alumina, In-Ceram Spinell e InCeram Zircônia. O primeiro a ser desenvolvido foi o In-Ceram Alumina, onde uma massa de óxido de alumínio é aplicada sobre um troquel refratário e sinterizada por 2 horas a $1120^{\circ} \mathrm{C}$. Após a sinterização, este coping de alumina, que é extremamente poroso, sofre uma aplicação de infiltrado de vidro e é levado ao forno por mais 4 horas à $1400^{\circ} \mathrm{C}$, o que confere à estrutura um alto 
teor de dureza. Para reproduzir a forma final da restauração aplica-se uma cerâmica de cobertura que devem apresentar propriedades de refração e reflexão de luz semelhante ao esmalte dos dentes naturais. Além disso, a utilização de cerâmicas fluorescentes e opalescentes torna possível a confecção de restaurações com excelente resultado estético. Uma característica fundamental, relacionada às propriedades das cerâmicas de recobrimento, é o coeficiente de expansão térmico, que deve ser ligeiramente inferior ao do material da infra-estrutura. São indicadas para coroas anteriores e posteriores, inlays, onlays e próteses fixas de três elementos (BOTTINO et al, 2006).

A cerâmica aluminizada infiltrada com vidro foi criada como uma alternativa às restaurações com infra-estrutura metálica. No Brasil, o sistema Vitro-Ceram, desenvolvido pela Angelus, baseia-se nos mesmos princípios do In-Ceram Alumina e foi desenvolvido como uma nova opção para a confecção de infra-estruturas aluminizadas (MALLMANN, 2007).

O segundo sistema disponibilizado foi o In-Ceram Spinell, que está no mercado desde 1993 e é baseado no espinélio de magnésio e nos óxidos de alumínio. As propriedades estéticas deste material são superiores à In Ceram e In Ceram Zircônio, porém há uma diminuição de 30\% nas propriedades físicas. Indicado para inlays, onlays e coroas totais anteriores.

O terceiro sistema é o In-Ceram Zircônio. Disponível a partir de 1999, esta cerâmica contém $33 \%$ de zircônio e apresenta propriedades estéticas inferiores aos outros 2 sistemas e propriedades físicas superiores. É indicada para coroa total anterior e posterior, prótese parcial fixa de três elementos, inlays e onlays. 


\subsection{Cor}

\subsubsection{Definição e Teorias}

A cor de um objeto depende da composição espectral da luz incidente sobre ele, da refletância ou da transmitância do objeto, da resposta do observador e da geometria óptica de visualização, ou seja, a cor pode ser definida como sendo o resultado da interação entre três elementos distintos: o foco de luz, o objeto iluminado e o observador. Portanto, nós como observadores, também fazemos parte da cor (SALESKI, 1972; LAND, 1977).

O fenômeno da cor foi uma enorme incógnita por centenas de anos. Apenas com a descoberta de Isaac Newton (1643-1727) sobre a luz como fonte de todas as cores é que a análise científica da cor começou. Newton descobriu que a luz poderia se dividir em muitas cores, através de um prisma, fenômeno da dispersão da luz, e usou esse conceito experimental para analisar a luz. (HEGENBARTH, 1992).

Em 1672, Newton apresentou uma teoria conhecida como modelo corpuscular da luz. Nesta teoria, a luz era considerada como um feixe de partículas emitidas por uma fonte de luz que atingia o olho estimulando a visão. Posteriormente, na segunda metade do século XIX, James Clerk Maxwell, através da sua teoria de ondas eletromagnéticas, provou que a velocidade com que a onda eletromagnética se propagava no espaço era igual à velocidade da luz, estabelecendo teoricamente que a luz é uma modalidade de energia radiante que se propaga através de ondas eletromagnéticas. Atualmente se aceita o fato de que a luz tem caráter dual: os fenômenos de reflexão, refração, 
interferência, difração e polarização da luz podem ser explicados pela teoria ondulatória e os de emissão e absorção podem ser explicados pela teoria corpuscular (CARVALHO, 2005).

A luz se propaga através de ondas eletromagnéticas e o olho humano é sensível à radiação eletromagnética na faixa de 400 a 700 nanômetros, chamada espectro visível, dentro da qual estão localizadas as chamadas sete cores visíveis, distinguidas por seus respectivos comprimentos de onda em nanômetros: violeta 380-450, azul 450-480, ciano 480-490, verde 490-560, amarelo 560-580, laranja 580-600 e vermelho 600-700. A percepção da luz pelo ser humano ocorre através da incidência de um raio luminoso sobre seu olho. Este raio penetra até à retina, localizada no fundo do olho, que é responsável pela conversão desta energia luminosa em sinais elétricos que são transmitidos através do nervo ótico para o cérebro, que os interpreta. A retina é composta de mais de 100 milhões de células, cada uma responsável pela conversão de uma porção do estímulo luminoso. Estas células são divididas em dois grupos: 1)cones - sensíveis a alto nível de iluminação e responsáveis pela percepção das cores; 2)bastonetes - sensíveis a baixo nível de iluminação e distinguem os tons de cinza. Os cones estão concentrados no centro da retina (fóvea) e os bastonetes em sua parte externa, na periferia da retina. No fundo do olho, correspondendo à parte central, há uma interrupção de cones e bastonetes, em uma localização denominada ponto cego, onde está situado o nervo óptico (WERNER, 1998).

Durante séculos, os problemas relacionados com a visão das cores não encontraram mais que soluções e interpretações puramente empíricas. Foi somente por volta de 1801, que o físico e médico inglês Thomas Young 
formulou, em termos de hipótese, a primeira explicação científica para a sensibilidade do olho humano às cores. Cerca de cinqüenta anos mais tarde, Hermann Von Helmholtz, físico e fisiologista alemão, se encarregaria de desenvolver essa hipótese e convertê-la em teoria, que se tomou universalmente aceita. A teoria de Young-Helmholtz propôs que o olho humano continha três tipos de receptores de cor, que respondiam mais fortemente aos comprimentos de onda vermelho (Longo-L), verde (Médio-M) e azul (Curto-S). Estas seriam as cores primárias fisiológicas, que, por combinações, originariam todos os outros tons cromáticos. A teoria deduziu, ainda, que cada tipo de receptor devia possuir grande sensibilidade à incidência luminosa, porém, com diferentes pontos máximos. A percepção da cor, portanto, seria determinada pela média das três respostas. No entanto, a teoria tri cromática não conseguia explicar a variedade de fenômenos cromáticos encontrados na natureza. Em particular, ela falhava ao explicar por que certas combinações de cores cancelavam uma às outras e por que com outras combinações isso não ocorria. Assim, o fisiologista alemão Ewald Hering, em 1878, propôs a teoria da oponência das cores, que sugeria a existência de três canais de cores oponentes, mutuamente inibitórios: vermelho-verde, azul-amarelo e brancopreto (WERNER, 1998; BRUNI; CRUZ, 2006).

De acordo com a teoria de cores de Hering, a percepção da cor dependeria de três pares opostos de fotorreceptores: verde-vermelho, amareloazul e branco-preto. Cada par de fotorreceptores seria sensível a todos os comprimentos de onda físicos, embora o grau de sensibilidade fosse máximo para o comprimento de onda específico de cada par. A força desta teoria é baseada no pressuposto da ativação de um membro de cada par; assim, a 
luz amarela não só ativaria os fotorreceptores para o amarelo, mas ao mesmo tempo inibiria a percepção do azul. Esta teoria explica satisfatoriamente bem alguns fenômenos conhecidos, como a mistura e o contraste das cores e as pós-imagens negativas. Essas duas teorias, Young-Helmholtz e Hering, formaram a base do entendimento da visão das cores. Desde então, o estudo da sensibilidade cromática vem crescendo ao longo dos anos, com descobertas e avanços importantes (WERNER, 1998; BRUNI; CRUZ, 2006).

A percepção da cor é uma resposta psicofísica ao estímulo luminoso e altera de observador para observador, isto é, a percepção da cor é resultante das respostas fisiológicas e psicológicas ao estímulo da energia radiante e qualquer alteração destas respostas, como fadiga, envelhecimento, emoções, condições de iluminação, metamerismo, exposição prévia, posição objeto/iluminação ou outros fatores não controlados, comprometem o resultado. Apesar destas limitações, o olho humano é um detector fantástico e insuperável na identificação de diferenças de cor entre dois objetos. A percepção da cor e a aceitação da diferença de cor detectada podem variar consideravelmente de observador para observador e mesmo no mesmo observador, com o passar do tempo. O grande problema é a comunicação da diferença de cor entre objetos; relatar sua magnitude e natureza é um trabalho complexo, limitado e subjetivo (SEGHI et al., 1989b). 


\subsubsection{Sistemas de Classificação}

A comunicação da cor é uma preocupação antiga e na tentativa de minimizar os problemas decorrentes desta comunicação foram criados inúmeros sistema de cor. Para que tenhamos um método objetivo de avaliação de diferenças de cores em pesquisas é necessário um sistema de classificação ordenado de cor e equipamentos capazes de quantificar estas diferenças (ESQUIVEL et al., 1995).

Em um experimento com cores podemos especificar a cor em termos físicos ou de percepção. A cor física é estudada pela ciência chamada espectrofotometria, a cor percebida, pela colorimetria (MOLLON, 1998).

Albert Munsell, um pintor norte-americano, propôs em 1905, um sistema que é considerado o melhor sistema baseado em princípios perceptuais. Este sistema, também conhecido como sistema HSV, é uma coleção de amostras pintadas, criadas para representar intervalos iguais de percepção visual entre amostras adjacentes, que são apresentadas em termos de três coordenadas (hue, saturation and value), onde:

- $\mathrm{H}($ hue) - Matiz: freqüentemente usado para definir a cor, ou seja, azul, amarela, vermelha. É o comprimento de luz observado.

- S (saturation) - Croma: grau de pureza da cor, medida da intensidade do matiz, ou ainda, o seu grau de saturação. Ex.: azul claro, azul médio e azul escuro.

- V (value) - Valor: é uma propriedade acromática, ou seja, existe com a ausência de qualquer matiz. É a variação de brilho que um matiz apresenta, é a sua luminosidade. Refere-se diretamente a reflexão da luz, sendo responsável 
pelo aspecto de vitalidade da estrutura dental e está diretamente relacionada com o grau de opacidade, de translucidez e transparência de uma estrutura, sendo considerada a característica mais importante na escolha da cor (SPROULL, 1973; HEGENBARTH, 1992; MOLLON, 1998; ADOLFI, 2002; MAGNE, URS, 2003; MENDES, 2007).

Este sistema, apesar de não ser muito indicado para ser utilizado em pesquisas, é o mais utilizado para a escolha da cor de uma restauração odontológica. O sistema mais comumente utilizado para classificação de cor em pesquisas foi desenvolvido pela CIE - Commission Internacionale de I'Eclairage (Comissão Internacional de lluminação) em 1976 (WEE et al., 2002; DOUGLAS, BREWER, 2003; KOURTIS, 2004; ERTAN, SAIIIN, 2004; SHOKRY et al., 2006; HASSEL et al., 2007).

A CIE é uma organização voltada para cooperação internacional e troca de informações entre seus países membros sobre todas as disciplinas relacionadas à ciência e arte da luz. É uma comissão técnica, científica e cultural, sem fins lucrativos; desenvolvida há 90 anos e aceita como a melhor representante mundial sobre iluminação e cor. A CIE padronizou matematicamente as cores, apresentando-as em gráficos, sendo o CIE-RGB, criado em 1931, onde $\mathrm{R}=$ red, $\mathrm{G}=$ green e $\mathrm{B}=$ blue, ou seja, vermelho, verde e azul que são considerados as cores primárias em estudos científicos de cor. Posteriormente foi criado o diagrama CIE X, Y, Z (valores tristimulo), para evitar coordenadas negativas, existentes no CIE RGB, aprimorando-o. A CIE padronizou também os iluminantes e o observador padrão, sendo o iluminante a distribuição da energia espectral da fonte de luz e o observador padrão a representação da média da população com visão de cor normal. O iluminante padrão mais utilizado é o CIE D65, que é a 
representação de uma fase da luz do dia, com temperatura de cor de aproximadamente 6504 K. Os dados do observador padrão 1931 foram derivados de experimentos de igualação de cores com um arranjo que significa que o estímulo ativou uma área da retina de 2 graus (fóvea). A distribuição de bastonetes e cones sobre a superfície da retina não é uniforme, implicando que os valores tristímulos obtidos dos dados 1931 são somente válidos para observações feitas sob condições de visualização de 2 graus. Isto é equivalente a visualização de uma pequena área de $1,7 \mathrm{~mm}$ a uma distância do comprimento de um braço (50 cm) e não corresponde particularmente bem com as condições de visualização freqüentemente utilizada na indústria de colorantes. Devido ao observador padrão 1931 de 2 graus não ser apropriado para julgamento visual de cores em áreas maiores, a CIE definiu um segundo jogo de funções de observador em 1964, conhecido com dado suplementar de observador, baseado em experimentos de igualação de cores com um campo de 10 graus equivalente a visualização de uma pequena área de $8,8 \mathrm{~mm}$ a uma distância do comprimento de um braço (50 cm) (CIE, 1986; SCHANDA, 2005; LOPES et al., 2006).

O sistema de cor CIE 1931 considera a luz transmitida ou refletida de um objeto, com uma determinada curva de transmitância $T(\lambda)$ ou de refletância $R$ $(\lambda)$, produzida pela potência espectral de um determinado iluminante $S(\lambda)$ e que atinge o olho do observador padrão (a letra grega lamba $(\lambda)$ é, por convenção, indicação de comprimento de onda). A não uniformidade visual do diagrama CIE 1931 fez com que estudiosos matemáticos modificassem o espaço de cor, facilitando os cálculos de interpretação das cores; essas melhorias foram denominadas como espaço de cor CIEL*a*b* de 1976 ou CIELab (GOVEIA, 2004). 
O CIELab transformou os valores tristímulos $\mathrm{X}, \mathrm{Y}$, e $\mathrm{Z}$ do espaço CIE 1931, em valores $L^{*}, a^{*}$ e b*, e permite a especificação de percepções de cores em termos de um espaço tridimensional, introduzindo três atributos para a percepção da cor, sendo eles $o L^{*}, a^{*} e b^{*}$. A axial $L$ é conhecida como luminosidade, e é proporcional ao valor no sistema Munsell de cor, variando de 0 (preto) a 100 (branco). As outras duas coordenadas a* e b* são coordenadas de cromaticidade, onde $a^{*}$ corresponde ao eixo vermelho-verde no sistema de Munsell e $b^{*}$ corresponde ao eixo amarelo-azul, e podem ter valores de -80 a +80. Embora estes últimos não sirvam como correlatos diretos do matiz e croma, seus números respectivos servem para determinar numericamente correspondentes para estes atributos. O espaço de cores CIE $1976\left(L^{*} a^{*} b^{*}\right)$ proporciona uma representação tridimensional para a percepção do estímulo de cores. Se dois pontos no espaço representando dois estímulos são coincidentes, então a diferença de cores entre os dois estímulos é zero. Conforme aumenta a distância entre os dois pontos no espaço é razoável assumir que a diferença de cor percebida entre os estímulos representa aumentos correspondentes. $\mathrm{O}$ eixo $\mathrm{a}^{*} \mathrm{e} \mathrm{b}^{*}$ possuem ângulo reto. $\mathrm{O}$ terceiro eixo $L^{*}$ é perpendicular ao eixo $a^{*} b^{*}$. Com este sistema qualquer cor pode ser especificada com coordenadas $L^{*} a^{*} b^{*}$. Um dos principais aspectos deste sistema de cor é a sua organização em um espaço de cor tridimensional aproximadamente uniforme, no qual os elementos são igualmente espaçados com base na percepção de cor visual. Alternativamente são utilizadas coordenadas $L^{*}, C^{*}$ e $h^{*}$; onde $L^{*}$ representa a luminosidade, $C^{*}$ (chroma) representa a intensidade ou saturação da cor e $\mathrm{h}^{*}$ (Hue) é uma outra forma para expressar a tonalidade. (CIE, 1986; MORALES, 2006). 
A mudança total da cor no sistema CIELab é dada pelo $\Delta \mathrm{E}^{*}$, sendo o $\mathrm{E}$ originário da palavra alemã Empfindung que significa sensação. $O \Delta E$ é usado para diferenciar qualquer diferença de cor, mas não fornece indicação do caráter da diferença da cor, isto é, não indicam a quantidade relativa e direção das diferenças de luminosidade, croma e matiz. Estas informações só podem ser obtidas se cada componente que forma o $\Delta \mathrm{E}$ for analisado separadamente. $\mathrm{O} \Delta \mathrm{E}$ é calculado utilizando a seguinte fórmula:

$$
\Delta \mathrm{E}=\left[\left(\Delta \mathrm{L}^{*}\right)^{2}+\left(\Delta \mathrm{a}^{*}\right)^{2}+\left(\Delta \mathrm{b}^{*}\right)^{2}\right]^{1 / 2}
$$

Esta equação pode ser descrita mais detalhadamente desta maneira:

$$
\Delta E=\left[\left(L_{1}-L_{0}\right)^{2}+\left(a^{*}{ }_{1}-a^{*}{ }_{0}\right)^{2}+\left(b^{*}{ }_{1}-b^{*}{ }_{0}\right)^{2}\right]^{1 / 2} \text {, onde } L_{0}, a^{*}{ }_{0} \text { e } b^{*}{ }_{0}
$$
representam a leitura inicial ou leitura do padrão e $L_{1}, a^{*}{ }_{1}$ e $b^{*}{ }_{1}$ representam a leitura final ou leitura da amostra (WEE et.al., 2002; REIS, 2003; GOVEIA, 2004; SCHANDA, 2005; LOPES et al., 2006; MORALES, 2006).

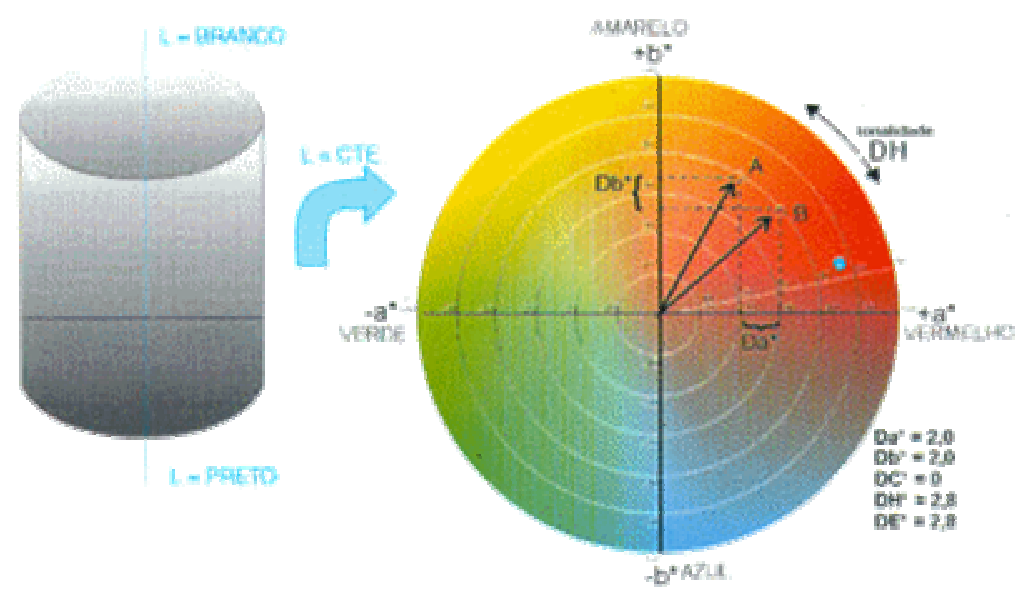

Figura 1: Representação gráfica do sistema CIELab e CIELCh . (Disponível em: $<$ http://www.cromexbrancolor.com.br> Acesso em 07/01/2007). 
Na prática odontológica, os profissionais utilizam escalas de cores para servirem como guias na seleção e envio de informações sobre cor dental entre dentistas e técnicos. A escala de cor mais utilizada é a VITAPAN Clássica (Vita), anteriormente chamada escala VITA Lumin Vacuum. Esta escala foi adotada por diversos fabricantes de resinas e cerâmicas como padrão de referência. A escala encontra-se ordenada em quatro famílias de matizes: A - marrom, B - amarelo, C - cinza, D - vermelho. Os números que acompanham as letras (1 a 4) correspondem à quantidade decrescente de luminosidade (valor). Ou seja, as cores vão se tornando mais escuras (diminuem o valor) à medida que aumentam os números. Entretanto, esta escala não oferece uma distribuição ordenada e uniforme de cores, o que implica em limitações no seu uso clínico. Por isto surgiram outras escalas como a VITAPAN 3D MASTER (Vita) e a CHROMASCOP (Ivoclar) para suprir estas deficiências. No entanto, ainda é restrita a disponibilidade de produtos restauradores que utilizam estas escalas, tornando pouco abrangente os materiais disponíveis (MYASHITA et al., 2006).

\subsubsection{Equipamentos para medição de cor.}

Existem dois tipos principais de instrumentos para medir a cor: os espectrofotômetros e os colorímetros de refletância. Os espectrofotômetros de refletância medem o montante de luz refletida por uma amostra em muitos intervalos de banda curta no comprimento de onda, resultando em um espectro de refletância. A vantagem de se usar dados de refletância ou transmitância espectral para se obter a cor de um objeto, é que estes dados 
espectrais podem ser calculados para diferentes iluminantes e observadores padrões e computados para vários sistemas de espaço de cor. Em contraste, colorímetros tristímulos empregam três filtros de banda larga para obter três números que podem ser convertidos diretamente para valores tristímulos, conseqüentemente, os colorímetros não podem providenciar dados de refletância espectral. A palavra colorímetro é frequentemente aplicada a uma classe de instrumentos descritos mais precisamente como medidores de diferença de cor e são mais usados no controle de produção de indústrias, tendo como objetivo apenas aceitar ou rejeitar a cor de um produto. Os espectrofotômetros fornecem informações mais completas da cor de um corpo de prova e podem ser classificados como colorímetro, mas usualmente não são considerados como tal. Até recentemente os colorímetros eram preferidos aos espectrofotômetros devido ao seu baixo custo de fabricação e portabilidade. Hoje, com o avanço da tecnologia, os espectrofotômetros se tornaram portáteis e com uma grande redução em seu custo, com os colorímetros perdendo as vantagens competitivas que existiam no passado (LOPES et al., 2006).

A operação de um espectrofotômetro é basicamente de iluminar a amostra com luz branca e calcular o montante de luz que é refletido pela amostra em cada intervalo do comprimento de onda. Tipicamente os dados são medidos para 31 intervalos de comprimento de onda centrados em 400 $\mathrm{nm}, 410 \mathrm{~nm}, 420 \mathrm{~nm}, \ldots . ., 700 \mathrm{~nm}$. Isto é feito passando-se a luz refletida através de filtros de interferência ou de grade de difração que dividem a luz em intervalos separados de comprimentos de onda. O instrumento é calibrado usando-se uma cerâmica branca cuja refletância em cada 
comprimento de onda seja conhecida e comparada a uma superfície que permita uma perfeita difusão. A refletância de uma amostra é expressa entre 0 e 1 (como uma fração) ou entre 0 e 100 (como uma percentagem). É importante compreender que os valores de refletância obtidos são valores relativos e, a distribuição da potencia espectral da luz que ilumina a amostra na medição não é importante, mas deve conter todos os comprimentos de onda do espectro visível e em quantidade suficiente para gerar um sinal precisamente detectável (LOPES et al., 2006).

0 princípio do equipamento chamado espectrofotômetro de luz visível, que utiliza o sistema CIELAB, está em posicionar a cor no espaço. Um espaço é definido por uma combinação de coordenadas cilíndricas ou cartesianas onde um ponto está associado a uma cor única (MORALES, 2006).

O desempenho de um espectrofotômetro é uma função de numerosos parâmetros instrumentais. A geometria óptica do instrumento é importante, em alguns instrumentos é usada uma esfera integradora que capacita à amostra ser iluminada de forma difusa (igualmente de todos os ângulos) e a luz refletida a ser coletada em um ângulo perpendicular a superfície da amostra. Alternativamente, outros instrumentos iluminam a amostra a certo ângulo e coletam a luz em outro ângulo. Por exemplo, a amostra pode ser iluminada em 45 graus na superfície e a luz refletida medida em 0 grau - isto é conhecido como geometria de 45/0. O contrário a isto é $0 / 45$. A geometria por iluminação difusa pode ter o componente especular incluído ou excluído. A reflexão especular é a luz que é refletida da superfície do material. É extremamente difícil, se não impossível, correlacionar medidas tomadas entre instrumentos se a geometria óptica não for idêntica. As quatro geometrias padrão CIE são: 
iluminação difusa e coleta de luz no normal, D/8; iluminação normal e coleta de luz difusa, 8/D; iluminação em 45 graus e coleta de luz no normal, 45/0; iluminação normal e coleta de luz em 45 graus, 0/45. (JJLTECHNOLOGIES, 2003; BYKGARDNER, 2007).

Espectrofotômetros são capazes de medir a opacidade de uma determinada amostra. A opacidade é o resultado do espalhamento da luz refletida pelo objeto e sua magnitude depende da diferença de índice de refração do material e do número e tamanho das partículas que compõem este material. Normalmente a opacidade de uma amostra é medida para se obter a propriedade inversa, a translucidez. Sabe-se que medidas de cor de materiais translúcidos são menos exatas do que as de materiais opacos, pois a cor de fundo influencia a medida da coordenada $L^{*}$ (luminosidade). Devido à translucidez, quanto menor a espessura do corpo de prova, maior a influência da cor de fundo no resultado final (OKUBO et al., 1998; GOVEIA, 2004; HEFFERNAN et al., 2002a; DOZIC, 2003; BARATH et al., 2003). 


\subsection{Cerâmica x Cor}

\subsubsection{Espectrofotometria em Odontologia}

O interesse pela cor em odontologia não é recente. Clark, em 1932, já demonstrava interesse pelo assunto e preocupava-se com a dificuldade que os cirurgiões dentistas da época encontravam para assemelhar dentes naturais com restaurações, principalmente devido à falta de preparo dos profissionais em lidar com as três dimensões da cor. A partir de então, várias pesquisas têm sido realizadas com o intuito de aprimorar as restaurações e educar os profissionais da odontologia, com a finalidade de resolver o problema da cor das restaurações quando comparadas à dos dentes naturais (SALENSKI, 1972; SPROULL, 1973).

A familiaridade com as teorias da cor e da interação da luz com a matéria pode ajudar na difícil tarefa de escolher a tonalidade de um material restaurador, pois a cor não é uma propriedade da luz, e sim o efeito das ondas de luz refletida de materiais opacos ou transmitida de materiais transparentes ou translúcidos. A cor de uma cerâmica dental ou resina, assim como a cor de todo material, é determinada pela fonte de luz sob a qual é observada; pela forma como as ondas de luz que incidem sobre o material é absorvida, transmitida ou refletida; pelos efeitos do ambiente na mente do observador e pelas condições visuais do observador; pois a cor é só uma das inúmeras qualidades que o olho humano é capaz de perceber (GOVEIA, 2004).

A estabilidade da cor é uma característica muito importante para o sucesso clínico de uma restauração odontológica. Há décadas, vários estudos 
têm utilizado o envelhecimento artificial acelerado e a espectrofotometria como instrumentos para avaliar a estabilidade de cor de restaurações. Powers et al., em 1980, estudaram a estabilidade de sete resinas compostas sob envelhecimento acelerado. Três discos de $36 \mathrm{~mm}$ de diâmetro e 1,3 mm de espessura de cada material testado foram confeccionados e expostos à $900 \mathrm{~h}$ a $43^{\circ} \mathrm{C}$ e $90 \%$ de umidade relativa. Foram feitas leituras com espectrofotômetro antes e após o envelhecimento, utilizando dados de refletância e comprimentos de onda para cada amostra. Uma estimativa de opacidade foi calculada utilizando fundo padrão preto e branco e calculando a média de contraste entre as leituras. O estudo concluiu que os compostos se tornaram mais escuros, mais cromáticos e mais opacos após o envelhecimento, devido principalmente à degradação da superfície das amostras.

Johnston e Kao (1989), em um estudo clássico de avaliação de cor por colorímetro, julgaram os critérios visuais na comparação entre restaurações de resina e dentes. Usando um colorímetro (45/0) e análise visual, eles calcularam que um $\Delta \mathrm{E}>3,7$ era necessário para visualizar diferenças clinicamente significantes entre dente e restaurações.

Seghi et al. (1989a), analisaram espectrofotômetros e colorímetros como instrumentos para auxiliar no processo da escolha da cor de uma restauração. Eles selecionaram 20 tipos de cerâmicas, entre opacas e translúcidas com várias cores da escala Vita e confeccionaram três corpos de prova de $12 \mathrm{~mm}$ de diâmetro e 3mm de espessura para cada grupo. Após o polimento estes corpos eram levados a dois diferentes espectrofotômetros de refletância e a um colorímetro tri estímulo. As leituras eram então convertidas para o sistema CIELab e a precisão de cada aparelho era dada comparando as leituras deste 
aparelho com as leituras feitas por um instrumento de referência padrão, e também pela capacidade que cada aparelho possuía em repetir a leitura dos corpos. Concluíram que os resultados que tinham melhor relação com a percepção visual eram aqueles fornecidos pelo sistema CIELab, independentemente do aparelho testado, e que os colorímetros eram mais portáteis, facilitando o trabalho de leitura.

Em outro estudo, Seghi et al. (1989b) avaliaram as limitações dos colorímetros na identificação de pequenas diferenças de cor entre cerâmicas translúcidas. Para isto confeccionaram 31 corpos de prova de cerâmica, onde pequenas quantidades de pigmentos eram adicionadas em diferentes concentrações, de maneira que entre uma amostra e outra adjacente, uma mínima diferença visual de cor era percebida. Os corpos eram submetidos a uma avaliação visual da cor realizada por 27 observadores treinados e depois era realizada a avaliação espectrofotométrica. Os autores concluíram que a análise de cor com instrumentos era uma importante ferramenta na avaliação da cor da cerâmica e reportaram a necessidade de maiores estudos para o desenvolvimento de espectrofotômetros para aplicação clínica odontológica, como um instrumento com potencial para auxiliar na escolha da cor de restaurações dentais.

Em 1994, Razzog e Russel, investigaram a estabilidade de cor de duas diferentes cerâmicas, Procera (Nobel) e Ceramco (Dentsply), após o envelhecimento artificial. Para isto confeccionaram 40 discos de titânio de 20 $\mathrm{mm}$ de diâmetro e $3 \mathrm{~mm}$ de espessura, que serviram de substrato para a aplicação das cerâmicas testadas. Foram utilizadas quatro cores para cada cerâmica (A3, A3.5, C3, D3). Leituras espectrofotométricas foram realizadas 
antes e após o envelhecimento artificial de 900h, onde, segundo as especificações da máquina de ensaio utilizada, 300h correspondia a um ano de uso. Concluíram que três das quatro cores testadas tiveram mudanças de cor estatisticamente significantes e que ambas as cerâmicas tiveram pequenas mudanças de cor de acordo com o índice NBS $(\Delta \mathrm{E} \times 0,92)$; e sugeriram maiores pesquisas de estabilidade de cor de cerâmicas.

Esquivel et al., em 1995, pesquisaram a estabilidade de cor das cerâmicas, Procera (Nobel), Duceratin (Degussa) e Vita VMK-68 (Vita), com o uso de colorímetro e compararam as amostras glazeadas com as não glazeadas. Amostras de $20 \mathrm{~mm}$ de diâmetro e $2 \mathrm{~mm}$ de espessura foram confeccionadas, num total de 40 amostras para cada cerâmica testada, todas na cor A1 da escala Vita Clássica. Vinte amostras tiveram o glaze removido, e nas outras 20 amostras o glaze foi mantido. Dez amostras glazeadas e 10 amostras não glazeadas foram imersas por $24 \mathrm{~h}$ em azul de metileno, as outras ficaram imersas em água destilada. Leituras espectrofotométricas foram obtidas antes e após a imersão das amostras, e foi calculado o $\Delta \mathrm{E}$ para cada amostra. Concluíram que todas as amostras não glazeadas imersas em azul de metileno exibiram mudanças no valor e foram visivelmente pigmentadas, já as amostras glazeadas foram resistentes ao manchamento por azul de metileno.

Em outro estudo de estabilidade de cor de cerâmicas após envelhecimento artificial acelerado, Heydecke et al. (2001) comparou mudanças de cor em facetas cerâmicas feitas com Procera (Nobel) recobertas com cerâmica feldspática Allceram (Ducera) após ensaio de envelhecimento (300h). Foram confeccionadas 15 facetas de Procera sendo 5 recobertas com Allceram na cor A1, 5 recobertas com Allceram B4 e 5 sem recobrimento. Os 
discos foram cimentados em substratos que simulavam dentes escurecidos. Pequenas mudanças de cor foram percebidas após o envelhecimento e apenas no grupo de facetas B4 as mudanças foram clinicamente significantes $(\Delta \mathrm{E}>$ $3,3)$.

Em 2002, pesquisa de cor realizada por Schulze et al. compararam cinco resinas fotopolimerizáveis diferentes antes e após o envelhecimento artificial de 122h. Foram confeccionados 5 discos de $8 \mathrm{~mm}$ de diâmetro e $5 \mathrm{~mm}$ de espessura para cada resina testada, que foram polidos e levados à máquina de ensaio. Todos os grupos tiveram mudanças na cor clinicamente significantes de uma restauração odontológica

A translucidez e opacidade da cerâmica sempre foi também um fator de preocupação. Na pesquisa de Yaman et al. (1997), foi utilizado o espectrofotômetro para avaliar a alteração na opacidade de discos de cerâmica quanto estes foram cimentados com cimento resinoso translúcido em substratos pigmentados. Para isto foram confeccionados 40 discos sendo 20 de cada porcelana testada - Fortune (Ivoclar) e Optec (Pentron), que foram formuladas em 4 graus de opacidade $(0 \%, 25 \%, 50 \%$ e $75 \%)$. O substrato foi feito com resina auto polimerizável da cor $\mathrm{C} 4$, portanto de baixo valor e alto croma (saturação). A cor de cada substrato foi medida antes e após a cimentação do disco e foi feito um cálculo de $\Delta \mathrm{E}$. Os autores concluíram que houve uma mudança na cor de todas as amostras após a cimentação quando comparadas ao substrato original e que a variação da opacidade tem efeito notável na cor final da faceta.

O trabalho de Heffernan et al. (2002a) comparou a translucidez de seis infra-estruturas de sistemas totalmente cerâmicos: IPS Empress dentina, IPS 
Empress 2 (Ivoclar), In-Ceram Alumina, In-Ceram Spinell, In-Ceram Zircônia (Vita), Procera (Nobel). Os discos cerâmicos de $13 \mathrm{~mm}$ de diâmetro foram fabricados conforme instruções do fabricante quanto à espessura e discos de liga metálica foram usados como grupo controle e a cerâmica Vitadur Alpha dentina foi usada como padrão. Medidas de opacidade sobre fundo preto e branco foram realizadas com espectrofotômetro. Os autores concluíram que as cerâmicas se distribuíam assim em ordem decrescente de translucidez: Vitadur Alpha $>$ In-Ceram Spinell $>$ Empress $>$ Procera $>$ Empress2 $>$ In-Ceram Alumina $>$ In-Ceram Zircônia = liga metálica e que a espessura da infraestrutura influenciava no grau de opacidade.

Na segunda parte deste trabalho, os autores Heffernan et al. (2002b) ainda pesquisando opacidade, recobriram as infra-estruturas cerâmicas IPS Empress dentina, IPS Empress 2 (Ivoclar), In-Ceram Alumina, In-Ceram Spinell, In-Ceram Zircônia (Vita) e Procera (Nobel) e discos de metal com seus correspondentes de cerâmica dentina para cobertura até a espessura de $1,47 \mathrm{~mm}( \pm 0,01 \mathrm{~mm})$, e compararam medidas de opacidade realizadas com espectrofotômetro antes e após o glazing final. Concluíram que o ciclo de glazeamento diminui a opacidade para todas as cerâmicas testadas, exceto para as totalmente opacas como In-Ceram Zircônia e metalocerâmica.

Vichi et al. (2003) testaram a influência da exposição à água na opacidade e estabilidade de cor de três resinas (Spectrum TPH, Tetric Ceram e Z100). Eles utilizaram seis cores da escala Vita Clássica para cada resina, confeccionando três discos para cada resina e para cada cor, com $15 \mathrm{~mm}$ de diâmetro e $1 \mathrm{~mm}$ de espessura. As amostras foram analisadas por um espectrofotômetro utilizando um fundo cinza como padrão. Para a analise de 
opacidade foi utilizado primeiramente um fundo padrão preto e depois um fundo branco. A opacidade foi calculada pela razão de refletância da medida sob o fundo preto pela de fundo branco. Após as medidas iniciais, as amostras foram guardadas em água por 30 dias em uma temperatura de $60^{\circ} \mathrm{C}$ e medidas novamente. Como resultado, mostrou-se que a água agiu como um agente de descoloração sob as resinas e a resina Spectrum TPH teve uma pior performance quando comparada às outras duas $(\Delta \mathrm{E}>3,3)$. Os resultados de opacidade demonstraram que a água agiu como um fator de opacificação das amostras, aumentando a opacidade das resinas, principalmente da resina Spectrum TPH.

Já Dozic et al. (2003) preocuparam-se com a influência da espessura das camadas de cerâmica na cor final destas restaurações. Eles propuseram um estudo para determinar o efeito de diferentes espessuras de porcelana opaca e translúcida na cor final do corpo de prova. Para isto confeccionaram corpos de prova com $0,7 \mathrm{~mm}$ de infra-estrutura cerâmica Synthoceram, e diferentes espessuras de opaco e translúcido sendo elas: 0,$25 ; 0,5 ; 0,75$; ou 1 $\mathrm{mm}$ de cerâmica Syntagon Plus opaca e 1,$00 ; 0,75 ; 0,5 ; 0,25$ ou $0 \mathrm{~mm}$ de cerâmica Syntagon Plus translúcida (Elephant Dental). Cada disco foi mensurado 5 vezes com micrômetro para certificar a espessura. Os discos foram levados ao espectrofotômetro cuja geometria óptica era D/8 com componente especular incluído. Como resultado, os autores relacionaram a proporção entre opaco e translúcido com diferenças nas coordenadas $a^{*}$ e $b^{*}$. Já a coordenada $L^{*}$ variou com mudanças nas proporções, porém de acordo com a cor da escala. O estudo demonstrou que a luminosidade aumenta quando aumenta a espessura da cerâmica opaca para cor A1, porém diminui 
para cor A3. Isto se deve a maior opacidade da cerâmica translúcida nesta cor da escala. Concluíram também que uma espessura de $0,7 \mathrm{~mm}$ de infraestrutura cerâmica é suficiente para mascarar a influência da cor de fundo na cor final da amostra.

Barath et al. (2003) investigaram os efeitos da cor de fundo preto e branco, e de agentes cimentantes na cor final de amostras cerâmicas. Confeccionaram 15 corpos de prova para cada grupo e as cerâmicas testadas foram: IPS Empress 2 (Ivoclar) e In-Ceram Alumina (Vita). Foram feitos vários grupos de diferentes combinações de cor entre cerâmica da infra-estrutura, de dentina e de esmalte. Os agentes cimentantes foram: fosfato de zinco cor neutra (Phosphacem - Ivoclar), cimento de ionômero de vidro cor universal (Ketac Cem - ESPE), cimento resinoso cor A3 (Compolute - Espe). A avaliação espectrofotométrica foi realizada utilizando os padrões branco e preto como fundo de leitura, e um $\Delta \mathrm{E}>2,0$ foi considerado clinicamente inaceitável. Os autores concluíram: 1) tanto a cor de fundo como o agente cimentante precisam ser levados em consideração na cor final da restauração, 2) uma cor mais opaca do agente cimentante não mascara um substrato escuro e 3) quando a espessura da cerâmica aumenta ocorre uma diferença clinicamente relevante na cor da restauração.

Estudos de reprodução de cor em restaurações cerâmicas são de interesse de alguns pesquisadores. Wee et al. (2002) avaliaram "in vitro" a diferença de cor no processo de replicação de 3 porcelanas dentais com sistemas de seleção de cor adequados para cada cerâmica. Eles fabricaram 11 discos de cerâmica (padrão) e determinaram visualmente e com instrumento, a cor de cada um, e replicaram usando três sistemas cerâmicos 
diferentes: 1) cerâmica Vita VMK 68 e determinação visual da cor com escala Vita Clássica, 2) cerâmica Vita Omega 900 com determinação da cor com escala Vitapan 3D-Master e 3) cerâmica Vintage Halo com uso do colorímetro ShofuEye -EX. Cada padrão foi replicado três vezes em cada sistema. Posteriormente cada padrão e os discos fabricados foram medidos com espectrofotômetro $\left(45^{\circ} / 0^{\circ}\right)$ e diferenças foram calculadas (CIELab) no total da cor $\Delta \mathrm{E}$ e nos parâmetros $\Delta \mathrm{L}, \Delta \mathrm{a}$ e $\Delta \mathrm{b}$. Os resultados sugeriram que nenhum dos três sistemas se provaram clinicamente seguro na reprodução de cor das restaurações cerâmicas $(\Delta \mathrm{E}>2,7)$.

Em 2003, Douglas e Brewer determinaram através de colorímetro a variabilidade na reprodução de cor de coroas metalocerâmicas fabricadas por diferentes laboratórios comerciais. Eles fabricaram 50 estruturas metálicas padronizadas e pediram para 5 laboratórios construírem 10 coroas metalocerâmicas de uma mesma cor A 3.5 da escala Vita Lumin, e os profissionais utilizaram a técnica de sua escolha para a aplicação da cerâmica. A diferença de cor foi determinada com o uso de colorímetro entre a coroa e a escala. Os autores concluíram que a maioria das coroas fabricadas estava aquém do limite de aceitabilidade clinica quanto à cor $(\Delta \mathrm{E}>3,7)$.

A espectrofotometria também foi utilizada para avaliar a influência de diferentes ligas metálicas e diferentes cerâmicas em restaurações metalocerâmicas. Ligas de Co-Cr e Au produzem restaurações cerâmicas mais luminosas (valores de $\mathrm{L}^{*}$ maiores) do que ligas de $\mathrm{Ni}-\mathrm{Cr}$ e $\mathrm{Pd}$, a cerâmica Ceramco (Dentsply) mostrou se mais avermelhada (valores de $a^{*}$ maiores) em todas as ligas quando comparadas a cerâmica Vita Omega (Vita) e as ligas de 
ouro e paládio provocam um ligeiro aumento na coordenada $b^{*}$ (amarelo) (KOURTIS et. al., 2004).

Paul et al. (2004) testaram a cor de restaurações metalocerâmicas comparadas com dentes naturais adjacentes, sendo as restaurações fabricadas de acordo com informações de uma escala de cor visual (Vita Clássica - Vita) e de um espectrofotômetro (LUA005 Medical High Technologies). As restaurações foram confeccionadas e testadas intraoralmente e $\mathrm{O} \Delta \mathrm{E}$ (dente adjacente e restauração) foi calculado. Como conclusão, os autores avaliaram que o espectrofotômetro pode ser usado para avaliar cor de restaurações metalocerâmicas.

Ertan e Saiiin (2004) estimaram a estabilidade de cor de quatro sistemas cerâmicos - Vita Omega (Vita), Vita Titankeramic (Vita), Ceramco Finesse (Detsply) e Ceramco II (Dentsply), usando envelhecimento artificial acelerado. Para isto confeccionaram 10 amostras cerâmicas para cada grupo e para cada material foram criados 3 grupos preparados com as cores A3, B3 e C3, resultando em um total de 120 amostras de $11 \mathrm{~mm}$ de diâmetro e 1,4 mm de espessura. Após o glazeamento, um espectrofotômetro foi utilizado para analisar a cor das amostras, que então foram submetidas à $100 \mathrm{~h}$ de envelhecimento artificial. $O \Delta E$ foi calculado através da fórmula $\Delta E=\left[\left(L_{1}-L_{2}\right)^{2}+\right.$ $\left.\left(a^{*} 1-a^{*}\right)^{2}+\left(b^{*} 1-b^{*}\right)^{2}\right]^{1 / 2}$, sendo $L_{1}, a^{*_{1}}, b^{*_{1}}$ leituras pré-experimental (padrão) e L2, a*2, b*2 as leituras pós-experimental (amostra). Os autores concluíram que todos os materiais mostraram mudanças pequenas na cor segundo $\circ$ índice NBS $=\Delta \mathrm{E} \times 0,92$. Apenas $\circ$ material Ceramco Finesse mostrou mudança de cor detectável pelo olho humano $(\Delta E>1)$ e que as variações foram maiores na cor C3 do que nas cores A3 e B3. 
Em 2006, Shokry et al. pesquisaram também os efeitos da espessura da infra-estrutura e da cerâmica de recobrimento na cor de sistemas totalmente cerâmicos. Para isto confeccionaram amostras de 2 tipos de sistema cerâmico - IPS Empress (Ivoclar) e In-Ceram Spinell (Vita) com diferentes espessuras tanto da infra-estrutura quanto da cerâmica de recobrimento. Os parâmetros usados foi do sistema CIELab e foi calculado o $\Delta \mathrm{E}$ entre amostras. Os autores concluíram que a cor das amostras foi fortemente influenciada não só pelas espessuras da infra-estrutura e da camada de recobrimento, como pela sua interação.

Mais recentemente estão sendo concluídos estudos com novos espectrofotômetros. Hassel et al. (2007) investigaram cores de dentes naturais medidos pelo aparelho Easyshade (Vita), analisando o efeito de diferentes treinamentos em diferentes examinadores. Os autores concluíram que novos estudos devem ser realizados utilizando esta nova tecnologia para obtenção de resultados mais consistentes.

\subsubsection{Pigmentos}

Os pigmentos utilizados em pintura são, em grande parte, materiais inorgânicos, cristalinos e insolúveis e distinguem-se dos corantes, igualmente usados pela cor, pelo fato de estes últimos serem materiais orgânicos e normalmente solúveis. Os pigmentos podem ser identificados através de análise micro química, espectrometria e difractometria de raio $\mathrm{X}$, espectroscopia de absorção de infravermelho e espectroscopia de difusão de Raman (CRUZ, 2000). 
A cor que nos é mostrada por um pigmento, assim como se sucede em qualquer outro material, resulta de uma absorção seletiva da luz, que corresponde à parte visível do espectro eletromagnético. Sendo a luz branca uma mistura de luz de várias cores como se vê, por exemplo, nos arco-íris, há materiais que absorvem de desigual modo essa radiação de diferentes comprimentos de onda e assim, a cor de um pigmento vermelho, por exemplo, resulta da absorção dos componentes das outras cores e da reflexão predominantemente do componente vermelho. A cor branca é observada quando a luz não é absorvida pelo objeto, sendo toda refletida na sua superfície.

Ao longo da história, os pigmentos têm sido muito mais utilizados em pintura do que os corantes. As razões para esta preponderância são talvez; a maior acessibilidade, já que muitos pigmentos se encontram na natureza numa forma que pode ser utilizada sem grandes manipulações; a maior estabilidade de cor dos pigmentos em comparação com os corantes e a maior opacidade dos pigmentos.

Os pigmentos podem ser classificados pela cor, sendo as cores mais utilizadas, de uma maneira geral o branco, vermelho, azul, verde, castanho, amarelo e preto.

A utilização de espectrofotometria (infravermelho e Raman) na identificação dos pigmentos é muito corriqueira em análise de pinturas artísticas para catalogar e datar obras de arte. Isto porque os compósitos contidos em um pigmento interagem diferentemente com a radiação incidente sobre eles (CRUZ, 2000). 
Em odontologia, os pigmentos para pintura extrínseca são muito utilizados para caracterização e correção da cor de uma restauração cerâmica. Segundo Reis e Bastos (1996), a pintura extrínseca de uma restauração só deveria ser empregada para corrigir pequenos desencontros entre a cor dos dentes naturais e a restauração. Este desacordo é passível de ser corrigido se a restauração tiver, no tocante à coloração, uma luminosidade $\left(L^{*}\right)$ ligeiramente mais alta e/ou apresentar uma saturação $\left(C^{*}\right)$ mais baixa. Se o oposto ocorrer, tal correção de cor torna-se impossível de ser realizada.

Segundo McPhee (1985), as principais indicações e aplicações da pintura extrínseca são:

- Aumentar a saturação e reduzir a luminosidade de uma restauração cerâmica,

- Pintura de faces oclusais para realçar fossas, fissuras e cicatrículas,

- Pintura de faces vestibulares para simular manchas por fumo, trincas de esmalte e hipoplasias.

Alguns problemas relacionados à coloração extrínseca de cerâmicas têm sido mencionados na literatura, entre eles podemos citar dissolução da cor e instabilidade de cor entre a aplicação e queima do pigmento (CRISPIN, 1991).

A cor das cerâmicas é alcançada pela adição de óxidos metálicos fundidos à massa vítrea (sílica, caulim e feldspato). O composto resultante é moído para se obter um pó fino. Acrescentam-se ainda pequenas quantidade de outros pigmentos e opacificadores e, desta forma, a cor da cerâmica é alcançada durante a fase de sinterização. Os pigmentos para caracterização e/ou modificadores de cor são manufaturados da mesma forma, sendo, no 
entanto, mais concentrados em óxidos metálicos do que os pós cerâmicos de dentina e esmalte.

Antes, os pigmentos eram fornecidos sob forma de óxidos metálicos puros. Estes, por apresentarem um alto ponto de fusão, quando aplicados sobre a superfície da porcelana e queimados, produziam enormes distorções na subestrutura cerâmica. Recentemente, estes pigmentos passaram a ser fabricados com baixo ponto de fusão, podendo ser aplicados à cerâmica sem produzir deformidades, tendo, portanto, seu ponto de maturação bem mais baixo do que aquele das cerâmicas de dentina e esmalte.

Em odontologia os pigmentos mais utilizados são:

- Verde = óxido metálico de cobre,

- Marrom = óxido metálico de ferro ou níquel,

- Amarelo-marrom = óxido metálico de titânio,

- Lilás = óxido metálico de manganês,

- Azul = óxido metálico de cobalto,

- $\quad$ Opaco = óxido de zircônio.

Para se utilizar os pós de pigmento, mistura-se este pó à água destilada pura ou combinada com glicerina, ou a um fluido já fabricado juntamente com o pó. O composto resultante é aplicado à porcelana com pincel fino. Somente uma camada fina deve ser aplicada por vez, já que camadas mais espessas podem tornar a superfície cerâmica rugosa. O pigmento pode ser aplicado sobre a superfície cerâmica antes do glazing e ser então queimada e glazeada ao mesmo tempo; ou juntamente do glazing artificial (1 etapa) ou ser aplicado sobre a cerâmica não glazeada, queimar o pigmento e depois retornar a cerâmica ao forno para o glazing final (2 etapas) (REIS; BASTOS, 1996). 
A longevidade das pinturas de caracterização extrínseca é desconhecida. Sabe-se que substâncias ácidas encontradas nas dietas alimentares; uso de géis de fluoreto acidulado, escovação, entre outros, podem afetar a estabilidade e permanência destes pigmentos na superfície da porcelana. Aker et al. (1980), avaliando o efeito abrasivo de escovas dentárias sobre porcelanas pintadas extrinsecamente "in vitro", sugeriram que, uma camada de glaze sobre a pintura seria mais resistente à abrasão causada pela escovação do que a aplicação do pigmento sobre uma superfície previamente glazeada.

O’ Keefe et al. (1993) submeteram corpos de prova cerâmicos após aplicação e queima de pigmento, à três ciclos de imersão em fluoreto acidulado, medindo em seguida as alterações de cor por meio de um espectrofotômetro. Concluíram que pigmentos aplicados previamente ao glaze e queimados a baixa temperatura apresentaram melhor consistência no que se refere à estabilidade de cor. Os autores afirmaram ainda que, a temperatura não foi a principal causa de alteração de cor, mas sim a técnica de aplicação e que a coordenada $\mathrm{H}^{*}$ (matiz) foi a mais afetada.

Outro fator relacionado à pintura é a estabilidade de cor após a queima. Mulla et al. (1991) avaliaram as diferenças de coloração $\left(\Delta \mathrm{E}^{*}\right)$ dos pigmentos antes e após a queima. Foram utilizadas duas cores de pigmentos e três marcas comerciais diferentes. Nenhuma diferença estatisticamente significante foi encontrada por alteração da temperatura de queima (de $1700^{\circ} \mathrm{F}$ a $1750^{\circ} \mathrm{F}$ ). Os autores também não encontraram diferenças entre técnicas de pintura. Queimas múltiplas também não demonstraram alterar de modo significativo a coloração dos pigmentos, embora alterações tenham ocorrido após a primeira queima. 
Lund e Piotrowski (1992) estudando as diferenças na coloração após a queima de dez cores de pigmentos Ceramco, por meio de espectrofotômetro, concluíram que a maior variação ocorreu no pigmento amarelo $\left(\Delta \mathrm{E}^{\star}=4\right)$. Nos demais pigmentos a variação foi de 0,41 a 1,24.

Cho et al. (2006) avaliaram a capacidade dos pigmentos externos de diminuírem a luminosidade e aumentarem o croma de uma restauração de cerâmica e determinaram a mudança de cor destas restaurações após repetidas aplicações de pintura extrínseca. Mudanças na translucidez e diferenças na rugosidade superficial também foram medidas. Os autores prepararam discos de cerâmica com $12 \mathrm{~mm}$ de diâmetro e $1 \mathrm{~mm}$ de espessura e utilizaram 4 tipos de pigmentos Vita. A sinterização foi repetida três vezes após a aplicação do pigmento. A cor de cada amostra foi medida antes e depois da pigmentação, com auxílio de espectrofotômetro. Mudanças na cor após o primeiro ciclo foram percebidas apenas em 2 dos 4 tipos de pigmento, mas após os três ciclos de queima, os 4 tipos de pigmento apresentaram $\Delta \mathrm{E}^{*}>$ 2. Diferenças de cor e aumento da luminosidade ocorreram significantemente após os ciclos de sinterização, mas as mudanças no croma e translucidez foram pequenas após os ciclos de queima.

Segundo Reis e Bastos (1996), nenhum fator é por si só, responsável pela alteração da cor das restaurações com pintura extrínseca. O sucesso deste procedimento e a estabilidade de cor estão diretamente relacionados à técnica de aplicação, temperatura e tempo de sinterização, velocidade de subida de temperatura e resfriamento, acúmulo de pigmento na superfície da restauração, mistura de pigmentos, qualidade da superfície cerâmica, calibragem do forno e tipo de pigmento utilizado. 
3. PROPOSIÇÃO 
O objetivo deste trabalho é:

1. Avaliar, por meio de dois diferentes espectrofotômetros (Color-Guide 45/0 Byk-Gardner e Easyshade Vita), a estabilidade de cor de cinco sistemas cerâmicos (metalocerâmica Ceramco3 Dentsply; Ceramco3 sem substrato; EX3 Noritake sem substrato; Vitro-Ceram Angelus recoberta por Allceram Degudent e Vitro-Ceram recoberta por Cerabien Noritake), quando submetidos ao envelhecimento artificial acelerado.

2. Avaliar a opacidade das cerâmicas testadas utilizando o espectrofotômetro Color Guide 45/0 (BYK-Gardner) antes e após o ensaio de envelhecimento artificial acelerado.

3. Verificar a influência da pintura extrínseca sobre a opacidade e a estabilidade de cor dos cinco sistemas cerâmicos utilizados neste estudo. 
4. MATERIAL E MÉTODO 


\subsection{Obtenção dos corpos de prova.}

Neste estudo foram confeccionados 14 corpos de prova para cada cerâmica testada, todos na cor B3 da escala Vita Clássica (Vita), sendo 07 glazeados naturalmente e 07 submetidas à aplicação de pintura extrínseca com pigmento Vita Chrom 712. Estas amostras eram compostas por discos de metalocerâmica (grupo 1), cerâmica pura (grupos 2, 3) e ceramo-cerâmicos (grupos 4 e 5) com diâmetro de $15 \mathrm{~mm}$ para os grupos 1, 4 e 5 e $13 \mathrm{~mm}$ para os grupos 2 e 3 devido à contração durante a sinterização; e com espessura variável conforme a cerâmica testada, sendo $5 \mathrm{~mm}$ para o grupo $1 ; 2 \mathrm{~mm}$ para os grupos 2 e 3 e $4 \mathrm{~mm}$ para os grupos 4 e 5 . 
Tabela 1: Cerâmicas testadas.

\begin{tabular}{|c|c|c|c|}
\hline $\begin{array}{l}\text { Grupos } \\
\text { Cerâmica }\end{array}$ & Espessura & $\begin{array}{l}\text { Componente de } \\
\text { resistência }\end{array}$ & $\begin{array}{l}\text { Fabricante da } \\
\text { cerâmica }\end{array}$ \\
\hline $\begin{array}{l}\text { 1Metalocerâmica } \\
\text { Ceramco } 3\end{array}$ & $\begin{array}{l}3 \mathrm{~mm} \text { metal } \\
1 \mathrm{~mm} \text { dentina Ceramco } 3 \\
1 \mathrm{~mm} \text { esmalte Ceramco } 3\end{array}$ & Liga $\mathrm{NiCr}$ & $\begin{array}{lr}\text { Dentsply } & \text { Int. } \\
\text { Co., } & \text { York, } \\
\text { EUA. } & \end{array}$ \\
\hline 2 Ceramco 3 & $\begin{array}{l}1 \mathrm{~mm} \text { dentina } \\
1 \mathrm{~mm} \text { esmalte }\end{array}$ & Nenhum & $\begin{array}{l}\text { Dentsply } \begin{array}{r}\text { Int. } \\
\text { Co., }\end{array} \text { York, } \\
\text { EUA. }\end{array}$ \\
\hline $3 E X-3$ & $\begin{array}{l}1 \mathrm{~mm} \text { dentina } \\
1 \mathrm{~mm} \text { esmalte }\end{array}$ & Nenhum & $\begin{array}{l}\text { Noritake Co. } \\
\text { Ltda, Nagoya, } \\
\text { Japão }\end{array}$ \\
\hline 4 Vitro-Ceram & $2 \mathrm{~mm}$ Vitro-Ceram & Alumina & $\begin{array}{l}\text { Angelus, } \\
\text { Londrina-PR, } \\
\text { Brasil. }\end{array}$ \\
\hline Allceram & $\begin{array}{l}1 \mathrm{~mm} \text { dentina Allceram } \\
1 \mathrm{~mm} \text { esmalte Allceram }\end{array}$ & & $\begin{array}{l}\text { DeguDent Co, } \\
\text { Hanau, } \\
\text { Alemanha. }\end{array}$ \\
\hline 5 Vitro-Ceram & $2 \mathrm{~mm}$ Vitro-Ceram & Alumina & $\begin{array}{l}\text { Angelus, } \\
\text { Londrina-PR, } \\
\text { Brasil. }\end{array}$ \\
\hline Cerabien & $\begin{array}{l}1 \mathrm{~mm} \text { dentina Cerabien } \\
1 \mathrm{~mm} \text { esmalte Cerabien }\end{array}$ & & $\begin{array}{l}\text { Noritake Co. } \\
\text { Ltda, Nagoya, } \\
\text { Japão. }\end{array}$ \\
\hline
\end{tabular}

Os corpos de prova foram confeccionados através de uma matriz de teflon contendo espaçadores de $1 \mathrm{~mm}, 2 \mathrm{~mm}, 3 \mathrm{~mm}$ e $4 \mathrm{~mm}$ (Fig. 2).

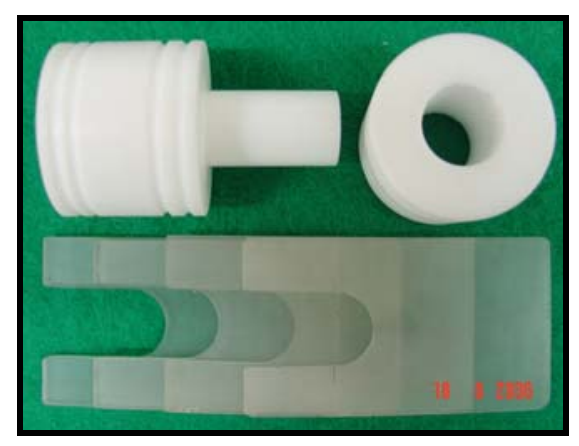

Figura 2: Matriz de teflon com espaçadores. 
4.1.1. Técnica de obtenção dos corpos de prova metalocerâmicos em cerâmica Ceramco 3 - Grupo 1.

Para a obtenção dos corpos de prova metalocerâmicos, primeiramente foram fundidos os discos de metal que serviram de subestrutura para a aplicação da cerâmica. Após a colocação do espaçador de $3 \mathrm{~mm}$ na matriz de teflon, a cera plastificada (Azul regular tipo C - Kerr) era vertida sobre o espaço superior criado com a colocação do mesmo e, após a completa solidificação da cera, o espaçador era removido e a haste vertical servia como um êmbolo para a remoção do disco de cera (Fig. 3). Assim, o padrão de cera criado era incluído em revestimento fosfatado e fundido em liga $\mathrm{NiCr}$ segundo técnica preconizada por Anusavice (REIS, 2003).

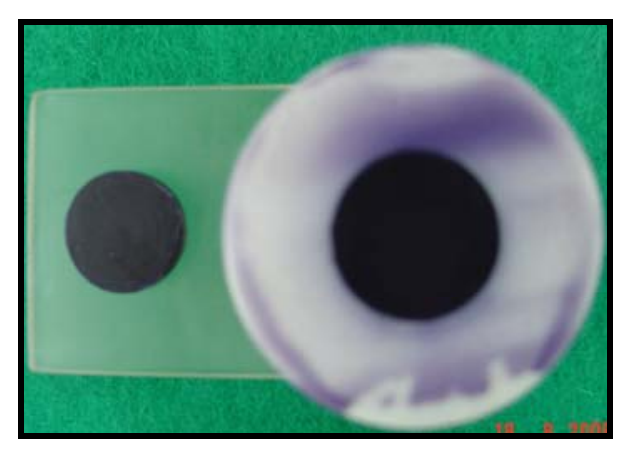

Figura 3: Matriz com cera plastificada no espaço superior e padrão de cera já confeccionado apoiado sobre espaçador.

Após a fundição desses padrões em liga $\mathrm{NiCr}$, estes eram preparados para receber a cerâmica. Inicialmente eram usinados com pedra de óxido de alumínio branca para a remoção de possíveis irregularidades. Depois, os discos metálicos eram jateados com óxido de alumínio e permaneciam em 
álcool isopropílico na cuba de ultra-som (Dabi Atlante) por 10 minutos. Após estes procedimentos, o disco metálico estava pronto para receber o sistema de cerâmica Ceramco3 (Fig 4).

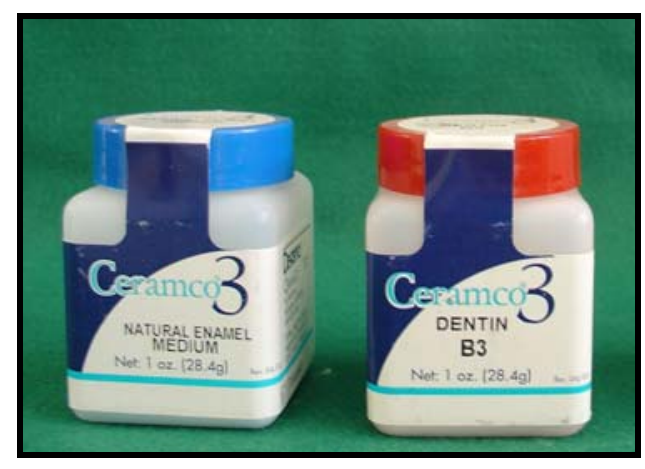

Figura 4: Cerâmica Ceramco 3 - esmalte e dentina.

Primeiramente foi aplicada a pasta base universal do sistema Ceramco 3, com o auxílio de um pincel. O disco com a primeira camada era então colocado sobre uma bandeja de material refratário e então levado ao forno (Phoenix - Ceramco - Dentsply) (Fig.5) já programado, conforme instruções do fabricante, para o seguinte protocolo de sinterização:

- Secagem: 5 minutos,

- Pré-aquecimento: 3 minutos,

- Temperatura inicial: $500{ }^{\circ} \mathrm{C}$,

- Temperatura final: $975^{\circ} \mathrm{C}$,

- Vácuo: 29 polegadas $/ \mathrm{cm}^{3}$,

- Taxa de elevação: $100{ }^{\circ} \mathrm{C}$ por minuto,

- Vácuo desligado: $975^{\circ} \mathrm{C}$. 


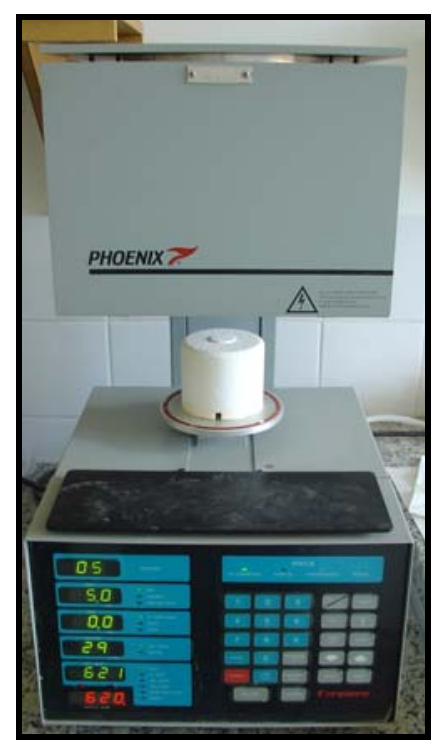

Figura 5: Forno Phoenix - Ceramco.

Na seqüência foi aplicada, também com a ajuda de um pincel, a pasta opaca na cor B3, que foi sinterizada obedecendo ao seguinte protocolo:

- Secagem: 3 minutos,

- Pré-aquecimento: 3 minutos,

- Temperatura inicial: $650^{\circ} \mathrm{C}$,

- Temperatura final: $970{ }^{\circ} \mathrm{C}$,

- Vácuo: 29 polegadas $/ \mathrm{cm}^{3}$,

- Taxa de elevação: $70{ }^{\circ} \mathrm{C}$ por minuto,

- Vácuo desligado: $970{ }^{\circ} \mathrm{C}$.

As duas camadas (pasta base universal mais pasta opaca B3) totalizavam menos de 0,1mm de espessura, conforme foi medido com espessímetro.

$\mathrm{Na}$ camada seguinte foram colocados espaçadores totalizando $5 \mathrm{~mm}$ de espessura, já que $3 \mathrm{~mm}$ foram ocupados pela subestrutura de metal, onde, com a ajuda de uma régua para conferir a espessura, foi colocado $1 \mathrm{~mm}$ de dentina da cerâmica Ceramco 3 na cor B3 e posteriormente $1 \mathrm{~mm}$ de esmalte incisal medium da cerâmica Ceramco 3. 
O pó da porcelana dentina foi misturado com água destilada sobre uma placa de vidro, até se obter uma massa cerâmica de consistência cremosa, que foi aplicada em incrementos no interior da matriz com o auxílio de uma espátula, imitando a técnica laboratorial convencionalmente empregada para a confecção de uma restauração cerâmica. Após a colocação de cada incremento e completando a espessura de $1 \mathrm{~mm}$, ocorria o afloramento do excesso de líquido por meio de uma pequena vibração produzida com a parte serrilhada do cabo de uma espátula LeCron, e com o auxílio de papel absorvente o excesso do líquido era então removido. Este procedimento permitiu uma menor inclusão de bolhas de ar na massa e uma menor contração de queima da porcelana (BELSUZARRI, 2004).

O mesmo procedimento foi realizado para a aplicação de $1 \mathrm{~mm}$ de cerâmica de esmalte, completando 2 mm de espessura de cerâmica.

Quando a massa cerâmica apresentava-se seca, procedia-se a desinclusão do corpo de prova da matriz de teflon, o espaçador era removido e a haste vertical servia como um êmbolo para a remoção do corpo de prova. O conjunto metal - cerâmica era colocado sobre uma bandeja de material refratário e levado ao forno, sendo o ciclo de sinterização programado conforme instruções do fabricante seguindo o protocolo:

- Secagem: 5 minutos

- Pré-aquecimento: 5 minutos,

- Temperatura inicial: $650^{\circ} \mathrm{C}$,

- Temperatura final: $960{ }^{\circ} \mathrm{C}$,

- Vácuo: 29 polegadas $/ \mathrm{cm}^{3}$,

- Taxa de elevação: $55^{\circ} \mathrm{C}$ por minuto,

- Vácuo desligado: $960{ }^{\circ} \mathrm{C}$. 
Terminado este ciclo era realizado o polimento dos corpos de prova, utilizando uma ponta diamantada para peça reta em baixa rotação (KG) seguida de disco branco para polimento de cerâmica (Cerapol) (Fig. 6). Todos os corpos eram então conferidos com espessímetro, sendo aceitos aqueles com $5 \mathrm{~mm} \pm 0,1 \mathrm{~mm}$ de espessura.

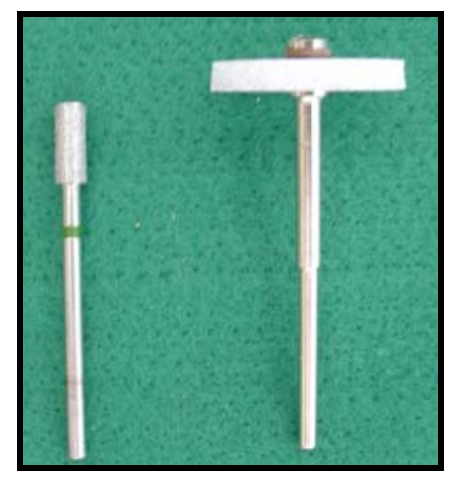

Figura 6: Pontas utilizadas para polimento da cerâmica.

Após o polimento, os 14 corpos de prova deste grupo foram divididos em 2 , onde 07 corpos foram antes pintados extrinsecamente com pigmento 712 da Vita Chrom (Vita) (Fig. 7), e então glazeados, e os 07 restantes foram apenas glazeados (sem se submeter à pintura extrínseca) conforme o protocolo:

- Secagem: 3 minutos,

- Pré-aquecimento: 3 minutos,

- Temperatura inicial: $650{ }^{\circ} \mathrm{C}$,

- Temperatura final: $945^{\circ} \mathrm{C}$,

- Vácuo: 0 ,

- Taxa de elevação: $70^{\circ} \mathrm{C}$ por minuto,

- Tempo de permanência na temperatura máxima: 0,5 minutos. 


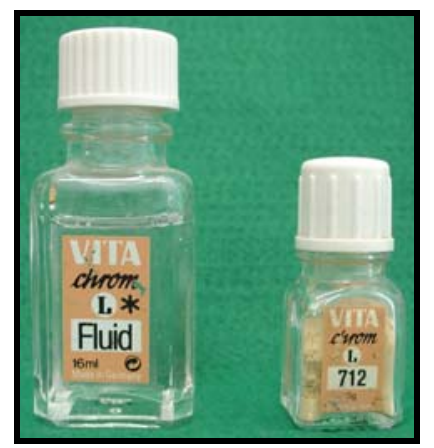

Fig. 7. Pigmento Vita Chrom 712 - pó e fluido.

Após o término desses procedimentos, os corpos de prova eram então armazenados à temperatura ambiente para posterior leitura em espectrofotômetro (Fig. 8).

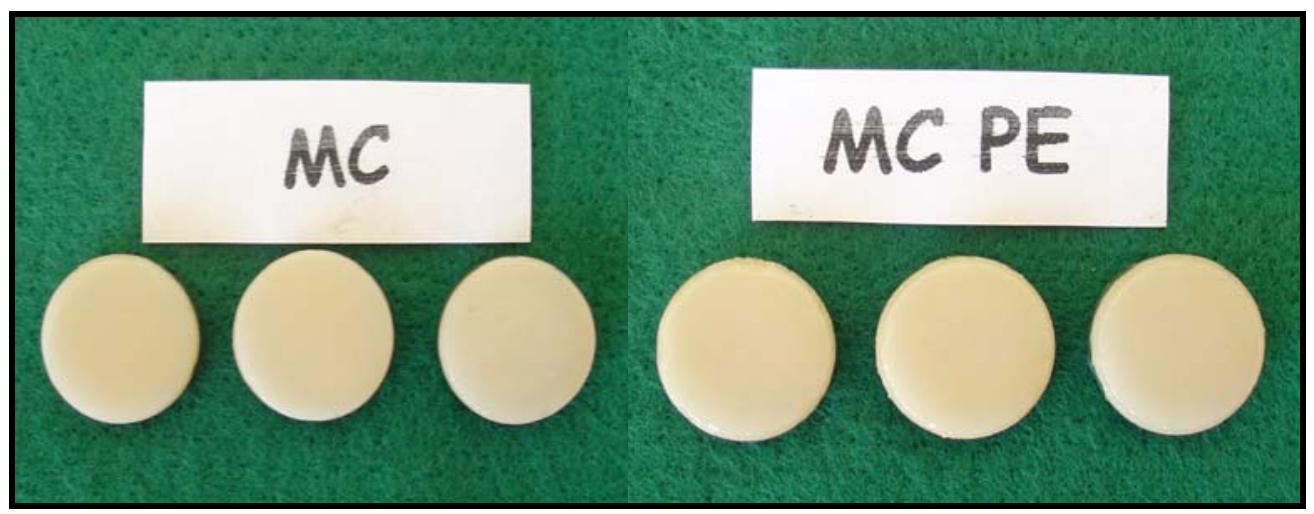

Figura 8: Corpos de prova do Grupo 1 (metalocerâmica - Ceramco 3), sendo MC subgrupo formado pelos discos sem pintura extrínseca e MC PE subgrupo formado pelos discos submetidos à pintura extrínseca.

4.1.2. Técnica de obtenção dos corpos de prova totalmente cerâmicos em cerâmica Ceramco 3 - Grupo 2.

Para a confecção dos corpos de prova deste grupo foi utilizado um espaçador de $2 \mathrm{~mm}$ na matriz, onde, com a ajuda de uma régua para conferir 
espessura, foi colocado $1 \mathrm{~mm}$ de dentina da cerâmica Ceramco 3 na cor B3 e posteriormente $1 \mathrm{~mm}$ de esmalte incisal medium da cerâmica Ceramco 3.0 conjunto composto de dentina e esmalte totalizando $2 \mathrm{~mm}$ era então retirado da matriz e levado ao forno Phoenix para sinterizar em um único ciclo, seguindo o mesmo protocolo já descrito para a cerâmica esmalte e dentina, conforme instruções do fabricante da Ceramco 3. (Fig. 9).

O preparo e aplicação da massa cerâmica de dentina e esmalte deste grupo ocorreram de forma semelhante ao descrito na aplicação da dentina e esmalte do grupo 1.

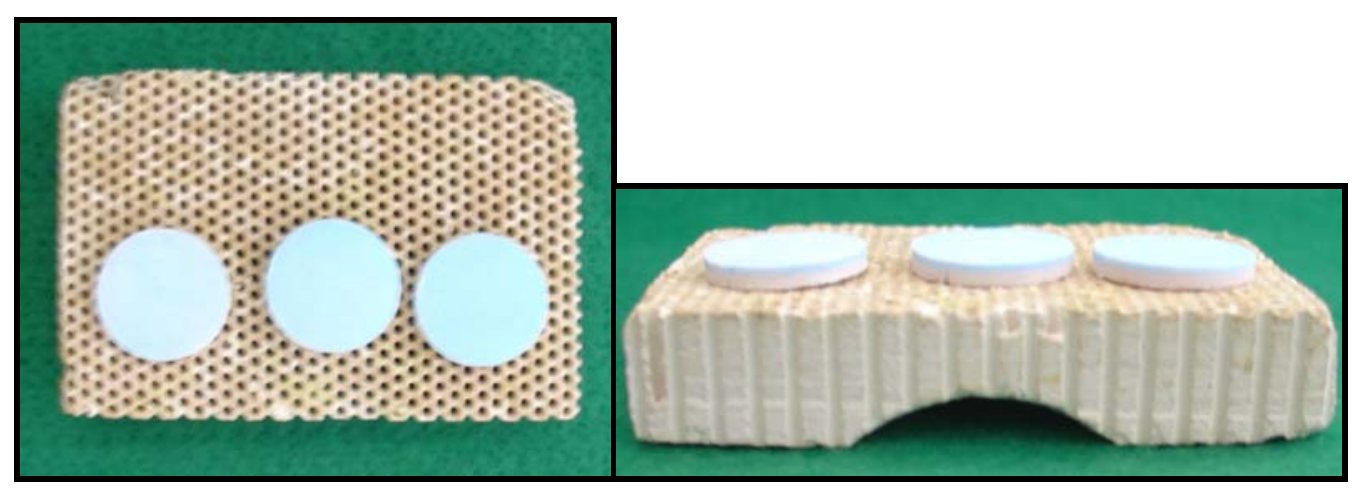

Figura 9: Pastilhas confeccionadas com cerâmica Ceramco 3 antes da queima.

O polimento dos corpos de prova do grupo 2 foi realizado da mesma maneira dos corpos do grupo 1 , sendo então conferidos com espessímetro e aceitos aqueles com $2 \mathrm{~mm} \pm 0,1 \mathrm{~mm}$ de espessura.

As 14 amostras deste grupo foram divididas em 2, onde 07 amostras foram pintadas extrinsecamente com pigmento 712 da Vita Chrom, e então glazeadas, e as 07 restantes foram apenas glazeadas (sem se submeter à pintura extrínseca) conforme o protocolo já descrito (Fig. 10). 


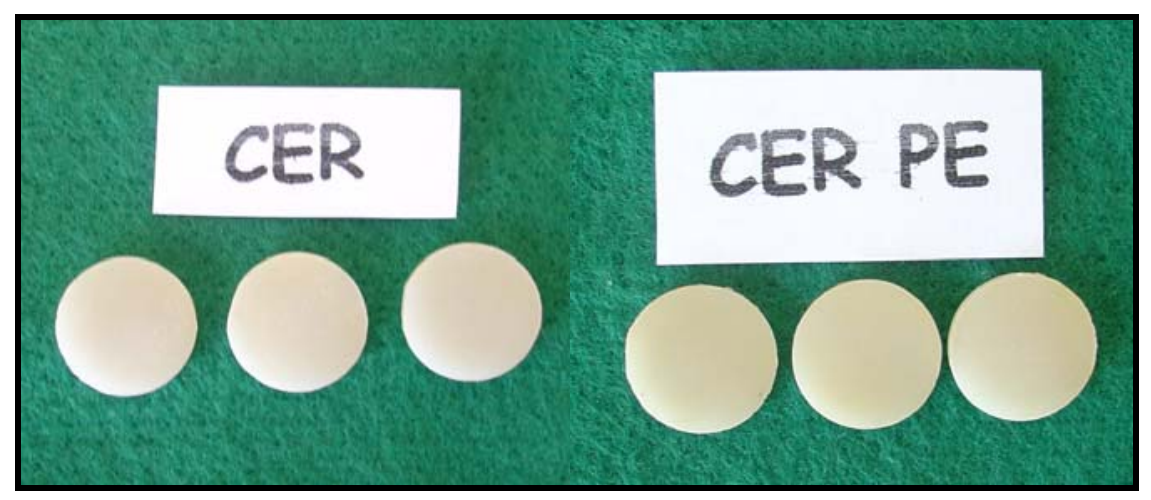

Figura 10: Corpos de prova do Grupo 2 (cerâmica pura - Ceramco 3), sendo CER subgrupo formado pelos discos glazeados naturalmente e CER PE subgrupo formado pelos discos submetidos à pintura extrínseca.

4.1.3. Técnica de obtenção dos corpos de prova totalmente cerâmicos em cerâmica EX-3 - Grupo 3.

Os 14 corpos de prova deste grupo foram confeccionados utilizando um espaçador de $2 \mathrm{~mm}$ na matriz, onde, com a ajuda de uma régua para conferir espessura, foi colocado $1 \mathrm{~mm}$ de dentina da cerâmica EX-3 e posteriormente $1 \mathrm{~mm}$ de esmalte da cerâmica EX-3, denominado E3 (Fig. 11). O conjunto composto de dentina e esmalte totalizando $2 \mathrm{~mm}$ era então retirado da matriz e levado ao forno Phoenix para sinterizar de uma só vez, conforme o seguinte protocolo preconizado pelo fabricante:

- Secagem: 8 minutos,

- Temperatura inicial: $600{ }^{\circ} \mathrm{C}$,

- Temperatura final: $930{ }^{\circ} \mathrm{C}$,

- Vácuo: 29 polegadas $/ \mathrm{cm}^{3}$,

- Taxa de elevação: $45^{\circ} \mathrm{C}$ por minuto,

- Vácuo desligado: $920{ }^{\circ} \mathrm{C}$. 


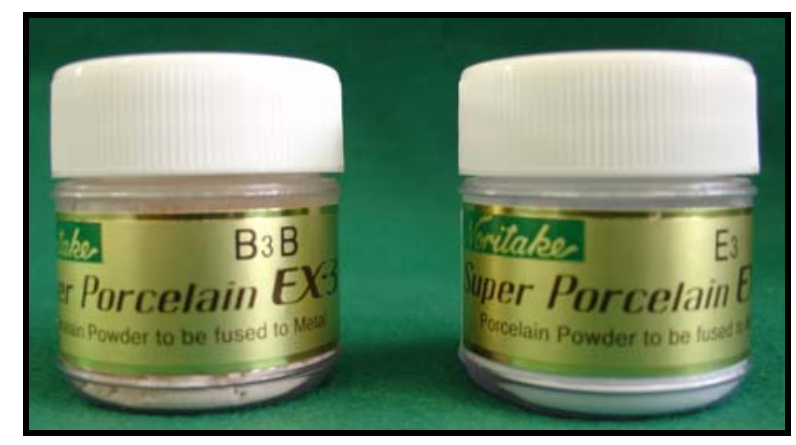

Figura 11: Cerâmica EX-3 - dentina e esmalte.

Sendo o polimento realizado da mesma maneira dos grupos 1 e 2 , todos os corpos eram então conferidos com espessímetro, sendo aceitos aqueles com $2 \mathrm{~mm} \pm 0,1 \mathrm{~mm}$ de espessura.

Os corpos de prova deste grupo (Fig. 12) foram divididos em 2, onde 07 corpos foram pintados extrinsecamente com pigmento 712 da Vita Chrom, e então glazeados, e os 07 restantes foram apenas glazeados (sem se submeter à pintura extrínsica) conforme o seguinte protocolo:

- Secagem: 5 minutos,

- Temperatura inicial: $650{ }^{\circ} \mathrm{C}$,

- Temperatura final: $890{ }^{\circ} \mathrm{C}$,

- Vácuo: 0,

- Taxa de elevação: $45^{\circ} \mathrm{C}$ por minuto,

- Tempo de permanência na temperatura máxima: 0 . 


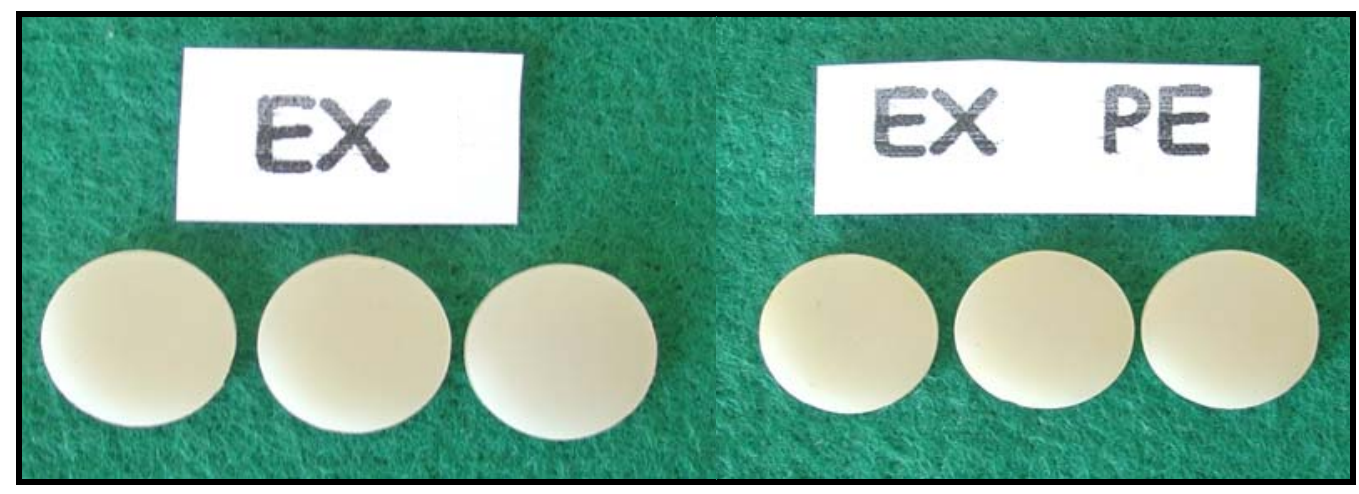

Figura 12: Corpos de prova do Grupo 3 (cerâmica pura - EX), sendo EX o subgrupo formado pelos discos sem pintura extrínsica e EX PE subgrupo formado pelos discos submetidos à pintura extrínsica.

4.1.4. Técnica de obtenção dos corpos de prova sistema ceramo-cerâmico Vitro-Ceram recoberta com Allceram - Grupo 4.

Para a obtenção dos corpos de prova ceramo-cerâmicos, primeiramente foram confeccionadas as pastilhas de cerâmica aluminizada Vitro-Ceram, que serviram de subestrutura para a aplicação da cerâmica Allceram, conforme os passos abaixo:

A) Preparo da pasta de alumina.

Em um frasco de vidro de $50 \mathrm{ml}$ foi adicionado 1 frasco do líquido e 1 gota de aditivo. O frasco de vidro foi então levado ao aparelho de ultra-som e vagarosamente o conteúdo de um sache de pó de alumina foi adicionado à solução líquida (Fig. 13). A solução foi constantemente misturada com espátula de vidro por 2 minutos. O frasco foi mantido no banho de ultra-som por 10 minutos. Após a colocação do espaçador de $2 \mathrm{~mm}$ na matriz de teflon, a solução já preparada era vertida sobre a matriz e, após a secagem (20 minutos), as pastilhas de alumina eram retiradas da matriz. 


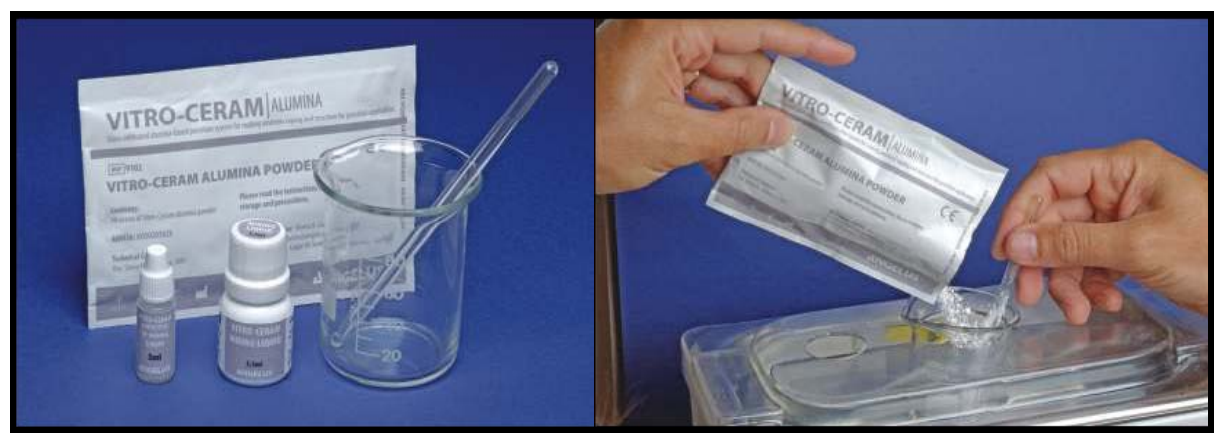

Figura 13: Esquerda - Pó de alumina, líquido de mesclar e frasco de aditivo Vitro-Ceram. Direita - pó de alumina sendo incorporado à solução durante vibração ultra-sônica.

As pastilhas de alumina foram sinterizadas em um forno próprio para sinterização e infiltração de vidro Sinter Plus (FDG) (Fig. 14) seguindo o protocolo:

- Secagem: 6 minutos

- Temperatura inicial: $120^{\circ} \mathrm{C}$,

- Temperatura final: $1.120^{\circ} \mathrm{C}$,

- Vácuo: 0,

- Taxa de elevação: $25^{\circ} \mathrm{C}$ por minuto,

- Tempo de permanência na temperatura máxima: 60 minutos.

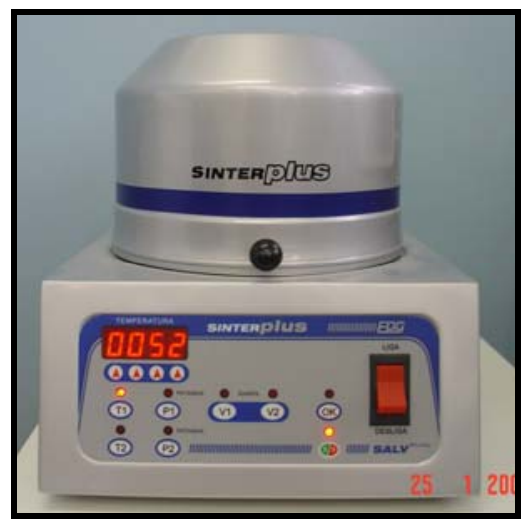

Figura 14: Forno Sinter Plus (FDG). 
B) Aplicação e infiltração do vidro.

O pó de vidro foi misturado com água destilada, formando uma pasta de vidro de consistência média, e foi aplicado sobre as pastilhas de alumina sinterizadas, e foram novamente levadas ao forno seguindo o protocolo:

- Secagem: 6 minutos

- Temperatura inicial: $120^{\circ} \mathrm{C}$,

- Temperatura final: $1.110^{\circ} \mathrm{C}$,

- Vácuo: 0 ,

- Taxa de elevação: $9{ }^{\circ} \mathrm{C}$ por minuto,

- Tempo de permanência na temperatura máxima: 40 minutos.

Decorrida a infiltração, os excessos de vidro foram removidos usando pontas e discos diamantados para posteriormente ser realizado o acabamento com disco de borracha, ficando evidente a superfície opaca (Fig. 15).

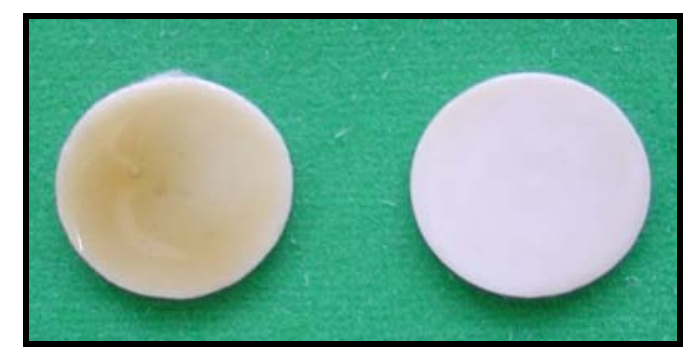

Figura 15: Esquerda - Pastilha de alumina infiltrada de vidro, Direita - Pastilha infiltrada já com o excesso de vidro removido.

Sobre a pastilha de alumina infiltrada e polida foi inicialmente aplicada com o auxílio de um pincel, uma camada de opaco sinterizada seguindo o protocolo:

- Secagem: 5 minutos,

- Temperatura inicial: $575^{\circ} \mathrm{C}$, 
- Temperatura final: $930^{\circ} \mathrm{C}$,

- Vácuo: 29 polegadas $/ \mathrm{cm}^{3}$,

- Taxa de elevação: $55^{\circ} \mathrm{C}$ por minuto,

- Tempo de permanência na temperatura máxima: 1 minuto.

Terminado o ciclo, a pastilha foi novamente colocada na matriz de teflon, agora com espaçador de $4 \mathrm{~mm}$ (sendo $2 \mathrm{~mm}$ ocupado pela infra-estrutura de alumina infiltrada), e em seguida foi aplicada $1 \mathrm{~mm}$ de dentina e $1 \mathrm{~mm}$ de esmalte da cerâmica Allceram na cor B3 (Fig. 16), utilizando o forno Centurion (Dentsply) (Fig. 17). A massa cerâmica foi preparada da mesma maneira que a dos grupos 1,2 e 3 e a pastilha foi removida da matriz e sinterizada de uma só vez seguindo o protocolo:

- Secagem: 5 minutos

- Temperatura inicial: $575^{\circ} \mathrm{C}$,

- Temperatura final: $920^{\circ} \mathrm{C}$,

- Vácuo: 29 polegadas $/ \mathrm{cm}^{3}$,

- Taxa de elevação: $55^{\circ} \mathrm{C}$ por minuto,

- Tempo de permanência na temperatura máxima: 1 minuto.

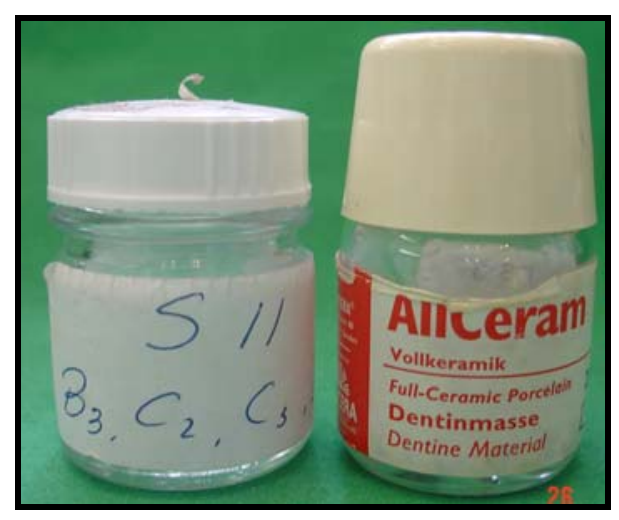

Figura 16: Cerâmica Allceram - esmalte e dentina. 


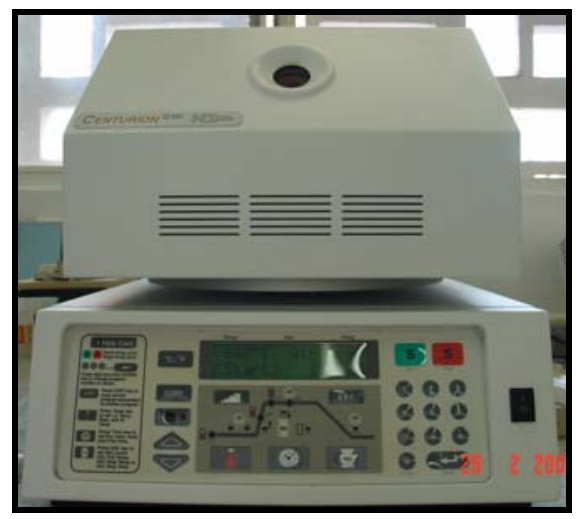

Figura 17: Forno Centurion Q100 (Dentsply).

Após o polimento, que foi realizado da mesma maneira dos grupos 1, 2 e 3, todos os corpos eram então medidos com espessímetro, sendo aceitos aqueles com $4 \mathrm{~mm} \pm 0,2 \mathrm{~mm}$ de espessura.

Os corpos de prova deste grupo (Fig. 18) foram divididos em 2, onde 07 corpos foram pintados extrinsecamente com pigmento 712 da Vita Chrom, e então glazeados, e os 07 restantes foram apenas glazeados (sem se submeter à pintura extrínsica) conforme o seguinte protocolo preconizado pelo fabricante:

- Secagem: 3 minutos,

- Temperatura inicial: $575^{\circ} \mathrm{C}$,

- Temperatura final: $900{ }^{\circ} \mathrm{C}$,

- Vácuo: 0,

- Taxa de elevação: $55^{\circ} \mathrm{C}$ por minuto,

- Tempo de permanência na temperatura máxima: 3 minutos. 


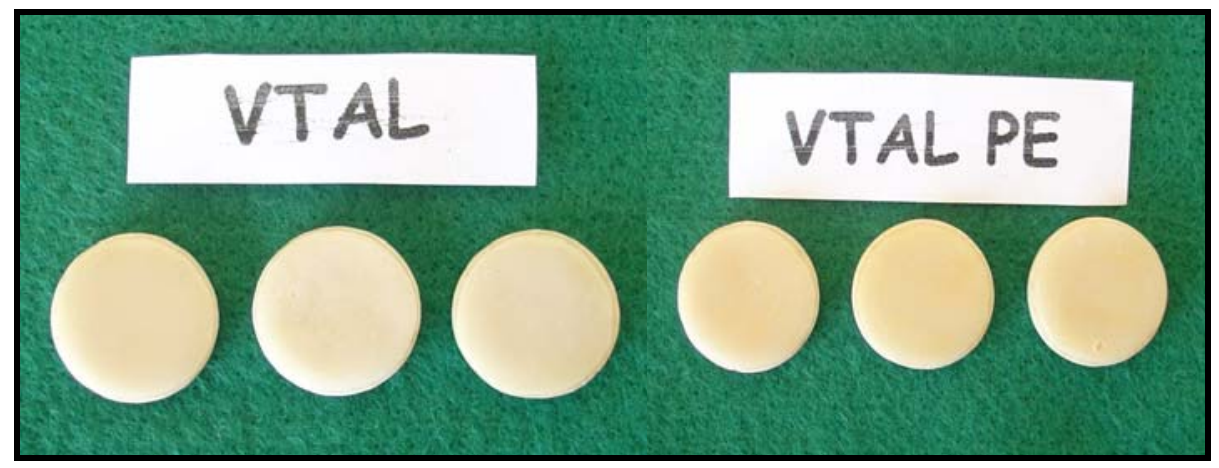

Figura 18: Corpos de prova do Grupo 4 (ceramo-cerâmica - VitroCeram/Allceram), sendo VTAL subgrupo formado pelos discos sem pintura extrínsica e VTAL PE subgrupo formado pelos discos submetidos à pintura extrínsica.

4.1.5. Técnica de obtenção dos corpos de prova sistema ceramo-cerâmico Vitro-Ceram recoberta com Cerabien - Grupo 5.

Para a obtenção dos corpos de prova ceramo-cerâmicos do grupo 5, primeiramente foram confeccionadas as pastilhas de cerâmica aluminizada Vitro-Ceram, que serviram de subestrutura para a aplicação da cerâmica Cerabien, seguindo os mesmos passos A e B do grupo 4.

Posteriormente, sobre a pastilha de alumina infiltrada foi aplicada uma camada de shade base, sinterizada conforme instruções do fabricante, seguindo o protocolo:

- Secagem: 5 minutos,

- Temperatura inicial: $600{ }^{\circ} \mathrm{C}$,

- Temperatura final: $960^{\circ} \mathrm{C}$,

- Início do vácuo: $600{ }^{\circ} \mathrm{C}$,

- Vácuo: 29 polegadas $/ \mathrm{cm}^{3}$,

- Taxa de elevação: $45^{\circ} \mathrm{C}$ por minuto,

- Tempo de permanência na temperatura máxima: 1 minuto. 
Após a sinterização do shade base, a pastilha foi novamente colocada na matriz de teflon, agora com espaçador de $4 \mathrm{~mm}$, e em seguida foi aplicado 1 $\mathrm{mm}$ de dentina e $1 \mathrm{~mm}$ de esmalte da cerâmica Cerabien na cor B3 (Fig. 19). A massa cerâmica foi preparada da mesma maneira que a dos grupos 1, 2, 3 e 4, sendo removida da matriz e sinterizada em uma só vez utilizando o forno Centurion e seguindo o protocolo conforme instruções do fabricante:

- Secagem: 7 minutos,

- Temperatura inicial: $600{ }^{\circ} \mathrm{C}$,

- Temperatura final: $960^{\circ} \mathrm{C}$,

- Início do vácuo: $600{ }^{\circ} \mathrm{C}$,

- Vácuo: 29 polegadas $/ \mathrm{cm}^{3}$,

- Taxa de elevação: $45^{\circ} \mathrm{C}$ por minuto,

- Tempo de permanência na temperatura máxima: 2 minutos.

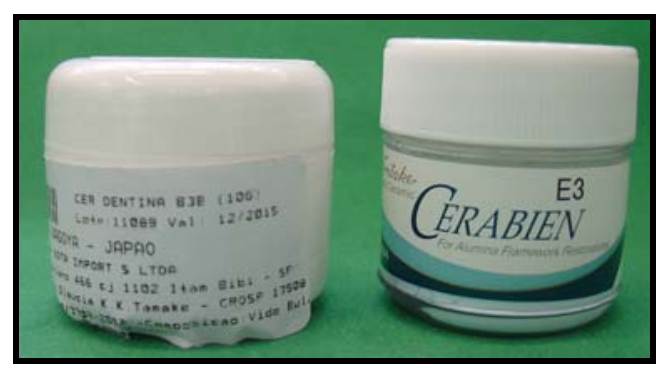

Figura 19: Cerâmica Cerabien - esmalte e dentina.

Após o polimento, que foi realizado da mesma maneira dos outros grupos, todos os corpos eram então medidos com espessímetro, sendo aceitos aqueles com $4 \mathrm{~mm} \pm 0,2 \mathrm{~mm}$ de espessura. 
Os corpos de prova deste grupo (Fig. 20) foram divididos em 2, onde 07 corpos foram pintados extrinsecamente com pigmento 712 da Vita Chrom, e então glazeados, e os 07 restantes foram apenas glazeados (sem se submeter à pintura extrínsica) conforme o seguinte protocolo preconizado pelo fabricante:

- Secagem: 5 minutos,

- Temperatura inicial: $600^{\circ} \mathrm{C}$,

- Temperatura final: $960^{\circ} \mathrm{C}$,

- Vácuo: 0 ,

- Taxa de elevação: $50{ }^{\circ} \mathrm{C}$ por minuto,

- Tempo de permanência na temperatura máxima: 0,5 minuto.

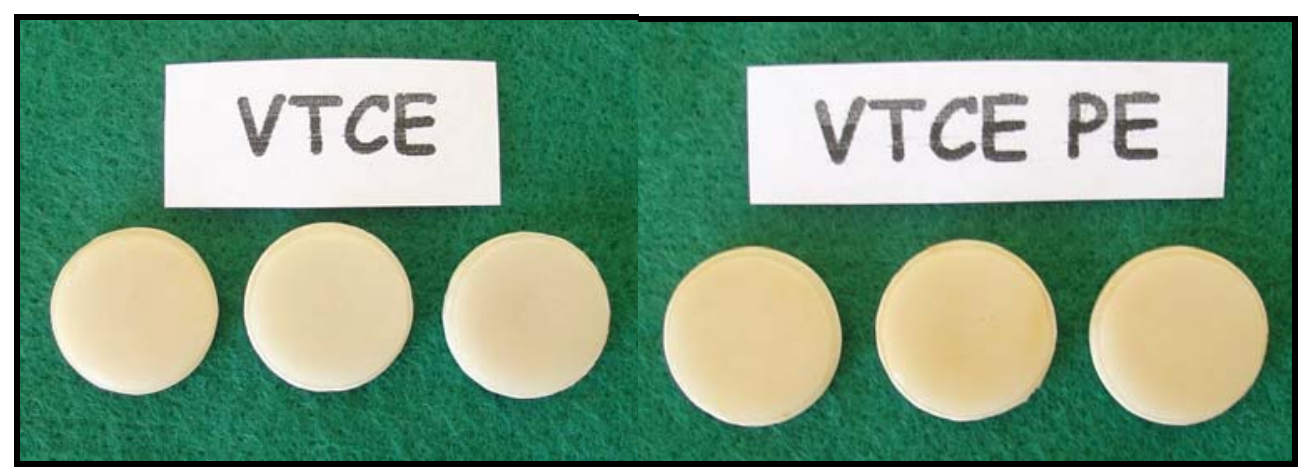

Figura 20: Corpos de prova do Grupo 5 (ceramo-cerâmica - VitroCeram/Cerabien), sendo VTCE subgrupo formado pelos discos sem pintura extrínsica e VTCE PE subgrupo formado pelos discos submetidos à pintura extrínsica.

As amostras dos 5 grupos foram levadas então para os espectrofotômetros Color Guide 45/0 (BYK-Gardner) e EasyShade (Vita) para a leitura inicial da cor. 


\subsection{Leitura dos corpos de prova com espectrofotômetro Color Guide 45/0 (BYK-Gardner).}

O espectrofotômetro modelo Color Guide 45/0 utilizado neste estudo é um aparelho portátil, desenvolvido para indústrias em geral e tem como função à medição de cor de uma determinada amostra, cujos valores são apresentados em padrões numéricos (Fig. 21).

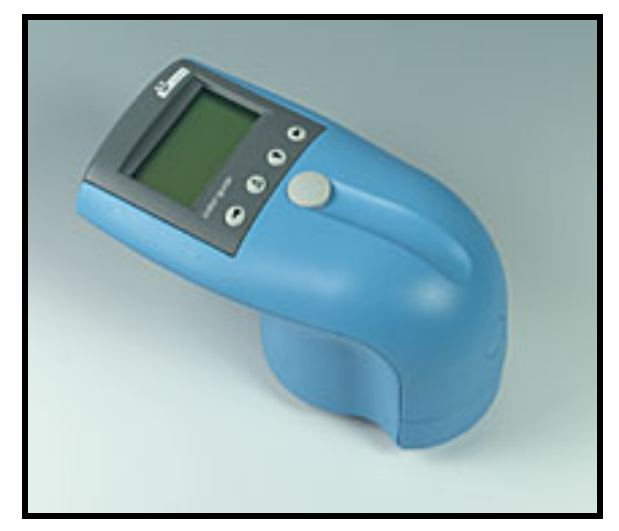

Figura 21: Espectrofotômetro modelo Color Guide 45/0 (Disponível em: < http://www.byk-gardner.com > Acesso 07/01/2007).

A abertura de medição de cor deste aparelho é de $11 \mathrm{~mm}$ e a geometria óptica é de 45/0, ou seja, a amostra é iluminada em 45 graus na superfície e a luz refletida é medida em 0 grau (Fig. 22), sendo o padrão de iluminante o D65 e o observador padrão de $10^{\circ}$. 


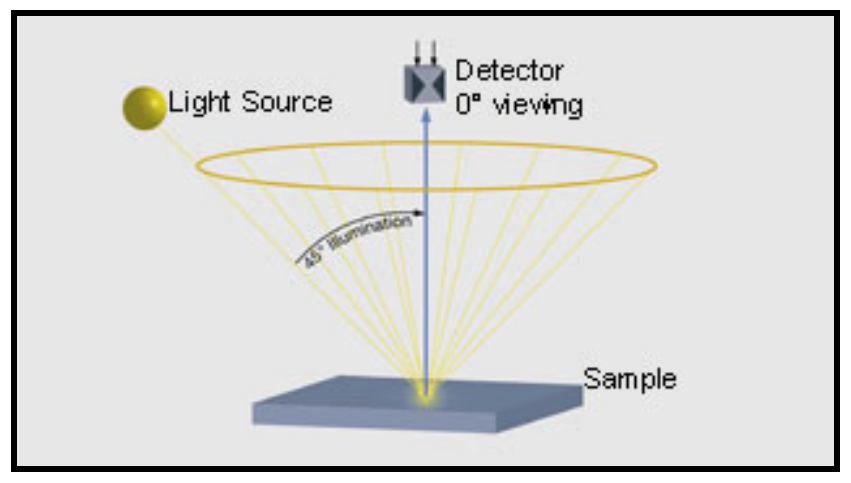

Figura 22: Geometria óptica 45/0 (Disponível em: < http://www.byk-gardner.com > Acesso 07/01/2007).

Este aparelho possui vários sistemas possíveis de leitura de cor. Cada sistema nada mais é do que uma ferramenta para comunicar e documentar cor e diferenças de cores. O sistema escolhido neste estudo foi o CIELab (Fig 23), por ser o mais comumente utilizado em estudos de espectrofotometria na odontologia (RAZZOG, et al, 1994; YAMAN, et al., 1997; SCHULZE, et al, 2001; BARATH, 2003; ERTAN , SAIIIN, 2004).

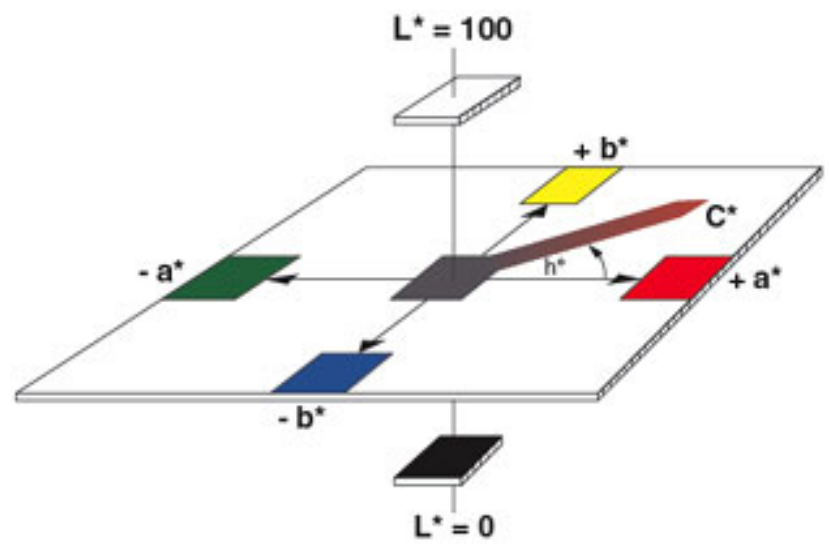

Figura 23: Representação do sistema de cor CIELab. (Disponível em: < http://www.byk-gardner.com > Acesso 07/01/2007). 
4.2.1. Leitura de opacidade.

Antes do procedimento de leitura de opacidade das amostras, foi realizada a calibração do aparelho conforme orientação do fabricante. Fundos preto e branco são necessários para o calculo de opacidade, sendo utilizado neste estudo os fundos preto e branco padrão BYK-Gardner. O corpo de prova era primeiramente colocado sobre o fundo preto padrão e procedia-se uma leitura inicial. Feito isto, procedia-se à leitura novamente da mesma amostra agora sobre um fundo branco. A razão de contraste da refletância $(R C)$ ou opacidade é calculada diretamente pelos valores de luminosidade $\left(L^{*}\right)$ medidos pelo espectrofotômetro, através da equação:

$$
R C=\left[\left(L^{*}{ }_{P}+16\right) /\left(L^{*}{ }_{B}+16\right)\right]
$$

onde $L^{*}$ r representa valores de luminosidade com fundo preto e $L^{*}{ }_{B}$ são valores de luminosidade com fundo branco (GOVEIA, 2004; VICHI, et.al., 2004).

Os valores de opacidade foram expressos em porcentagem, sendo $100 \%$ para os objetos totalmente opacos. Estes valores foram armazenados digitalmente para posterior comparação com os valores gerados na leitura final após o envelhecimento artificial das amostras.

\subsubsection{Leitura de cor.}

Antes do procedimento de leitura de cor das amostras foi realizada a calibração do aparelho conforme orientação do fabricante. Uma leitura inicial de cada corpo de prova foi feita num total de 70 leituras e cada leitura registrava valores numéricos das coordenadas $L^{*}, a^{*} e b^{*}$. 
As leituras dos corpos de prova do grupo 1 foram realizadas sem a necessidade de qualquer anteparo ou fundo, já que eram amostras com infraestrutura totalmente opaca. Já para os corpos de prova dos outros grupos foi colocado um fundo padrão branco (Fig. 24) (SEGHI, 1989b).

Para todas as leituras dos corpos de prova foi utilizado um dispositivo de reposicionamento da amostra para garantir a fidelidade das medições, na tentativa de eliminar os erros decorrentes de posicionamento da amostra.

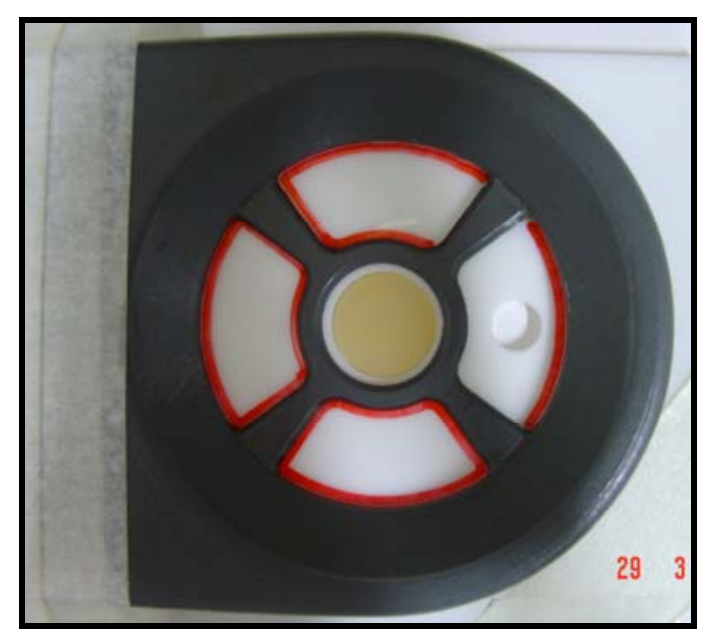

Figura 24: Corpo de prova posicionado para a leitura, com ajuda de dispositivo de medição e fundo padrão branco.

Após submeter os corpos de prova ao envelhecimento artificial, foram realizadas novas leituras, da mesma maneira que as leituras iniciais. 0 aparelho então fornecia novos dados de $L^{*}, a^{*}$ e $b^{*}$ e dados já calculados de $\Delta \mathrm{L}^{*}, \Delta \mathrm{a}^{*}, \Delta \mathrm{b}^{*}$ e $\Delta \mathrm{E}^{*}$. Estes dados iniciais e finais foram então avaliados estatisticamente para verificação de possíveis alterações na cor das amostras cerâmicas e estudo de como estas alterações influenciaram na mudança total da cor final das amostras. 


\subsection{Leitura dos corpos de prova com espectrofotômetro Easyshade} (Vita).

O espectrofotômetro Easyshade é um aparelho portátil, desenvolvido especialmente para odontologia e possui uma ponteira digital capaz de ler numericamente a cor de um dente ou verificar a cor de uma restauração dental, comparando-a com as escalas de cor Vita Clássica e VitaPan 3D Master, independentemente da iluminação do ambiente (Fig. 25).

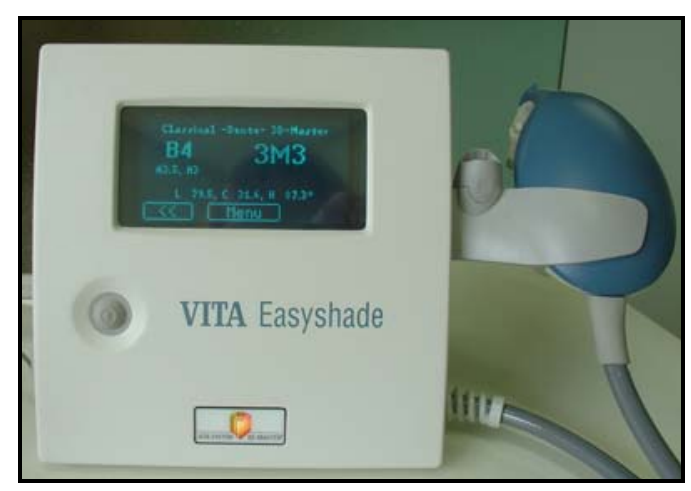

Figura 25: Aparelho Easyshade.

O aparelho é composto de uma ponteira que possui 19 fibras ópticas individuais que iluminam o dente e têm 2 sensores espectrofotométricos. Estes componentes somados possibilitam uma variação na profundidade de medição da cor da amostra, de acordo com a função previamente escolhida.

O Easyshade possui um visor interativo que possibilita a escolha da medição de cor de várias maneiras, como a leitura individual da cor de um dente, leitura de cor de um dente nos seus terços, cervical, médio e incisal e a função "verificação de restauração", que permite ao profissional confirmar se a cor de uma dada restauração está compatível com a cor anteriormente selecionada 
através da escala de cor (Vita Clássica ou Vita 3D Master). O espectro dos 2 espectrofotômetros é matematicamente combinado de acordo com o material escolhido, para produzir um espectro representativo deste material, portanto o aparelho Easyshade é material dependente e o usuário é requerido para selecionar um modo de medição baseado no tipo de material: dente natural, cerâmica ou tabela de cor (Fig. 26) (JJL TECHNOLOGIES, 2003).

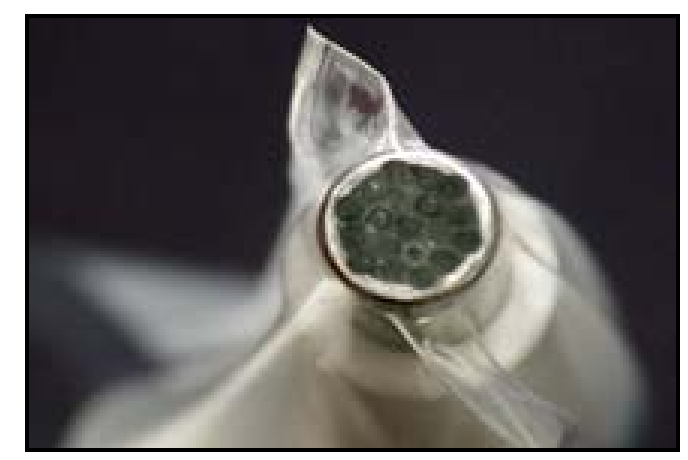

Figura 26: Fibras ópticas presentes na ponteira do aparelho Easyshade. (Disponível em: < http://www.vident.com> Acesso em 07/01/2007).

A geometria óptica de medição de cor deste aparelho é circular com o componente especular excluído, o que simula uma medição 45/0. O iluminante padrão é o D65 e o observador padrão de $2^{\circ}$. O componente especular excluído é relacionado à medição da cor na superfície da amostra, para evitar a interferência do brilho da superfície (JJL TECHNOLOGIES, 2003).

A função escolhida neste estudo foi a de "verificação de restauração" onde foi possível verificar as discrepâncias da cor dos corpos de prova (amostras) com a cor escolhida na escala de cor Vita Clássica B3 (padrão) (Fig. 27).

Antes do procedimento de leitura de cor das amostras foi realizada a calibração do aparelho conforme orientação do fabricante. Uma leitura foi feita 
para cada corpo de prova em um total de 70 leituras (Fig. 28). As leituras eram realizadas com o cuidado de sempre posicionar a ponteira no centro do corpo de prova, previamente determinado, com a ponteira formando um ângulo de $90^{\circ}$ em relação à amostra.

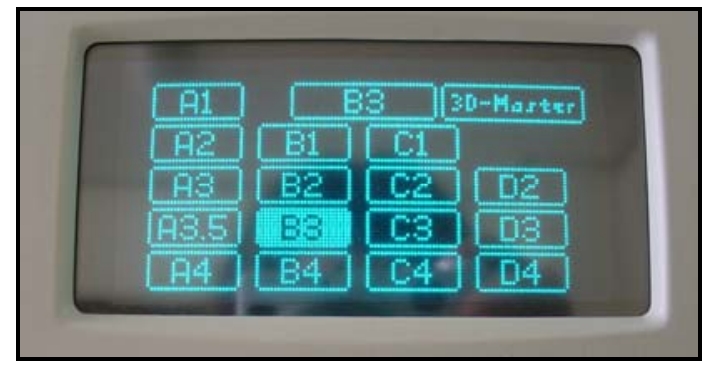

Figura 27: Seleção da cor padrão B3 para comparação com cor da amostra.
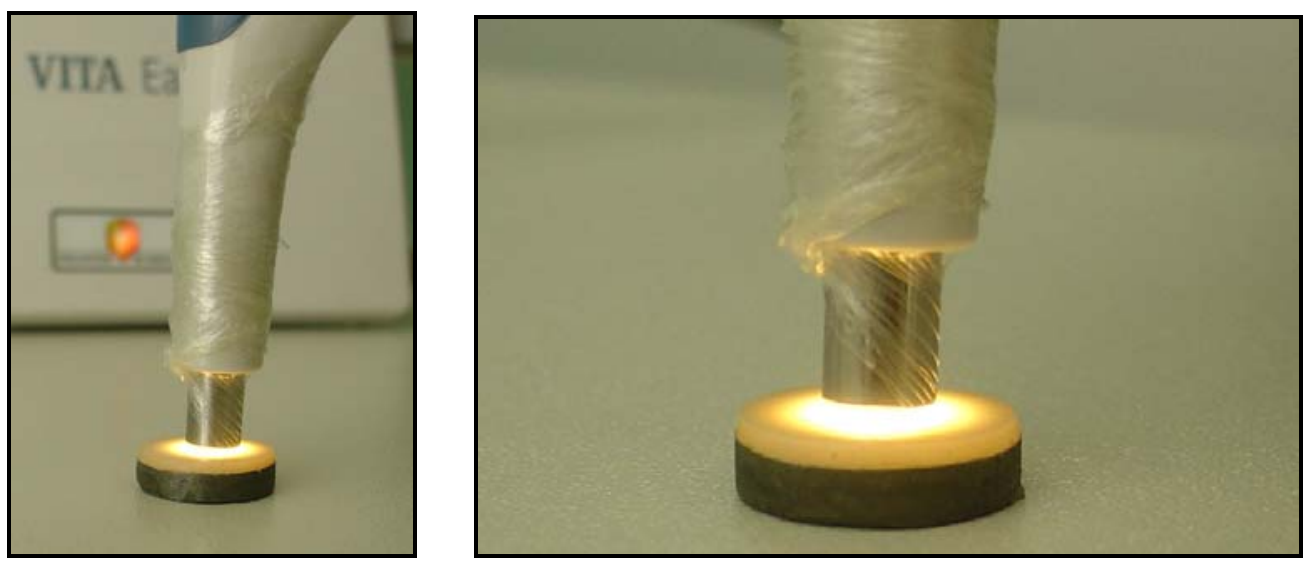

Figura 28: Leitura de amostra de cerâmica pelo aparelho Easyshade.

Para cada corpo de prova, o visor mostrava gráficos de matiz, croma e valor e comparava esta medida com os valores de matiz, croma e valor da cor selecionada B3(padrão), sendo "Good" para quando não havia necessidade de ajuste, "Fair" quando estava satisfatória e "Adjust" quando a cor do corpo era inaceitável quando comparada à selecionada (Fig. 29). 


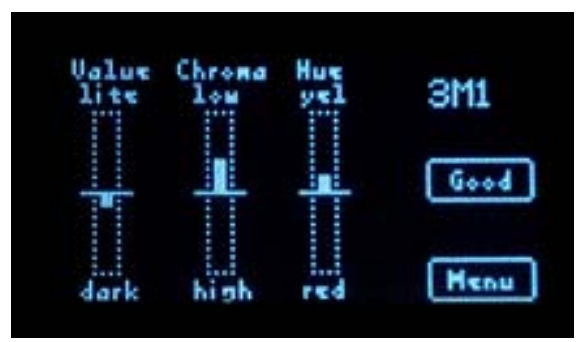

Figura 29: Visor do aparelho Easyshade na função "Verificação de Restauração". (Disponível em: < http://www.vident.com> Acesso em 07/01/2007).

Para cada corpo de prova foram obtidos também valores numéricos interpretativos dos gráficos apresentados de valor, croma e matiz. Estes valores eram a diferença entre a cor do corpo de prova e a cor selecionada B3. Exemplo: $\left(\Delta L^{*}=L^{*}\right.$ amostra $-L^{*}$ padrão $\left.B 3\right)$ e eram medidas as variáveis $L^{*}, C^{*}, h^{*} e$ $\Delta \mathrm{E}^{*}$ (sistema CIELCh). As variáveis $\mathrm{C}^{*}$ e $\mathrm{h}^{*}$ são uma alternativa para as variáveis $\mathrm{a}^{*} \mathrm{e} \mathrm{b}^{*}$ do sistema CIELab, onde $\mathrm{C}^{*}$ dá coordenadas de intensidade ou croma e $\mathrm{h}^{*}$ (ângulo) dá coordenadas de tonalidade ou matiz.

Para os corpos de prova com infra-estrutura metálica (Grupo 1) não foram colocados fundo para a leitura. Nos outros grupos, de maior translucidez, a fim de evitar que a cor de fundo do ambiente pudesse interferir na leitura, foi colocado um fundo padrão branco (SEGHI, 1989b). Segundo informações do fabricante, a presença do fundo branco não seria necessária, já que o aparelho é capaz de ler a uma profundidade de apenas $0,7 \mathrm{~mm}$ e os corpos possuíam espessura de no mínimo $2 \mathrm{~mm}$.

Após submeter os corpos de prova ao envelhecimento artificial, foram realizadas novas leituras, da mesma maneira que as leituras iniciais e todos os dados foram armazenados digitalmente. Os dados iniciais e finais foram então analisados e comparados para verificação de possíveis alterações na cor das amostras cerâmicas. 


\subsection{Ensaio de envelhecimento artificial acelerado}

Após a medição inicial da cor de todas as amostras cerâmicas com os espectrofotômetros Color Guide 45/0 e Easyshade, estas foram levadas à máquina de ensaio de envelhecimento artificial (Fig. 30).

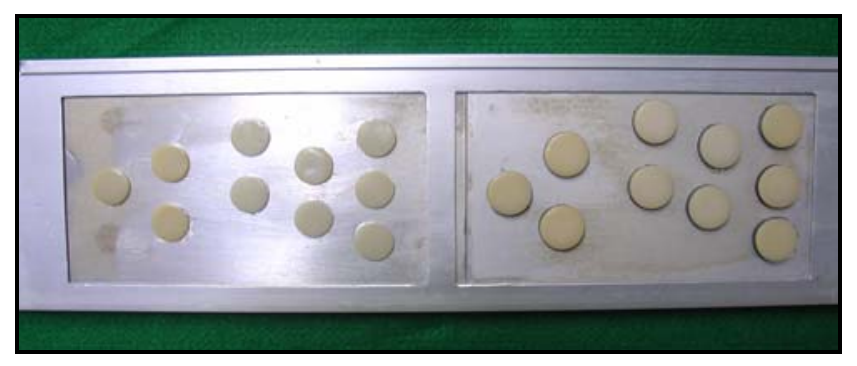

Figura 30: Corpos de prova cerâmicos colados à placa, prontos para serem submetidos ao envelhecimento artificial.

Esta máquina emprega um sistema acelerado de envelhecimento para não metálicos, com o uso de ultravioleta B e condensação de umidade (C-UV). Fabricado pela empresa Adexim-Comexim, foi o primeiro sistema brasileiro de envelhecimento acelerado para não metálicos, confeccionado de acordo com normas internacionais (Fig. 31) (ADEXIM-COMEXIM, 2007).

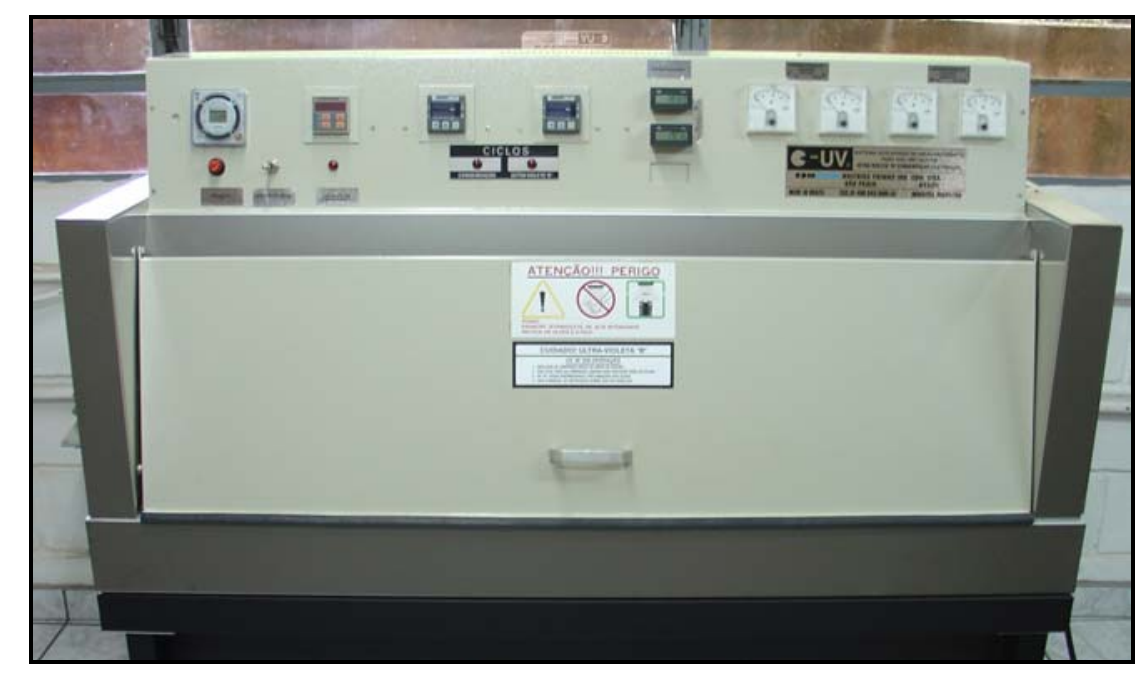

Figura 31: Sistema de envelhecimento acelerado para não metálicos (Adexim Comexim). 
O sistema C-UV é uma máquina que simula em laboratório as forças de destruição da natureza de forma acelerada, predizendo a durabilidade relativa dos materiais não metálicos quando expostos diretamente a ação das intempéries. A chuva e a neblina foram simuladas por um processo de condensação com água destilada saturada de oxigênio, tudo auto gerado pelo sistema. O reservatório de água foi aquecido produzindo vapor de forma a manter a câmara de teste com uma umidade de $100 \%$ e uma temperatura elevada. A montagem das placas forrou as paredes laterais da câmara, ficando o lado em teste em contato com o vapor e a face reversa em contato com o meio ambiente. Essa diferença de temperatura no painel propiciou a condensação de forma natural. A água condensada sobre os corpos de prova ficou saturada pelo oxigênio, sendo por isso muito agressiva. Como ocorre na natureza, os períodos de luz e condensação também foram independentes. Assim, processaram-se os testes em ciclos de 4 em 4 horas com boa reprodutibilidade ao processo natural. Os efeitos da luz do sol, onde apenas $1 \%$ provoca degradação (reação fotoquímica), foi simulado por uma rede de 8 fontes de luz UV-B com radiação concentrada entre 280/320 nanômetros, como na natureza. Tendo o sistema 2 bancos de 4 fontes fluorescentes cada, houve sempre uma radiação média devido a sua reposição escalonada. Isso evitou picos e as baixas irradiações como os sistemas de uma só fonte. Um rígido controle das fontes evitou a irradiação abaixo de $280 \mathrm{~nm}$ por tratar-se de energia não natural. A temperatura de exposição selecionada foi de $50^{\circ} \mathrm{C}$, e foi automaticamente controlada, assim como a simulação dos ciclos de incidência de UV-B e de condensação. O sistema operou 24 horas por dia, produzindo o programa conforme o planejado. As amostras foram submetidas a 500 horas de envelhecimento e após o término do ensaio novas leituras foram realizadas. 
5. RESULTADOS E DISCUSSÃO 
Os resultados deste estudo consistiram em 840 dados numéricos fornecidos pelo espectrofotômetro Color Guide 45/0 correspondentes aos valores de opacidade antes e depois do envelhecimento artificial acelerado; das coordenadas $L^{*}, a^{*}$ e $b^{*}$ antes e depois do envelhecimento artificial acelerado; e também dos valores de $\Delta \mathrm{L}^{*}, \Delta \mathrm{a}^{*}, \Delta \mathrm{b}^{*}$, e $\Delta \mathrm{E}^{*}$ dos 5 sistemas cerâmicos glazeados naturalmente e com a aplicação do pigmento Vita Chrom 712, caracterizando a pintura extrínseca.

O espectrofotômetro Easyshade forneceu 560 dados numéricos correspondentes aos valores de $\Delta \mathrm{L}^{*}, \Delta \mathrm{a}^{*}, \Delta \mathrm{b}^{*}$, e $\Delta \mathrm{E}^{*}$ antes e depois do envelhecimento artificial acelerado dos 5 sistemas cerâmicos glazeados e com pintura extrínseca.

Todos os dados foram submetidos a testes preliminares com o propósito de decidir qual o tipo de teste estatístico que deveria ser empregado: teste paramétrico ou não paramétrico. Os testes indicaram a utilização da estatística paramétrica, pois a distribuição amostral foi normal, sendo o programa estatístico utilizado neste estudo o Statistica for Windows, versão 6.0. 


\subsection{Espectrofotômetro Color Guide 45/0 BYK-Gardner}

\subsubsection{Resultados de Opacidade}

Os valores médios e desvios-padrão das leituras iniciais e finais de opacidade dos 5 sistemas cerâmicos glazeados e pintados extrinsecamente estão demonstrados na tabela 2, sendo os valores originais apresentados no apêndice $A$.

Tabela 2: Valores médios e desvios-padrão da opacidade (\%) dos 5 sistemas cerâmicos glazeados e com pintura extrínseca antes (inicial) e depois (final) do envelhecimento artificial acelerado.

\begin{tabular}{cc|c|c}
\hline \multicolumn{3}{c}{} & \multicolumn{2}{c}{ Envelhecimento artificial } \\
\hline \multicolumn{2}{c}{ Cerâmicas } & Inicial & Final \\
\hline \multirow{2}{*}{ Grupo 1 } & MC & $100 \pm 0,02$ & $100 \pm 0,02$ \\
& MCPE & $100 \pm 0,01$ & $100 \pm 0,01$ \\
\cline { 1 - 2 } Grupo 2 & CER & $78,42 \pm 2,17$ & $79,32 \pm 1,81$ \\
& CERPE & $78,02 \pm 2,27$ & $79,06 \pm 2,48$ \\
\multirow{2}{*}{ Grupo 3 } & EX & $71,81 \pm 1,69$ & $72,47 \pm 1,57$ \\
& EXPE & $72,3 \pm 1,14$ & $72,9 \pm 1,11$ \\
\cline { 1 - 1 } Grupo 4 & VTAL & $99,47 \pm 2,28$ & $99,99 \pm 0,02$ \\
& VTALPE & $99,96 \pm 0,03$ & $100 \pm 0,01$ \\
\cline { 1 - 1 } Grupo 5 & VTCE & $99,95 \pm 0,04$ & $99,97 \pm 0,01$ \\
& VTCEPE & $99,91 \pm 0,04$ & $99,96 \pm 0,07$ \\
\hline
\end{tabular}

Analisando a tabela 2, observa-se que a cerâmica do grupo 3 (EX e EXPE), tanto glazeada quanto pigmentada foi a que apresentou a menor média de opacidade antes e também depois do envelhecimento artificial, seguida pela 
cerâmica do grupo 2 (CER e CERPE). Isto ocorreu porque são cerâmicas feldspáticas sem substrato metálico ou cerâmico e com menor espessura da amostra.

Os dados contidos na tabela 2 foram avaliados estatisticamente, aplicando-se o teste $\mathrm{t}$ de Student para dados vinculados com $\mathrm{p}<0,05$ (tabela $3)$.

Tabela 3: Análise estatística (teste t de Student) dos valores de opacidade com fator de variação envelhecimento artificial (dados vinculados) para $p<0,05$.

\begin{tabular}{|c|c|c|c|c|}
\hline & & \multicolumn{3}{|c|}{ Teste $t$ de Student } \\
\hline & & $\neq$ (médias) & $t$ & $p$ \\
\hline \multicolumn{5}{|c|}{ Cerâmicas } \\
\hline \multirow{2}{*}{ Grupo 1} & $\mathrm{MC}$ & $-0,01$ & $-0,94$ & 0,39 \\
\hline & MCPE & 0,00 & 0,81 & 0,45 \\
\hline \multirow{2}{*}{ Grupo 2} & CER & 0,90 & 3,93 & 0,008 \\
\hline & CERPE & 1,03 & 3,26 & 0,02 \\
\hline \multirow{2}{*}{ Grupo 3} & EX & 0,67 & 6,64 & 0,0006 \\
\hline & EXPE & 0,67 & 4,69 & 0,02 \\
\hline \multirow{2}{*}{ Grupo 4} & VTAL & 0,52 & 4,69 & 0,003 \\
\hline & VTALPE & 0,04 & 2,77 & 0,03 \\
\hline \multirow{2}{*}{ Grupo 5} & VTCE & 0,02 & 2,19 & 0,07 \\
\hline & VTCEPE & 0,05 & 1,37 & 0,22 \\
\hline
\end{tabular}

O estudo estatístico apresentado na tabela 3 mostrou que a opacidade das cerâmicas dos grupos 2 (CER e CERPE), 3 (EX e EXPE) e 4 (VTAL e VTALPE) foi influenciada estatisticamente pelo envelhecimento artificial acelerado.

Sabe-se que a aceleração do tempo de envelhecimento de uma amostra é proporcionada pelo aumento controlado de temperatura e exposição à umidade e radiação, sem causar resultados anormais. Em poucos dias ou semanas há uma reprodução em laboratório do que ocorreria em meses ou 
anos em um corpo de prova não metálico sob a ação das intempéries. Com os efeitos destrutivos do intemperismo acelerado observam-se fenômenos como a calcinação, perda de cor ou brilho, perda de opacidade e plasticidade, perda de aderência, aparecimento de trincas e bolhas (ADEXIM-COMEXIM, 2007).

A opacidade é o resultado do espalhamento da luz refletida ao atravessar o objeto, assim a opacidade do material é medida para se obter a propriedade inversa: a translucidez. Com isto pode-se afirmar que os grupos de cerâmicas feldspáticas sem substrato (Grupos 2 e 3), de maior translucidez inicial, foram influenciados com significância estatística, pelo envelhecimento artificial, diminuindo esta propriedade, ou, aumentando a opacidade das mesmas.

Já entre os grupos de amostras ceramo-cerâmicas (Grupos 4 e 5), observa-se que, apesar dos dois grupos terem, inicialmente, uma opacidade próxima da total $(100 \%)$, o fator envelhecimento trouxe um aumento na média de opacidade. Na cerâmica glazeada do grupo 5 (VTCE) este aumento de opacidade se aproximou da significância estatística $(p=0,07)$, já na cerâmica com pintura extrínseca deste mesmo grupo (VTCEPE), o aumento da opacidade não se aproximou da significância $(p=0,22)$.

Na cerâmica do grupo 4 (VTAL e VTALPE), a influência do envelhecimento foi estatisticamente significante e o grupo 1 não sofreu qualquer alteração de opacidade devido à presença do substrato metálico, sendo a média de opacidade inicial igual a média da opacidade final.

Estes resultados vêm de encontro com o estudo de Vichi et al. (2003), que pesquisando a influência da exposição de água em resinas, demonstraram que a água agia como opacificador das resinas, assim como neste estudo, a 
exposição às intempéries provenientes do envelhecimento, agiu como um fator de opacificação para as cerâmicas dos grupos 2,3 e 4, em especial para a cerâmica do grupo 3 glazeada EX ( $p=0,0006)$. É importante salientar, porém, que as resinas sofrem muito mais influência do tempo de uso, tanto na opacificação quanto na mudança de cor, do que as cerâmicas, que são consideradas muito mais estáveis quimicamente.

A opacidade de uma restauração cerâmica é um fator muito importante, já que elas são usadas muitas vezes para mascarar manchas de superfície ou dentinas pigmentadas e escurecidas. Yaman et al. (1997), em seu estudo de opacidade de cerâmicas demonstraram que mesmo cerâmicas com $75 \%$ de opacidade, ou seja, valores próximos aos encontrados nos grupos 2 e 3, são fortemente influenciadas pela cor do cimento escolhido e que mudanças de opacidade influenciam a cor final da restauração. Portanto ao se escolher uma restauração cerâmica, deve-se levar em consideração o seu grau de opacidade na escolha da cor do cimento e o tipo de substrato dentinário remanescente (dentina clara ou escurecida).

Uma limitação deste estudo diz respeito à espessura das amostras. Segundo Heffernan et al. (2000a) e Shokry et al. (2006) a espessura pode influenciar no grau de opacidade e neste estudo foram utilizadas diferentes espessuras das amostras, conforme o tipo de cerâmica, devido ao grau de dificuldade em manipular os materiais estudados e obter os corpos de prova.

Este estudo, ainda assim, corrobora os achados de Heffernan et al. (2000a), que classificaram as cerâmicas feldspáticas puras como mais translúcidas do que aquelas com reforço de alumina, assim como ocorreu com 
as médias de opacidade das cerâmicas dos grupos 2 e 3 quando comparadas com as das cerâmicas dos grupos 4 e 5 (Gráfico 1).

\section{Médias de Opacidade}

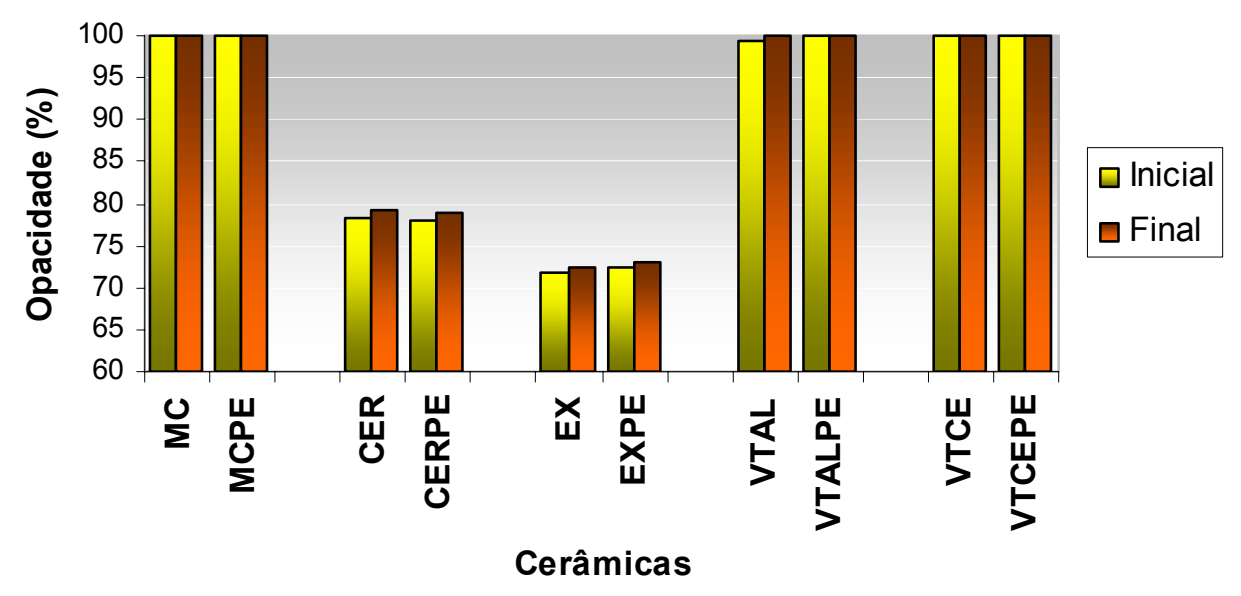

Gráfico 1: Médias de opacidade das cerâmicas testadas antes (inicial) e depois (final) do envelhecimento artificial acelerado.

Observando o nível de significância da tabela 3, nota-se também que as cerâmicas com pigmentação extrínseca (PE) foram menos influenciadas pelo envelhecimento quando comparadas com as mesmas cerâmicas apenas glazeadas. Talvez, a pintura extrínseca possa ter agido como uma barreira para os efeitos do envelhecimento na opacidade devido à presença de óxidos metálicos. Isto vai de encontro os achados de Cho et al. (2006), que pesquisando cerâmicas pigmentadas concluíram que houve pequenas mudanças de translucidez quando estas foram submetidas a vários ciclos de sinterização, porém estes ciclos foram de queima e não de envelhecimento artificial. 
5.1.2. Resultados de leitura da coordenada L* (luminosidade)

Os valores médios e desvios-padrão da coordenada $L^{*}$ das leituras iniciais e finais e dos $\Delta L^{*}$ resultantes, dos 5 sistemas cerâmicos glazeados naturalmente e pintados extrinsecamente estão demonstrados na tabela 4, sendo os valores originais apresentados no apêndice B.

Tabela 4: Valores médios e desvios-padrão da coordenada $L^{*}$ dos 5 sistemas cerâmicos glazeados e com pintura extrínseca antes (inicial) e depois (final) do envelhecimento artificial acelerado e respectivos $\Delta L^{*}$.

\begin{tabular}{|c|c|c|c|c|}
\hline & \multicolumn{3}{|c|}{ Envelhecimento artificial } & \multirow[b]{2}{*}{$\Delta \mathrm{L}^{*}$} \\
\hline & & Inicial & Final & \\
\hline \multicolumn{2}{|c|}{ Cerâmicas } & & & \\
\hline \multirow[b]{2}{*}{ Grupo 1} & $M C$ & $69,22 \pm 1,34$ & $68,82 \pm 1,26$ & $-0,39 \pm 0,12$ \\
\hline & MCPE & $67,64 \pm 0,86$ & $67,19 \pm 0,85$ & $-0,44 \pm 0,17$ \\
\hline \multirow[b]{2}{*}{ Grupo 2} & CER & $71,72 \pm 0,39$ & $71,2 \pm 0,40$ & $-0,51 \pm 0,16$ \\
\hline & CERPE & $69,16 \pm 0,09$ & $68,89 \pm 0,12$ & $-0,26 \pm 0,14$ \\
\hline \multirow[b]{2}{*}{ Grupo 3} & EX & $70,15 \pm 0,58$ & $69,69 \pm 0,59$ & $-0,44 \pm 0,18$ \\
\hline & EXPE & $68,51 \pm 0,07$ & $68,15 \pm 0,17$ & $-0,35 \pm 0,13$ \\
\hline \multirow[b]{2}{*}{ Grupo 4} & VTAL & $71.62 \pm 0,38$ & $71,10 \pm 0,53$ & $-0,51 \pm 0,18$ \\
\hline & VTALPE & $69,85 \pm 0,57$ & $69,16 \pm 0,53$ & $-0,69 \pm 0,13$ \\
\hline \multirow[b]{2}{*}{ Grupo 5} & VTCE & $69,15 \pm 0,35$ & $67,81 \pm 0,36$ & $-1,33 \pm 0,08$ \\
\hline & VTCEPE & $68,24 \pm 0,40$ & $66,91 \pm 0,41$ & $-1,32 \pm 0,10$ \\
\hline
\end{tabular}

A coordenada $L^{*}$ fornece valores de luminosidade da amostra, que pode variar de 0 (preto absoluto) a 100 (branco absoluto), sendo os valores 
intermediários uma escala de cinza variando do mais escuro (valores menores) aos mais claros (valores maiores). Essa coordenada é representada por um eixo perpendicular ao plano cartesiano formado pelas coordenadas $a^{*}$ e $b^{*}$ do sistema CIEL*a*b* (Fig. 32).

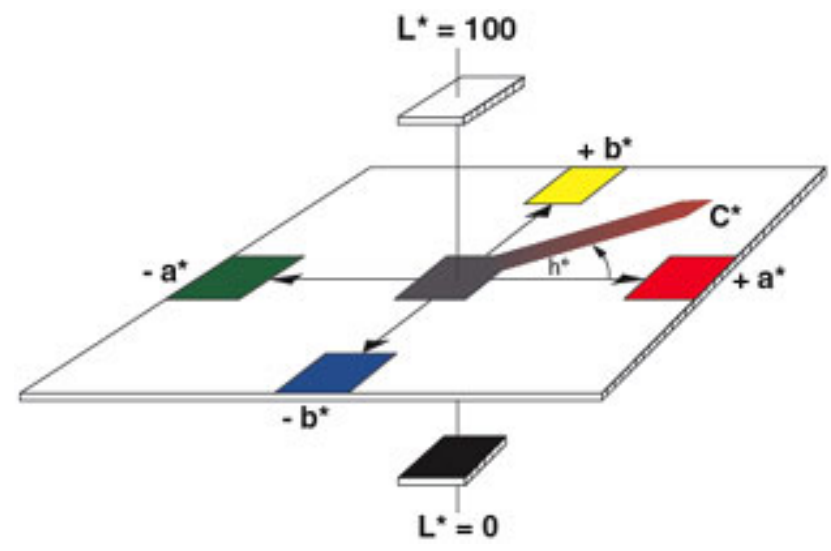

Figura 32: Representação do sistema de cor CIELab. (Disponível em: < http://www.byk-gardner.com > Acesso 07/01/2007).

Analisando a tabela 4, observa-se que os valores médios de luminosidade de todas as amostras variaram entre 66,91 e 71,72, ou seja, valores mais próximos do branco (100), compatível com a luminosidade de uma restauração cerâmica.

Verifica-se também que as cerâmicas pintadas extrinsecamente possuem valores de luminosidade menores do que as mesmas quando apenas glazeadas, tanto antes quando após o envelhecimento artificial. De acordo com McPhee (1985) a principal indicação de uso de pintura extrínseca é exatamente esta; diminuir a luminosidade de determinada cerâmica, como ocorreu neste estudo (Gráfico 2). 


\section{Coordenada L*}

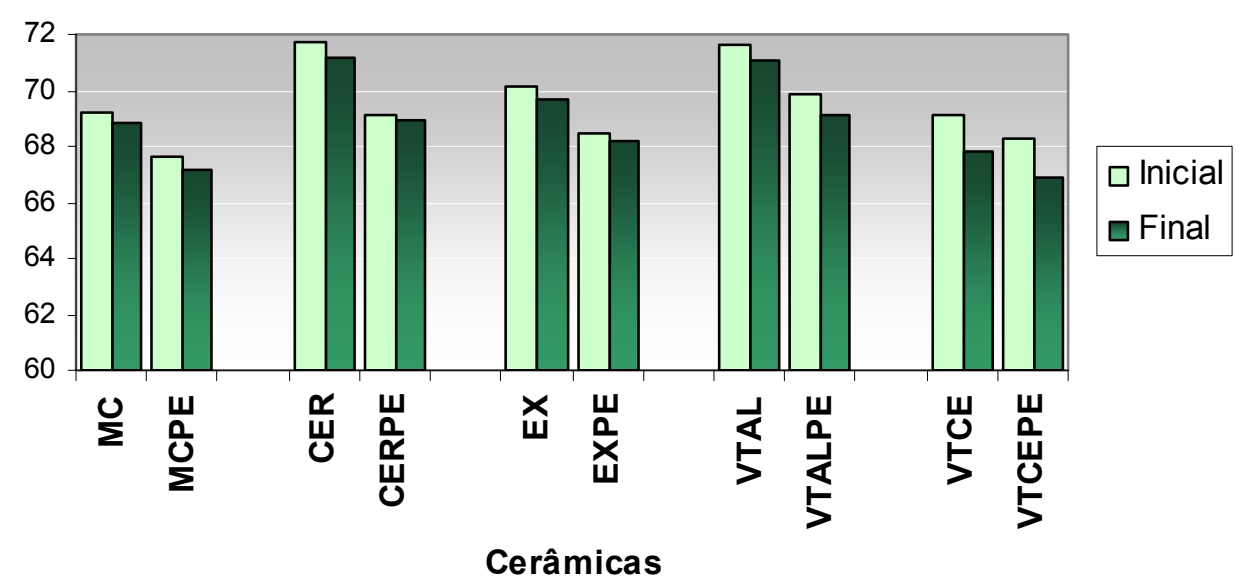

Gráfico 2: Médias da coordenada $L^{*}$ das cerâmicas testadas antes (inicial) e depois (final) do envelhecimento artificial acelerado.

Analisando a tabela 4 e o gráfico 2 , nota-se que entre as médias iniciais de luminosidade das cerâmicas apenas glazeadas, a que apresentou maior luminosidade foi a CER, feldspática sem substrato (grupo 2), seguida muito proximamente pela VTAL (grupo 4), e depois pela EX (grupo 3) e MC (grupo 1).

A que apresentou a menor luminosidade foi a VTCE (grupo 5), mas que foi muito semelhante a da MC (grupo 1). Entre as cerâmicas pintadas, houve uma alteração na ordem de luminosidade inicial, sendo a cerâmica VTALPE (grupo 4) a que apresentou maior luminosidade, seguida pela CERPE (grupo 2), EXPE (grupo 3), VTCEPE (grupo 5) e por último a MCPE (grupo 1).

O trabalho de Dozic et al. (2003) demonstrou que mudanças na espessura do material cerâmico influenciam a luminosidade, o que confirma os resultados deste estudo, onde a cerâmica de maior luminosidade inicial é feldspática sem substrato (CER). 
Segundo Goveia (2004), os valores de luminosidade são afetados pela cor de fundo de medição. Provavelmente, a utilização de um fundo padrão branco na leitura dos corpos de prova translúcidos (grupos 2 e 3) tenha aumentado a luminosidade destas amostras, muito embora, neste trabalho, observou-se que a cerâmica de recobrimento Allceram (VTAL) possuía uma luminosidade muito elevada, ultrapassando a cerâmica EX, que pertence a uma categoria de cerâmica feldspática sem substrato, e portanto com menor espessura, mais facilmente influenciada pelo fundo branco.

Entre as pigmentadas, o mesmo se repetiu, já que a cerâmica VTALPE foi a que apresentou a maior luminosidade, seguida pelas feldspáticas sem substrato. Este resultado confirmou o achado de Shokry et al. (2006), que pesquisando os efeitos da infra-estrutura e da cerâmica de cobertura na cor final da restauração, concluíram que a cerâmica de cobertura influencia o seu resultado final, assim como a espessura.

Os dados contidos na tabela 4 foram avaliados estatisticamente, aplicando-se o teste t de Student para dados vinculados com $p<0,05$ (tabela $5)$. 
Tabela 5: Análise estatística (teste $t$ de Student) dos valores da coordenada $L^{*}$ com fator de variação envelhecimento artificial (dados vinculados) para $p<$ 0,05 .

\begin{tabular}{|c|c|c|c|c|}
\hline & & \multicolumn{3}{|c|}{ Teste $t$ de Student } \\
\hline & & $\neq$ (médias) & $\mathrm{t}$ & $\mathrm{p}$ \\
\hline \multicolumn{5}{|c|}{ Cerâmicas } \\
\hline \multirow{2}{*}{ Grupo 1} & MC & 0,40 & 8,35 & 0,0002 \\
\hline & MCPE & 0,45 & 6,75 & 0,0005 \\
\hline \multirow{2}{*}{ Grupo 2} & CER & 0,52 & 8,23 & 0,0002 \\
\hline & CERPE & 0,27 & 5,02 & 0,002 \\
\hline \multirow{2}{*}{ Grupo 3} & EX & 0,45 & 6,49 & 0,0006 \\
\hline & EXPE & 0,36 & 7,22 & 0,0004 \\
\hline \multirow{2}{*}{ Grupo 4} & VTAL & 0,51 & 7,20 & 0,0004 \\
\hline & VTALPE & 0,69 & 14,20 & 0,000008 \\
\hline \multirow{2}{*}{ Grupo 5} & VTCE & 1,33 & 42,5 & 0,000000 \\
\hline & VTCEPE & 1,33 & 35,32 & 0,000000 \\
\hline
\end{tabular}

O estudo estatístico apresentado na tabela 5 mostrou que a luminosidade de todos os grupos foi fortemente influenciada pelo envelhecimento artificial acelerado, sendo esta influência mais acentuada no grupo 5, seguida pela cerâmica VTALPE do grupo 4. Já a cerâmica CERPE foi a que menos sofreu os efeitos do envelhecimento. As demais cerâmicas se comportaram semelhantemente quanto ao envelhecimento artificial.

Assim, evidenciou-se que a pintura extrínseca não interferiu na luminosidade das cerâmicas quando estas foram submetidas ao envelhecimento artificial, já que o comportamento das cerâmicas pintadas extrinsecamente foi semelhante ao das apenas glazeadas.

A avaliação dos $\Delta \mathrm{L}^{*}$ das cerâmicas testadas, que constam na tabela 4 , foi realizada utilizando a seguinte fórmula:

$$
\Delta L^{*}=L^{*} \text { final }-L^{*}{ }_{\text {inicial }}
$$


Desta maneira, valores de $\Delta L^{*}$ positivos significam que a amostra ganhou luminosidade, tornou-se mais clara após uma determinada intervenção; e valores de $\Delta L^{*}$ negativos significam que a amostra perdeu luminosidade após uma determinada intervenção, ou seja, tornou-se mais escura (GOVEIA, 2004; MORALES, 2006).

$\mathrm{Na}$ análise do $\Delta \mathrm{L}^{*}$ observa-se que todas as cerâmicas perderam luminosidade quando submetidas ao envelhecimento artificial acelerado, já que todos os valores encontrados foram negativos (Gráfico 3).

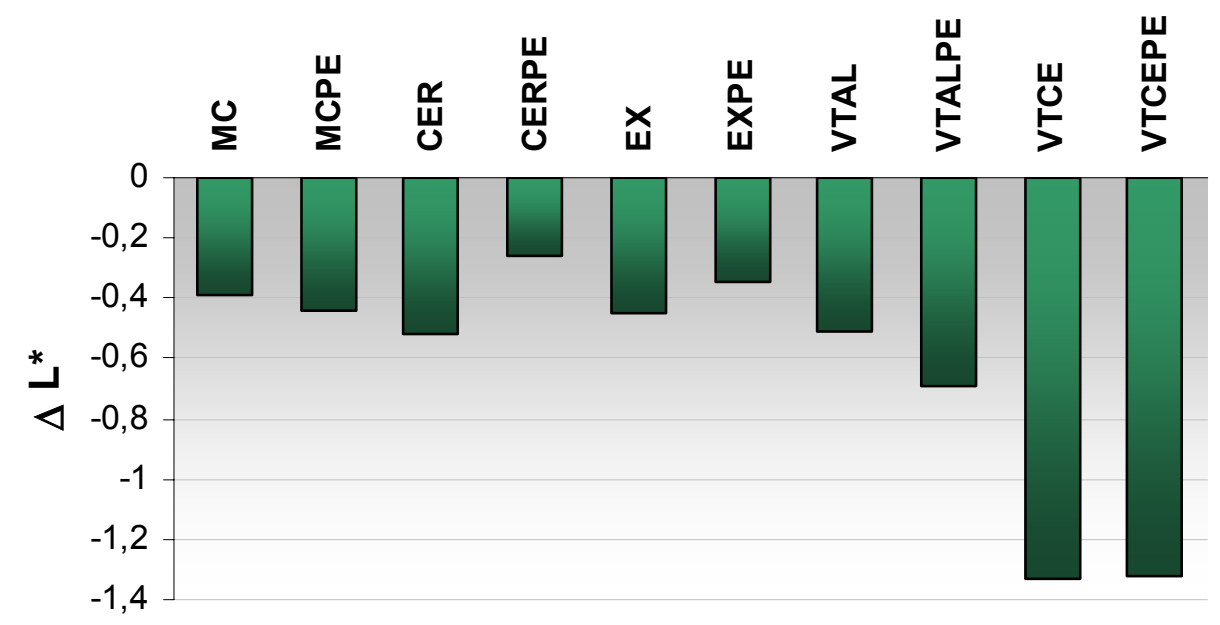

Gráfico 3: Médias de $\Delta L^{*}$ das cerâmicas testadas.

A maioria dos autores publica trabalhos sobre cores em restaurações odontológicas avaliando apenas o $\Delta \mathrm{E}^{*}$, que traduz a mudança total de cor de uma determinada amostra. Avaliações das coordenadas separadas são menos freqüentes.

Segundo Morales (2006), muitos analistas tendem a usar somente o $\Delta \mathrm{E}^{*}$ para fixar tolerâncias aceitáveis de cor, o que seria um erro, já que o termo não relata uma boa avaliação visual. O autor afirma ainda que a luminosidade não é 
o aspecto mais importante na percepção visual de uma determinada cor. Pequenas variações de luminosidade seriam menos perceptíveis do que variações do matiz, representados pelos $\Delta \mathrm{a}^{*} \mathrm{e} \Delta \mathrm{b}^{*}$, ou ainda o $\Delta \mathrm{H}$.

Em odontologia, no entanto, de acordo com vários relatos publicados, a luminosidade, ou o valor, é considerado a característica mais importante na escolha da cor de uma restauração. Estes autores afirmam também que a luminosidade está diretamente relacionada com o grau de opacidade e translucidez de uma restauração (SPROULL, 1973; HEGENBARTH, 1992; MOLLON, 1998; ADOLFI, 2002; MAGNE, URS, 2003; MENDES, 2007).

Neste estudo notou que as cerâmicas com menor opacidade (grupos 2 e 3) obtiveram valores iniciais de luminosidade maiores do que as mais opacas (grupos 1 e 5). 
5.1.3. Resultados de leitura da coordenada $\mathrm{a}^{*}$.

Os valores médios e desvios-padrão da coordenada $a^{*}$ das leituras iniciais e finais e dos $\Delta \mathrm{a}^{*}$ resultantes, dos 5 sistemas cerâmicos glazeados e pintados extrinsecamente estão demonstrados na tabela 6 , sendo os valores originais apresentados no apêndice C.

Tabela 6: Valores médios e desvios-padrão da coordenada $a^{*}$ dos 5 sistemas cerâmicos glazeados e com pintura extrínseca antes (inicial) e depois (final) do envelhecimento artificial acelerado e respectivos $\Delta \mathrm{a}^{*}$.

\begin{tabular}{|c|c|c|c|c|}
\hline & & \multicolumn{2}{|c|}{ Envelhecimento artificial } & \multirow[b]{2}{*}{$\Delta \mathrm{a}^{*}$} \\
\hline & & Inicial & Final & \\
\hline \multicolumn{2}{|c|}{ Cerâmicas } & & & \\
\hline \multirow[b]{2}{*}{ Grupo 1} & $\mathrm{MC}$ & $2,64 \pm 0,37$ & $2,55 \pm 0,36$ & $-0,08 \pm 0,07$ \\
\hline & MCPE & $3,16 \pm 0,12$ & $3,07 \pm 0,17$ & $-0,08 \pm 0,05$ \\
\hline \multirow[b]{2}{*}{ Grupo 2} & CER & $2,46 \pm 0,39$ & $2,74 \pm 0,47$ & $0,27 \pm 0,13$ \\
\hline & CERPE & $4,31 \pm 0,25$ & $4,52 \pm 0,29$ & $0,21 \pm 0,09$ \\
\hline \multirow[b]{2}{*}{ Grupo 3} & EX & $3,76 \pm 0,14$ & $3,92 \pm 0,15$ & $0,16 \pm 0,04$ \\
\hline & EXPE & $5,01 \pm 0,15$ & $5,22 \pm 0,22$ & $0,21 \pm 0,06$ \\
\hline \multirow[b]{2}{*}{ Grupo 4} & VTAL & $3,74 \pm 0,16$ & $3,73 \pm 0,19$ & $0 \pm 0,03$ \\
\hline & VTALPE & $5,32 \pm 0,05$ & $5,45 \pm 0,09$ & $0,13 \pm 0,06$ \\
\hline \multirow[b]{2}{*}{ Grupo 5} & VTCE & $3,26 \pm 0,17$ & $3,35 \pm 0,22$ & $0,09 \pm 0,03$ \\
\hline & VTCEPE & $4,48 \pm 0,53$ & $4,75 \pm 0,59$ & $0,27 \pm 0,09$ \\
\hline
\end{tabular}


A coordenada $a^{*}$ representa a escala de cromaticidade no eixo verde vermelho e podem ter valores entre -80 e +80 . Valores positivos tendem ao vermelho e valores negativos ao verde (Fig. 32) (SCHULZE et al., 2002).

Na tabela 6 observa-se que as médias de todas as cerâmicas foram positivas, indicando que a composição da cor está mais para o vermelho que para o verde, e que as cerâmicas com valores mais altos de $a^{*}$ foram as pintadas extrinsecamente para todos os grupos, demonstrando que a pintura extrínseca altera a cromaticidade de uma cor de cerâmica, aumentando a saturação de cor da mesma, assim como relatado por Mc Phee (1985) e Reis e Bastos (1996).

Os dados contidos na tabela 6 foram avaliados estatisticamente, aplicandose o teste $t$ de Student para dados vinculados com $p<0,05$ (tabela 7).

Tabela 7: Análise estatística (teste t de Student) dos valores da coordenada a* com fator de variação envelhecimento artificial (dados vinculados) para $p<$ 0,05 .

\begin{tabular}{|c|c|c|c|c|}
\hline & & \multicolumn{3}{|c|}{ Teste $t$ de Student } \\
\hline & & $\neq$ (médias) & $\mathrm{t}$ & $\mathrm{p}$ \\
\hline \multicolumn{5}{|c|}{ Cerâmicas } \\
\hline \multirow{2}{*}{ Grupo 1} & $\mathrm{MC}$ & 0,08 & 3,12 & 0,02 \\
\hline & MCPE & 0,09 & 3,89 & 0,01 \\
\hline \multirow{2}{*}{ Grupo 2} & CER & $-0,28$ & $-5,53$ & 0,001 \\
\hline & CERPE & $-0,21$ & $-6,37$ & 0,001 \\
\hline \multirow{2}{*}{ Grupo 3} & EX & $-0,17$ & $-10,19$ & 0,0001 \\
\hline & EXPE & $-0,21$ & $-8,00$ & 0,0002 \\
\hline \multirow{2}{*}{ Grupo 4} & VTAL & 0,0 & 0,13 & 0,90 \\
\hline & VTALPE & $-0,13$ & $-6,13$ & 0,001 \\
\hline \multirow{2}{*}{ Grupo 5} & VTCE & $-0,09$ & $-7,19$ & 0,0003 \\
\hline & VTCEPE & $-0,27$ & $-8,21$ & 0,0001 \\
\hline
\end{tabular}


O estudo estatístico apresentado na tabela 7 mostrou que a coordenada $a^{*}$ dos grupos $1,2,3$ e 5 foram influenciadas pelo envelhecimento artificial acelerado, sendo que para o grupo 4 esta influência ocorreu apenas na cerâmica com pintura extrínseca (VTALPE). Os maiores níveis de significância ocorreram nos grupos 3 e 5, que possuem cerâmicas da mesma marca comercial (Noritake), ou seja, com composição química semelhantes. Quando se avalia as cerâmicas como um todo, pelos níveis de significância observa-se que, a pintura extrínseca, quando relacionada ao envelhecimento artificial, não foi fator decisivo na alteração da coordenada $a^{*}$.

Coordenada $a^{*}$

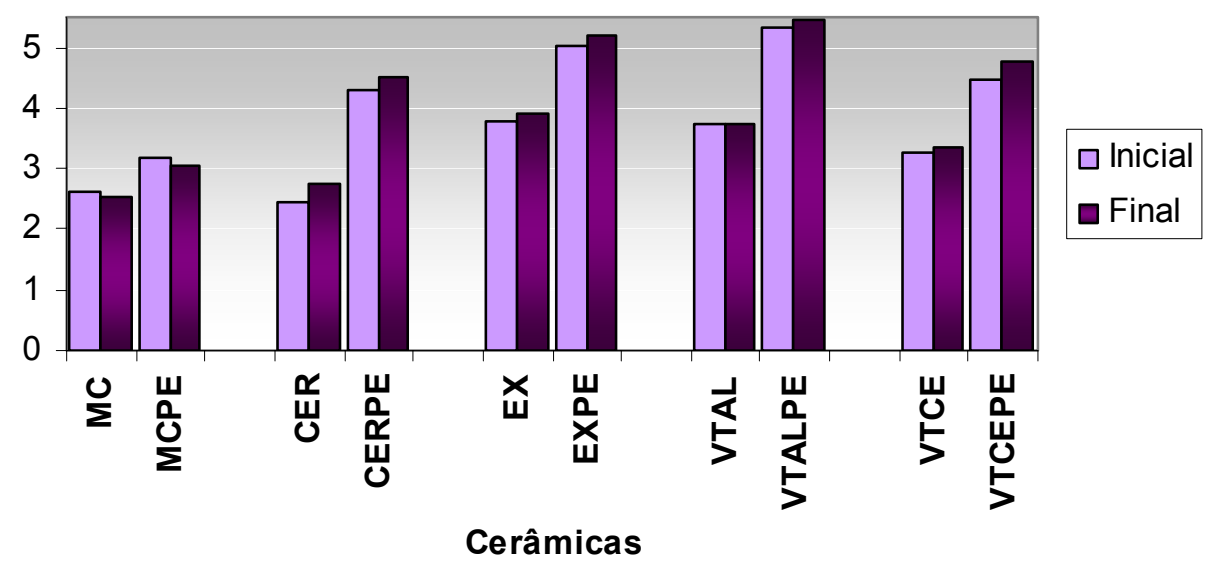

Gráfico 4: Médias da coordenada $a^{*}$ das cerâmicas testadas antes (inicial) e depois (final) do envelhecimento artificial acelerado.

Observa-se no gráfico 4 que o grupo com menor valor de a* é o grupo 1 , ou seja, a cerâmica que tem metal como infra-estrutura. $\mathrm{O}$ gráfico 4 revela também que a cerâmica do grupo 2 sem pintura (CER) possui o menor valor de $a^{*}$ dentre todas as cerâmicas. È importante lembrar que os grupos 1 e 2 foram 
confeccionados utilizando a mesma cerâmica (Ceramco 3), mudando apenas a presença de substrato metálico para o grupo 1.

Assim como salientado por Wee et al. (2002), a marca comercial de uma determinada cerâmica pode influenciar na cor final da restauração. Kourtis et al. (2004), pesquisaram alteração de cor em restaurações metalocerâmicas, e encontraram valores maiores de $a^{*}$ na cerâmica Ceramco do que nas outras cerâmicas testadas. Eles afirmaram que a Ceramco teria uma característica de cor mais avermelhada, o que não foi encontrado neste estudo quando se comparou a Ceramco com as demais cerâmicas.

Para a avaliação dos $\Delta \mathrm{a}^{*}$ das cerâmicas testadas, que constam na tabela 6 , a seguinte fórmula foi utilizada:

$$
\Delta a^{*}=a^{*}{ }_{\text {final }}-a^{*}{ }_{\text {inicial }}
$$

Valores de $\Delta \mathrm{a}^{*}$ positivos significam que a amostra sofreu um desvio para o vermelho e valores de $\Delta a^{*}$ negativos significam que a amostra sofreu um desvio para o verde (Gráfico 5) (GOVEIA, 2004; MORALES, 2006).

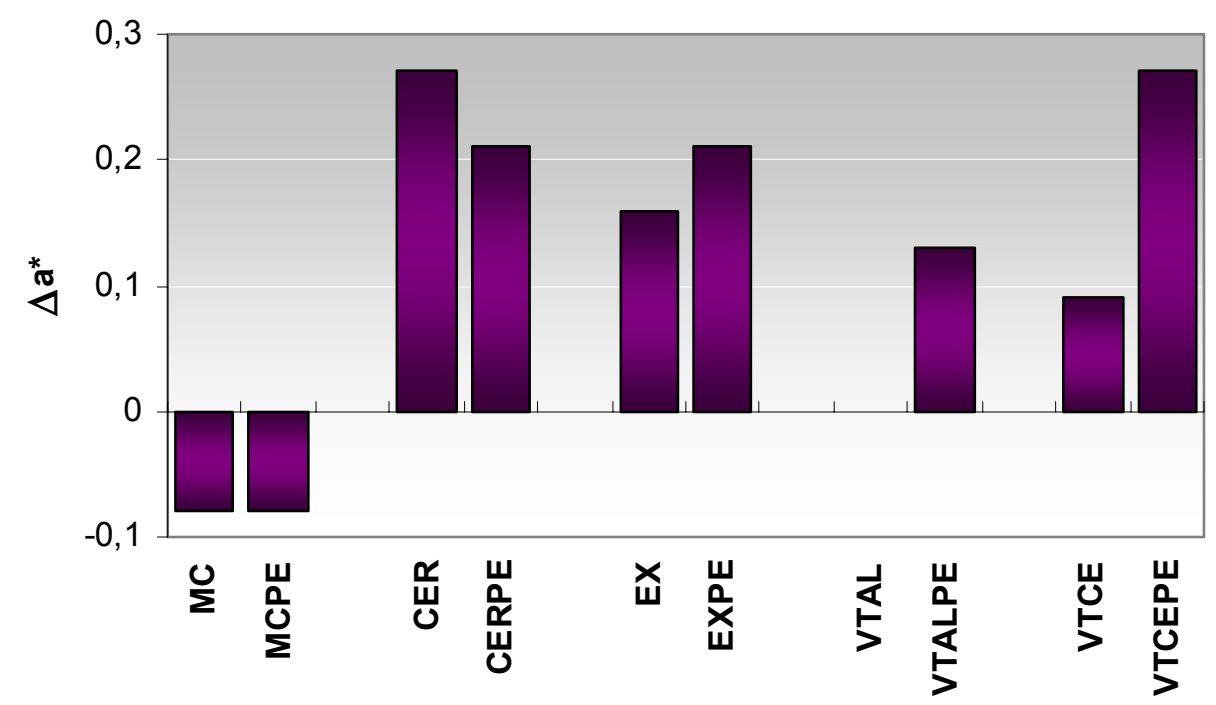

Gráfico 5: Médias de $\Delta \mathrm{a}^{*}$ das cerâmicas testadas. 
Avaliando o gráfico 5 observa-se que para o grupo 1, o envelhecimento artificial acelerado provocou um desvio negativo ( $\Delta \mathrm{a}^{*}$ negativo), ou seja, as amostras se tornaram mais verdes ou menos vermelhas. Para todos os outros grupos, o desvio foi positivo ( $\Delta \mathrm{a}^{*}$ positivo), ou seja, as amostras se tornaram mais vermelhas ou menos verdes, com exceção da cerâmica VTAL que não sofreu qualquer influência do envelhecimento artificial.

A presença de infra-estrutura metálica, assim como diminuiu o valor de $a^{*}$ quando avaliadas inicialmente, também levou a um desvio da cor cerâmica para o verde após o envelhecimento artificial. Segundo Kourtis et al. (2004), a presença de liga metálica influencia na cromaticidade e tonalidade da cerâmica, principalmente quando esta é submetida ao envelhecimento, provavelmente devido à liberação de óxidos metálicos durante este processo. 
5.1.4. Resultados de leitura da coordenada $b^{*}$

Os valores médios e desvios-padrão da coordenada $b^{*}$ das leituras iniciais e finais e dos $\Delta b^{*}$ resultantes, dos 5 sistemas cerâmicos glazeados e pintados extrinsecamente estão demonstrados na tabela 8 , sendo os valores originais apresentados no apêndice D.

Tabela 8: Valores médios e desvios-padrão da coordenada b* dos 5 sistemas cerâmicos glazeados e com pintura extrínseca antes (inicial) e depois (final) do envelhecimento artificial acelerado e respectivos $\Delta b^{*}$.

\begin{tabular}{|c|c|c|c|c|}
\hline & \multicolumn{3}{|c|}{ Envelhecimento artificial } & \multirow[b]{2}{*}{$\Delta \mathrm{b}^{*}$} \\
\hline & & Inicial & Final & \\
\hline \multicolumn{2}{|c|}{ Cerâmicas } & & & \\
\hline \multirow[b]{2}{*}{ Grupo 1} & $M C$ & $13,95 \pm 2,65$ & $13,79 \pm 2,58$ & $-0,16 \pm 0,18$ \\
\hline & MCPE & $16,13 \pm 0,21$ & $16,01 \pm 0,26$ & $-0,11 \pm 0,09$ \\
\hline \multirow[b]{2}{*}{ Grupo 2} & CER & $18,54 \pm 1,19$ & $18,33 \pm 1,24$ & $-0,21 \pm 0,23$ \\
\hline & CERPE & $24,19 \pm 1,31$ & $24,03 \pm 1,39$ & $-0,16 \pm 0,32$ \\
\hline \multirow[b]{2}{*}{ Grupo 3} & EX & $20,30 \pm 1,11$ & $20,43 \pm 1,13$ & $0,12 \pm 0,17$ \\
\hline & EXPE & $24,20 \pm 0,16$ & $24,26 \pm 0,09$ & $0,05 \pm 0,09$ \\
\hline \multirow[b]{2}{*}{ Grupo 4} & VTAL & $17,64 \pm 1,07$ & $17,30 \pm 1,14$ & $-0,34 \pm 0,24$ \\
\hline & VTALPE & $22,66 \pm 0,50$ & $22,45 \pm 0,46$ & $-0,21 \pm 0,31$ \\
\hline \multirow[b]{2}{*}{ Grupo 5} & VTCE & $16,84 \pm 0,24$ & $19,88 \pm 0,28$ & $3,04 \pm 0,32$ \\
\hline & VTCEPE & $22,33 \pm 1,14$ & $24,65 \pm 1,01$ & $2,31 \pm 0,24$ \\
\hline
\end{tabular}


A coordenada $b^{*}$ representa a escala de cromaticidade no eixo azul amarelo e podem ter valores entre -80 e +80 . Valores positivos tendem ao amarelo e valores negativos ao azul (Fig. 32) (SCHULZE et al., 2002).

$\mathrm{Na}$ tabela 8 observa-se que as médias de todas as cerâmicas foram positivas, indicando que a composição da cor está mais para o amarelo que para o azul, e que as cerâmicas com valores mais altos de $b^{*}$ foram as pintadas extrinsecamente para todos os grupos, demonstrando que a pintura extrínseca interfere na cromaticidade de uma cor de cerâmica, tanto na coordenada $\mathrm{a}^{*}$, demonstrada anteriormente como no $\mathrm{b}^{*}$, assim como relatado por Reis e Bastos (1996).

Os dados contidos na tabela 8 foram avaliados estatisticamente, aplicandose o teste t de Student para dados vinculados com $p<0,05$ (tabela 9).

Tabela 9: Análise estatística (teste t de Student) dos valores da coordenada b* com fator de variação envelhecimento artificial (dados vinculados) para $p<$ 0,05 .

\begin{tabular}{|c|c|c|c|c|}
\hline & & \multicolumn{3}{|c|}{ Teste $t$ de Student } \\
\hline & & $\neq$ (médias) & $\mathrm{t}$ & $\mathrm{p}$ \\
\hline \multicolumn{5}{|c|}{ Cerâmicas } \\
\hline \multirow{2}{*}{ Grupo 1} & $\mathrm{MC}$ & 0,16 & 2,30 & 0,06 \\
\hline & MCPE & 0,11 & 3,44 & 0,01 \\
\hline \multirow{2}{*}{ Grupo 2} & CER & 0,21 & 2,37 & 0,06 \\
\hline & CERPE & 0,16 & 1,99 & 0,09 \\
\hline \multirow{2}{*}{ Grupo 3} & EX & $-0,12$ & $-1,95$ & 0,10 \\
\hline & EXPE & $-0,05$ & $-1,44$ & 0,20 \\
\hline \multirow{2}{*}{ Grupo 4} & VTAL & 0,34 & 3,80 & 0,01 \\
\hline & VTALPE & 0,22 & 1,85 & 0,11 \\
\hline \multirow{2}{*}{ Grupo 5} & VTCE & $-3,04$ & $-25,34$ & 0,00000 \\
\hline & VTCEPE & $-2,31$ & $-25,98$ & 0,00000 \\
\hline
\end{tabular}


O estudo estatístico apresentado na tabela 9 mostrou que a coordenada $b^{*}$ do grupo 5 foi influenciada pelo envelhecimento artificial acelerado, sendo que para o grupo 4 esta influência ocorreu apenas na cerâmica glazeada (VTAL) e para o grupo 1 a influência ocorreu apenas na cerâmica com pintura extrínseca (MCPE). Pelos níveis de significância observa-se também que, a pintura extrínseca, quando relacionada ao envelhecimento artificial, não foi fator decisivo na alteração da coordenada b*.

\section{Coordenada b*}

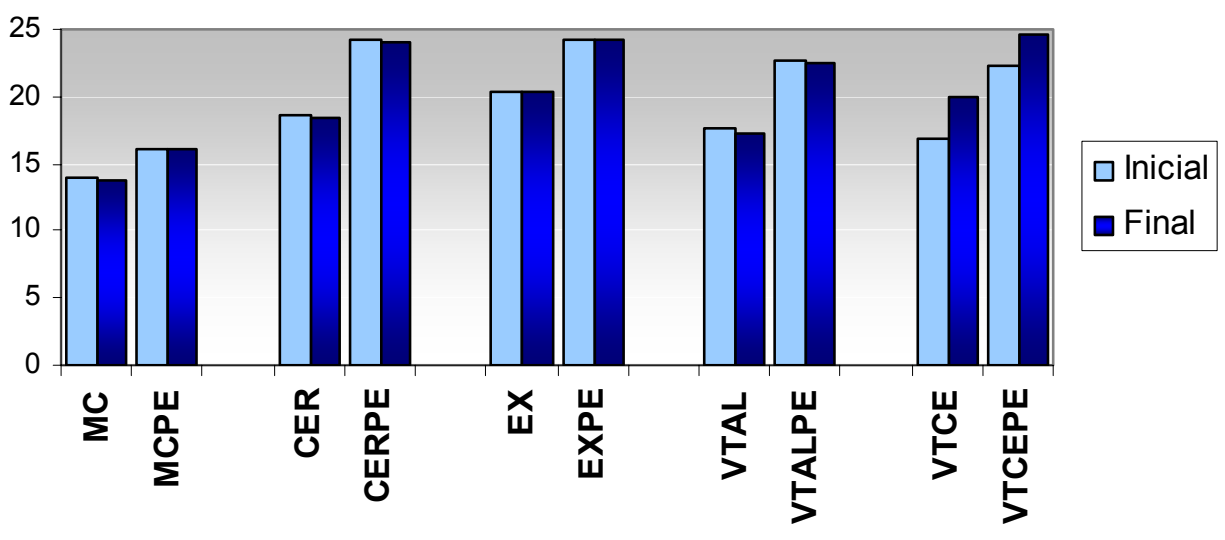

Cerâmicas

Gráfico 6: Médias da coordenada $b^{*}$ das cerâmicas testadas antes (inicial) e depois (final) do envelhecimento artificial acelerado.

Observa-se no gráfico 6 que o grupo com menor valor de b* é o grupo 1, assim como ocorreu com a coordenada $a^{*}$, pois este grupo possui metal como infra-estrutura.

Os valores de $\Delta \mathrm{b}^{*}$ das cerâmicas testadas, que constam na tabela 9 foram obtidos pelo aparelho Color Guide utilizando a seguinte fórmula:

$$
\Delta b^{*}=b^{*} \text { final }-b^{*}{ }_{\text {inicial }}
$$

Valores de $\Delta b^{*}$ positivos significam que a amostra sofreu um desvio para o amarelo e valores de $\Delta b^{*}$ negativos significam que a amostra sofreu um desvio para o azul (Gráfico 7) (GOVEIA, 2004; MORALES, 2006). 


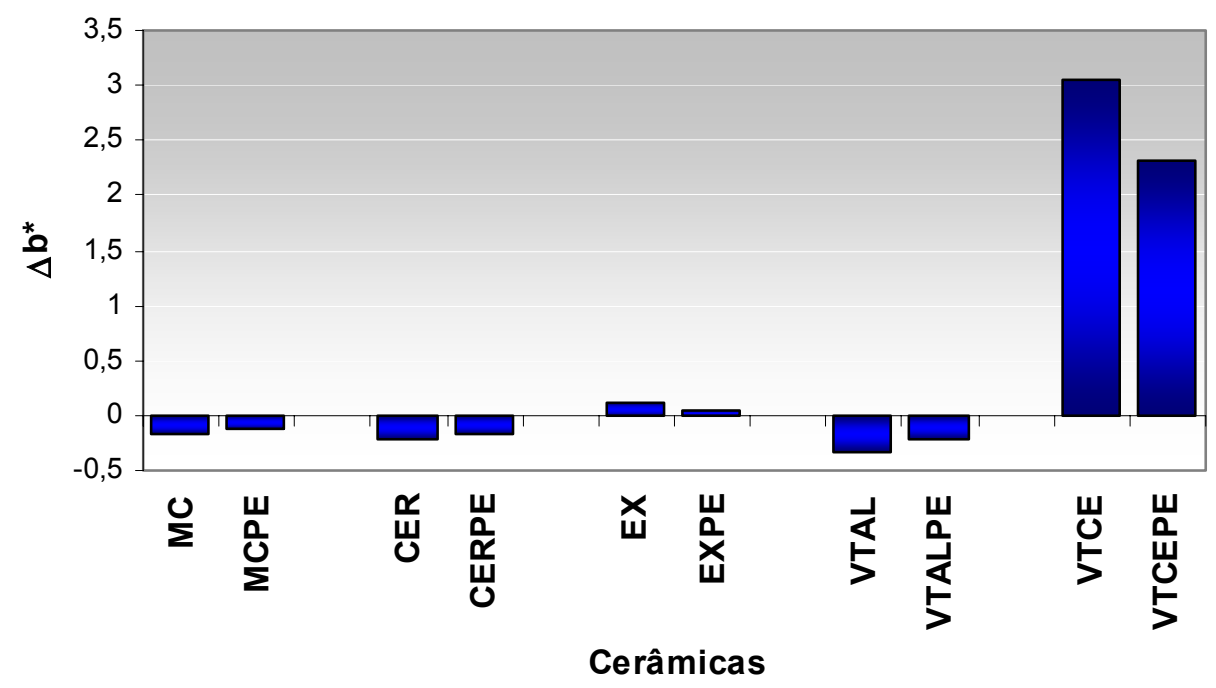

Gráfico 7: Médias de $\Delta b^{*}$ das cerâmicas testadas.

Avaliando o gráfico 7 observa-se que para os grupos 1,2 e 4 o envelhecimento artificial acelerado provocou um desvio negativo ( $\Delta \mathrm{b}^{*}$ negativo), ou seja, as amostras se tornaram mais azuis ou menos amarelas. Para os grupos 3 e 5, o desvio foi positivo ( $\Delta b^{*}$ positivo), ou seja, as amostras se tornaram mais amarelas ou menos azuis.

Nota-se também que os valores de $\Delta b^{*}$ do grupo 5 foram muito maiores do que nos outros grupos, revelando uma forte influência do envelhecimento artificial neste grupo.

A presença de metal no grupo 1 provavelmente levou a um aumento no componente azul. Porém, nos grupos 2 e 4 seria esperado um aumento de amarelo e não de azul, quando submetidas ao envelhecimento artificial. Observa-se, no entanto, que esta mudança na coordenada $b^{*}$ nestes grupos (2 e 4) não foi estatisticamente relevante. O grupo 3 foi o que menos sofreu influência do envelhecimento artificial acelerado. 


\subsubsection{Resultados de $\Delta \mathrm{E}^{*}$.}

Os valores médios e desvios-padrão do $\Delta \mathrm{E}^{*}$ dos 5 sistemas cerâmicos glazeados e pintados extrinsecamente, obtidos após o envelhecimento artificial e leitura final dos corpos de prova estão demonstrados na tabela 10, sendo os valores originais apresentados no apêndice $\mathrm{E}$.

Tabela 10: Valores médios e desvios-padrão do $\Delta \mathrm{E}^{*}$ dos 5 sistemas cerâmicos glazeados e com pintura extrínseca.

\begin{tabular}{cc|c}
\hline \multicolumn{2}{c}{ Cerâmicas } & \multicolumn{1}{c}{$\Delta \mathbf{E}^{*}$} \\
\cline { 1 - 2 } Grupo 1 & MCPE & $0,47 \pm 0,08$ \\
& CER & $0,47 \pm 0,17$ \\
Grupo 2 & CERPE & $0,67 \pm 0,16$ \\
& EX & $0,43 \pm 0,14$ \\
Grupo 3 & EXPE & $0,43 \pm 0,11$ \\
& VTAL & $0,63 \pm 0,22$ \\
Grupo 4 & VTALPE & $0,78 \pm 0,13$ \\
& VTCE & $3,32 \pm 0,30$ \\
\cline { 1 - 2 } Grupo 5 & VTCEPE & $2,68 \pm 0,18$ \\
& &
\end{tabular}

$\mathrm{O} \Delta \mathrm{E}^{*}$ representa a mudança total de cor de uma amostra quando esta é submetida a alguma intervenção, no caso, o envelhecimento artificial 
acelerado. $\mathrm{O} \Delta \mathrm{E}^{*}$ é calculado pelo espectrofotômetro por uma fórmula que leva em consideração as medidas de $\Delta \mathrm{L}^{*}, \Delta \mathrm{a}^{*} \mathrm{e} \Delta \mathrm{b}^{*}$.

$$
\Delta \mathrm{E}=\left[\left(\Delta \mathrm{L}^{*}\right)^{2}+\left(\Delta \mathrm{a}^{*}\right)^{2}+\left(\Delta \mathrm{b}^{*}\right)^{2}\right]^{1 / 2}
$$

Os dados contidos na tabela 10 foram avaliados estatisticamente. Para evidenciar a importância do tipo de cerâmica e do tipo de tratamento de superfície a que ela foi submetida, aplicou-se uma análise de variância para um modelo experimental envolvendo então dois fatores de variação independentes: cerâmicas (MC, CER, EX, VTAL, VTCE) e tratamento superfície (glazeado -G e com pintura extrínseca - PE) (tabela 11).

Tabela 11: Análise estatística ANOVA da variável $\Delta \mathrm{E}^{*}$ com dois fatores de variação independentes $(p<0,05)$.

\begin{tabular}{cccccc}
\hline Fonte de Variação & S.Q. & G.L. & Q.M. & $\mathbf{F}$ & $\mathbf{p}$ \\
\hline Interceptação & 75,816 & 1 & 75,816 & 2557,033 & 0,000000 \\
TS & 0,485 & 1 & 0,485 & 16,376 & 0,000151 \\
Cerâmica & 67,450 & 4 & 16,862 & 568,719 & 0,000000 \\
TS x Cerâmica & 1,272 & 4 & 0,318 & 10,727 & 0,000001 \\
erro & 1,779 & 60 & 0,029 & & \\
\hline
\end{tabular}

TS= tratamento de superfície

Após a análise de variância ter constatado significância estatística tanto para os fatores de variação isolados como pela interação entre eles, foi realizado o teste Tuckey. 
Tabela 12: Teste Tuckey - variável $\Delta E^{*}(p<0,05)$.

\begin{tabular}{|c|c|c|c|c|c|c|c|c|c|c|c|c|}
\hline & & & 1 & 2 & 3 & 4 & 5 & 6 & 7 & 8 & 9 & 10 \\
\hline & \multicolumn{2}{|c|}{ Médias } & 0,47 & 0,67 & 0,52 & 0,63 & 3,31 & 0,47 & 0,42 & 0,42 & 0,78 & 2,67 \\
\hline & TS & Cer & & & & & & & & & & \\
\hline 1 & G & MC & & ns & ns & ns & 0,00 & ns & ns & ns & 0,03 & 0,00 \\
\hline 2 & $\mathbf{G}$ & CER & ns & & ns & ns & 0,00 & ns & ns & ns & ns & 0,00 \\
\hline 3 & $\mathbf{G}$ & EX & ns & ns & & ns & 0,00 & ns & ns & ns & ns & 0,00 \\
\hline 4 & $\mathbf{G}$ & VTAL & ns & ns & ns & & 0,00 & ns & ns & ns & ns & 0,00 \\
\hline 5 & $\mathbf{G}$ & VTCE & 0,00 & 0,00 & 0,00 & 0,00 & & 0,00 & 0,00 & 0,00 & 0,00 & 0,00 \\
\hline 6 & PE & MC & ns & ns & ns & ns & 0,00 & & ns & ns & 0,03 & 0,00 \\
\hline 7 & PE & CER & ns & ns & ns & ns & 0,00 & ns & & ns & 0,00 & 0,00 \\
\hline 8 & PE & EX & ns & ns & ns & ns & 0,00 & ns & ns & & 0,00 & 0,00 \\
\hline 9 & PE & VTAL & 0,03 & ns & ns & ns & 0,00 & 0,03 & 0,00 & 0,00 & & 0,00 \\
\hline 10 & PE & VTCE & 0,00 & 0,00 & 0,00 & 0,00 & 0,00 & 0,00 & 0,00 & 0,00 & 0,00 & \\
\hline
\end{tabular}

Analisando a tabela 12, observa-se que o grupo 5 (VTCE e VTCEPE) foi diferente estatisticamente de todos os outros grupos. Neste caso, o fator de variação cerâmica foi responsável pela significância.

Observa-se também que a cerâmica VTALPE, ou seja, com pintura extrínseca, foi diferente de todas as cerâmicas com pintura extrínseca, com níveis de significância diferentes e também da cerâmica MC glazeada. Neste caso, o fator pintura extrínseca foi responsável pela significância, já que a cerâmica VTAL glazeada não obteve significância estatística. 
O grupo 5 foi, sem dúvida, o que sofreu maior alteração de cor e, além disto, com níveis de significância muito acentuados.

Desta forma conclui-se que a cerâmica Cerabien, que confeccionou o grupo 5, foi a que obteve o pior desempenho entre as cerâmicas testadas quanto à estabilidade de cor após o envelhecimento artificial acelerado. Isto ocorreu principalmente devido as coordenadas $L^{*}$ e $b^{*}$, já que nestas duas coordenadas, o nível de significância do grupo 5 foi maior e com alterações de $\Delta L^{*} e \Delta b^{*}$ numericamente maiores. Tem sido reportado, no entanto, que o olho humano é mais sensível às variações de vermelho $\left(a^{*}\right)$ do que de amarelo $\left(b^{*}\right)$ (HASSEL, et al., 2007).

No estudo de opacidade, observou-se que este grupo não sofreu alterações, muito provavelmente devido à opacidade inicial próxima de $100 \%$. Já quanto à estabilidade de cor, o grupo sofreu claramente uma perda de luminosidade ou escurecimento das amostras ( $\Delta \mathrm{L}^{*}$ negativo) e uma tendência ao amarelamento ( $\Delta \mathrm{b}^{*}$ positivo).

A cerâmica Cerabien é utilizada para recobrimento de infra-estruturas cerâmicas aluminizadas. Neste estudo, ela recobriu uma infra-estrutura de Vitroceram. Estudos de estabilidade cor em cerâmicas de recobrimento de infra-estruturas cerâmicas, sistemas ceramo-cerâmicos, são escassos na literatura.

Hoje, com a grande ênfase em estética, a estabilidade de cor de materiais odontológicos recebe uma grande importância. Conseqüentemente os novos materiais devem ter boas propriedades mecânicas, durabilidade e estética. A cerâmica, como material restaurador, tem propriedades muito boas em todos estes tópicos. Contudo, os fabricantes têm disponibilizado uma 
grande variedade de materiais cerâmicos no mercado, com maiores possibilidade de uso como os sistemas ceramo-cerâmicos e estes materiais devem ser pesquisados.

Nos estudos de estabilidade cor, dois fatores são importantes:

1) o meio utilizado para percepção da alteração da cor, seja ele, visual ou instrumental,

2) o meio utilizado para exercer a alteração de cor propriamente dita sobre o corpo de prova, seja imersão em água, azul de metileno, ciclos de sinterização, ciclagem térmica ou envelhecimento artificial acelerado.

A espectrofotometria é extensamente utilizada em estudos de cor e opacidade de cerâmicas e resinas. Há muito existe um consenso entre pesquisadores que o espectrofotômetro com o sistema CIELab de cor é o instrumento mais adequado para utilização em estudos de cor em Odontologia (SEGUI, et al., 1989; RAZZOG, et al., 1994, HEYDECKE, 2001; HASSEL, 2007).

Espectrofotômetros podem mensurar mudanças de cor muito menores do que aquelas percebidas pelo olho humano, porém a relevância clínica disto precisa ser avaliada.

Não existe, no entanto, um índice de mudança de cor $\left(\Delta \mathrm{E}^{*}\right)$ de relevância clínica estabelecido entre os autores. Alguns julgam que um $\Delta E^{*}>2$ é clinicamente inaceitável (BARATH, 2003), outros um $\Delta E^{*}>2,77$ (WEE et al., 2002), outros ainda um $\Delta \mathrm{E}^{*}>3,0$ (HEYDECKE et al., 2001) ou $\Delta \mathrm{E}^{*}>3,3$ (Schulze et al., 2002). O consenso existe quanto ao índice de $\Delta \mathrm{E}^{*}$ detectável pelo olho humano $\left(\Delta \mathrm{E}^{*}>1,0\right)$, ou seja, mudanças de cores maiores do que este índice são perceptíveis visualmente. Neste estudo foi estabelecido $\Delta \mathrm{E}^{*}>1,0$ 
para mudanças detectáveis pelo olho humano e $\Delta \mathrm{E}^{*}>3,0$ para aquelas clinicamente relevantes (Grafico 8).

\section{DE}

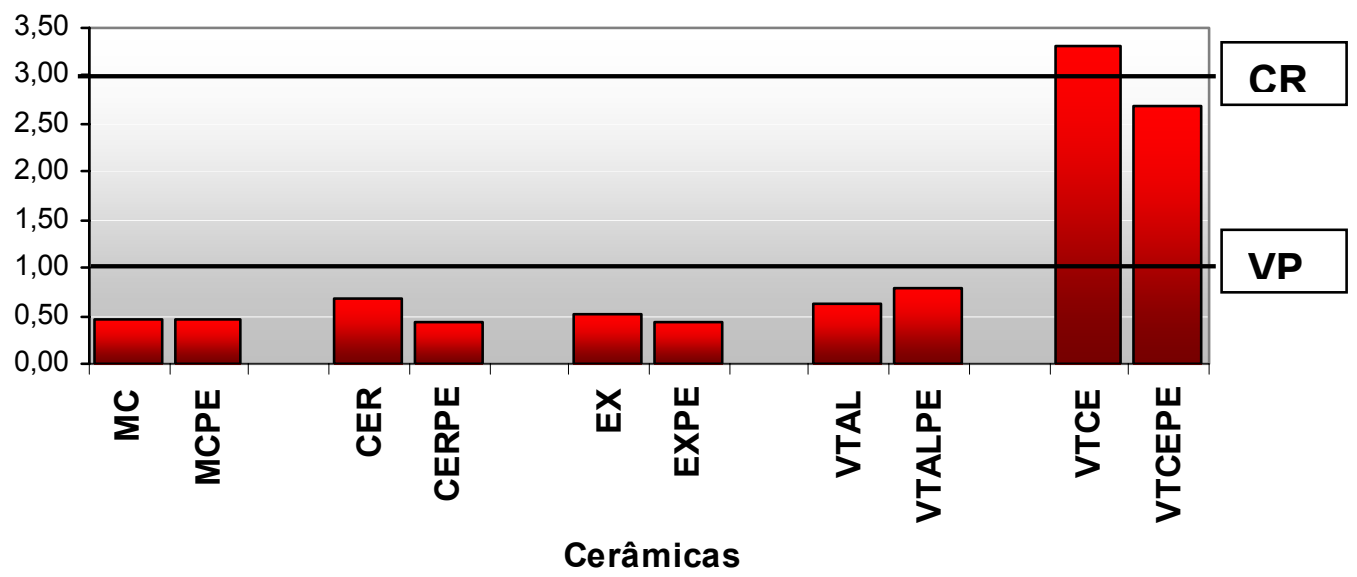

$\mathrm{CR}=$ clinicamente relevante

$\mathrm{VP}=$ visualmente perceptível

Gráfico 8: Médias de $\Delta \mathrm{E}^{*}$ das cerâmicas testadas.

Assim, evidenciou-se que os grupos 1, 2, 3 e 4 obtiveram mudanças de cor, porém não perceptível pelo olho humano. Já o grupo 4 teve uma mudança de cor facilmente percebida pelo olho humano e a cerâmica apenas glazeada (VTCE) foi classificada como inaceitável clinicamente pelos parâmetros adotados neste estudo.

Quanto ao meio utilizado para alterar a cor do material pesquisado, a máquina de envelhecimento artificial acelerado é a mais utilizada. No entanto, segundo Ertan e Saiiin (2004), a relevância clínica do envelhecimento na estabilidade de cor ainda não foi bem estudada e as modificações ocorridas devido ao envelhecimento podem ser comparadas a um período de uso 
prolongado variável dependente das condições e do número de horas a que o corpo de prova foi submetido ao envelhecimento.

Segundo Razzog, et al. (1994), as maiores modificações ocorrem nas primeiras 100 horas de envelhecimento artificial. Heydecke et al. (2001) considerou, no entanto, 300h de envelhecimento artificial como 1 ano de uso clínico. Portanto, neste estudo, foi utilizado 500h de envelhecimento artificial acelerado, o que corresponde a aproximadamente 1 ano e 8 meses de uso clínico.

Quanto à pintura extrínseca observamos que os grupos 2 e 3 tiveram as médias de mudanças de cor maior entre as glazeadas e não entre as pintadas, porém isto não teve relevância estatística.

No grupo 4, ocorreu relevância estatística para a cerâmica pigmentada. No grupo 1 as médias de $\Delta \mathrm{E}^{*}$ foram iguais tanto para as pigmentadas quanto para as apenas glazeadas. 


\subsection{Espectrofotômetro Easyshade (Vita)}

O aparelho Easyshade é um espectrofotômetro direcionado especialmente para os profissionais de odontologia. Ele possui duas funções básicas: medir a cor de um dente natural, posicionando-a dentro de uma das escalas padrão Vita (Vita Clássica ou 3D Master) e verificar a cor de uma restauração estética por comparação com uma cor previamente selecionada de uma dessas escalas. Neste estudo foi utilizada a função verificação de restauração onde todos os resultados eram apresentados pelo aparelho em forma de diferença $(\Delta)$ entre a cor dos corpos de prova e a cor padrão selecionada B3, já que todos os corpos de prova foram confeccionados nesta cor da escala Vita Clássica.

\subsubsection{Resultados de $\Delta \mathrm{L}^{*}$}

As leituras iniciais e finais dos $\Delta \mathrm{L}^{*}$ dos corpos de prova foram resultados da seguinte fórmula:

$\Delta L^{*}{ }_{\text {inicial }}=L^{*}{ }_{\text {inicial amostra }}-L^{*}$ padrão B3 $\mathrm{e} \Delta L^{*}{ }_{\text {final }}=L^{*}$ final amostra $-L^{*}$ padrão B3.

Os valores médios e desvios-padrão dos $\Delta \mathrm{L}^{*}$ iniciais e finais dos 5 sistemas cerâmicos glazeados e pintados extrinsecamente estão demonstrados na tabela 13, sendo os valores originais apresentados no apêndice $F$. 
Tabela 13: Valores médios e desvios-padrão dos $\Delta \mathrm{L}^{*}$ dos 5 sistemas cerâmicos glazeados e com pintura extrínseca antes (inicial) e depois (final) do envelhecimento artificial acelerado.

\begin{tabular}{|c|c|c|c|}
\hline & & \multicolumn{2}{|c|}{ Envelhecimento artificial } \\
\hline & & Inicial & Final \\
\hline \multicolumn{2}{|c|}{ Cerâmicas } & & \\
\hline \multirow[b]{2}{*}{ Grupo 1} & MC & $5,64 \pm 1,19$ & $4,99 \pm 1,02$ \\
\hline & MCPE & $5,30 \pm 0,35$ & $4,03 \pm 0,59$ \\
\hline \multirow{2}{*}{ Grupo 2} & CER & $4,31 \pm 0,59$ & $4,09 \pm 0,66$ \\
\hline & CERPE & $2,84 \pm 0,67$ & $2,70 \pm 0,63$ \\
\hline \multirow{2}{*}{ Grupo 3} & EX & $2,84 \pm 0,72$ & $2,91 \pm 1,96$ \\
\hline & EXPE & $1,94 \pm 0,22$ & $1,96 \pm 0,15$ \\
\hline \multirow{2}{*}{ Grupo 4} & VTAL & $8,27 \pm 0,60$ & $5,60 \pm 0,45$ \\
\hline & VTALPE & $6,44 \pm 1,48$ & $3,56 \pm 0,83$ \\
\hline \multirow{2}{*}{ Grupo 5} & VTCE & $6,66 \pm 1,35$ & $3,37 \pm 0,99$ \\
\hline & VTCEPE & $5,41 \pm 1,61$ & $3,24 \pm 0,98$ \\
\hline
\end{tabular}

Analisando a tabela 13 , observa-se que todos os valores de $\Delta L^{*}$, tanto antes como após o envelhecimento, foram positivos, portanto a luminosidade de todos os grupos estava maior do que a luminosidade da cor selecionada B3. Sendo assim, os corpos de prova estavam mais claros do que a cor B3. Sabese que o glazeamento da cerâmica tende a aumentar a luminosidade da mesma, sendo possivelmente o ocorrido neste estudo ( $\mathrm{CHO}$, et al., 2006). Observa-se que após o envelhecimento os valores de $\Delta \mathrm{L}^{*}$ diminuíram para todos os grupos, com exceção do grupo 3 (EX e EXPE). Isto significa que os corpos de prova escureceram com o envelhecimento, aproximando sua luminosidade com a da cor padrão B3, diminuindo a diferença inicial. 
Observa-se também que o grupo que melhor se aproximou da luminosidade da cor padrão foi o grupo 3 , que obteve os menores valores de $\Delta L^{*}$ inicial e final (Gráfico 9).

\section{$\Delta \mathbf{L}^{*}$}

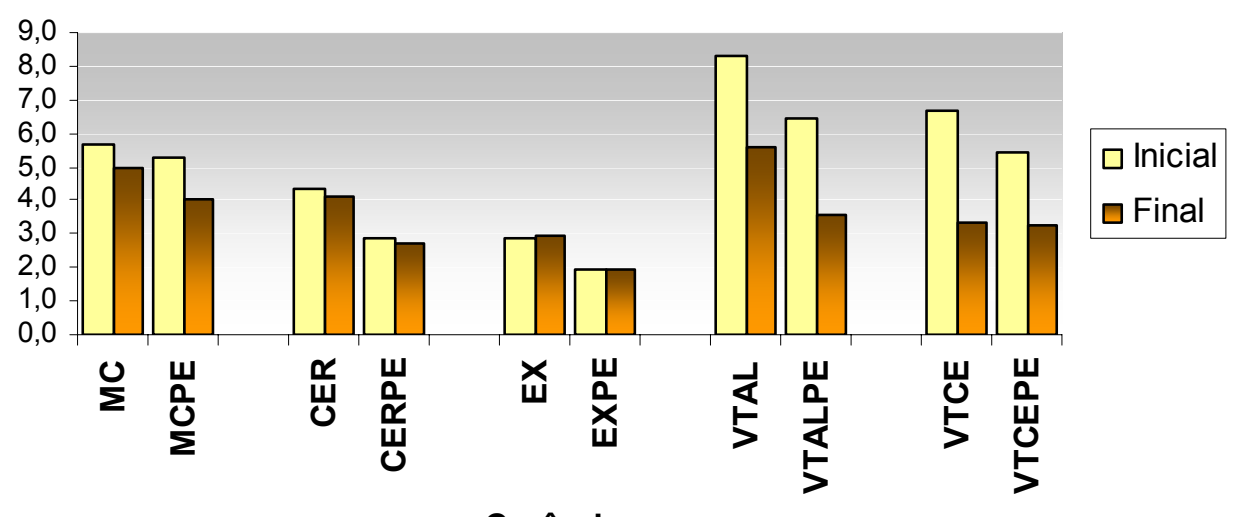

Gráfico 9: Média de $\Delta L^{*}$ inicial e final das cerâmicas testadas.

Os dados contidos na tabela 13 foram avaliados estatisticamente, aplicando-se o teste $t$ de Student para dados vinculados com $p<0,05$ (tabela 14). 
Tabela 14: Análise estatística (teste t de Student) dos valores de $\Delta \mathrm{L}^{*}$ com fator de variação envelhecimento artificial (dados vinculados) para $p<0,05$.

\begin{tabular}{|c|c|c|c|c|}
\hline & & \multicolumn{3}{|c|}{ Teste $t$ de Student } \\
\hline & & $\neq$ (médias) & $t$ & $p$ \\
\hline \multicolumn{5}{|c|}{ Cerâmicas } \\
\hline \multirow{2}{*}{ Grupo 1} & MC & 0,66 & 7,81 & 0,00002 \\
\hline & MCPE & 1,27 & 4,28 & 0,005 \\
\hline \multirow{2}{*}{ Grupo 2} & CER & 0,23 & 4,82 & 0,003 \\
\hline & CERPE & 0,14 & 1,55 & 0,17 \\
\hline \multirow{2}{*}{ Grupo 3} & EX & $-0,07$ & $-1,18$ & 0,28 \\
\hline & EXPE & $-0,01$ & $-0,14$ & 0,89 \\
\hline \multirow{2}{*}{ Grupo 4} & VTAL & 2,67 & 10,59 & 0,00004 \\
\hline & VTALPE & 2,89 & 3,91 & 0,008 \\
\hline \multirow{2}{*}{ Grupo 5} & VTCE & 3,29 & 7,31 & 0,0003 \\
\hline & VTCEPE & 12,17 & 8,57 & 0,0001 \\
\hline
\end{tabular}

Através desta análise nota-se que, as cerâmicas dos grupos 1 (MC e MCPE), 4 (VTAL e VTALPE) e 5 (VTCE e VTCEPE) e a cerâmica glazeada do grupo 2 (CER) sofreram modificação com o envelhecimento artificial, e esta modificação foi uma aproximação da luminosidade padrão, ou melhor, foi uma perda de luminosidade.

No grupo 3 e na cerâmica CERPE, esta modificação não foi estatisticamente significante. Estes dados foram diferentes daqueles encontrados na análise da coordenada $L^{*}$ pelo aparelho Color Guide, já que naquele espectrofotômetro todos os grupos sofreram modificação estatisticamente significante da luminosidade após o envelhecimento artificial Isto provavelmente ocorreu devido à mudança de metodologia e de aparelho de medição.

Pelos níveis de significância, nesta medição pode-se perceber que as cerâmicas com pintura extrínseca sofreram menos alterações de luminosidade do que as apenas glazeadas em todos os grupos. 
5.2.2. Resultados de $\Delta C^{*}$.

O vetor $C^{*}$ é uma coordenada de intensidade ou saturação. A diferença de intensidade é chamada de $\Delta C^{*}$. Neste estudo foram utilizadas as seguintes fórmulas:

$\Delta C^{*}{ }_{\text {inicial }}=C^{*}{ }_{\text {inicial amostra }}-C^{*}$ padrão B3 e $\Delta C^{*}{ }_{\text {final }}=C^{*}{ }_{\text {final amostra }}-C^{*}$ padrão B3.

$\mathrm{O} \Delta \mathrm{C}^{*}$ é uma diferença do comprimento do vetor. Um valor positivo de $\Delta C^{*}$ indica que a amostra está mais intensa ou mais viva do que o padrão e um valor negativo indica que a amostra está menos intensa ou menos saturada do que o padrão (MORALES, 2007).

Os valores médios e desvios-padrão dos $\Delta \mathrm{C}^{*}$ iniciais e finais dos 5 sistemas cerâmicos glazeados e pintados extrinsecamente estão demonstrados na tabela 15 , sendo os valores originais apresentados no apêndice $F$. 
Tabela 15: Valores médios e desvios-padrão dos $\Delta C^{*}$ dos 5 sistemas cerâmicos glazeados e com pintura extrínseca antes (inicial) e depois (final) do envelhecimento artificial acelerado.

\begin{tabular}{|c|c|c|c|}
\hline & & \multicolumn{2}{|c|}{ Envelhecimento artificial } \\
\hline & & Inicial & Final \\
\hline \multicolumn{2}{|c|}{ Cerâmicas } & & \\
\hline \multirow[b]{2}{*}{ Grupo 1} & MC & $-8,11 \pm 2,44$ & $-8,07 \pm 2,22$ \\
\hline & MCPE & $-4,99 \pm 1,09$ & $-6,33 \pm 0,47$ \\
\hline \multirow{2}{*}{ Grupo 2} & CER & $-8,19 \pm 2,03$ & $-7,74 \pm 2,05$ \\
\hline & CERPE & $-4,03 \pm 1,03$ & $-3,43 \pm 1,35$ \\
\hline \multirow{2}{*}{ Grupo 3} & EX & $-6,70 \pm 1,05$ & $-6,23 \pm 1,21$ \\
\hline & EXPE & $-4,09 \pm 0,20$ & $-3,40 \pm 0,45$ \\
\hline \multirow{2}{*}{ Grupo 4} & VTAL & $-4,74 \pm 2,13$ & $-5,23 \pm 1,02$ \\
\hline & VTALPE & $-0,37 \pm 4,07$ & $-2,99 \pm 0,79$ \\
\hline \multirow{2}{*}{ Grupo 5} & VTCE & $-5,01 \pm 1,48$ & $-3,49 \pm 0,56$ \\
\hline & VTCEPE & $-0,80 \pm 1,37$ & $-0,37 \pm 1,98$ \\
\hline
\end{tabular}

A tabela 15 mostra que todos os valores de $\Delta C^{*}$ foram negativos, apontando que as amostras estavam menos saturadas ou menos intensas do que a cor padrão. Isto continuou válido mesmo após o envelhecimento artificial.

Nota-se que após o envelhecimento artificial os valores de $\Delta C^{*}$ aumentaram para os grupos 2, 3 e 5 e para a cerâmica MC. Isto significou que as amostras se tornaram mais saturadas, se aproximando do croma da cor padrão, ou seja, se aproximando de zero. Isto não ocorreu na cerâmica MCPE e no grupo 4, onde os valores de croma das amostras se distanciaram do croma padrão (Gráfico 10).

A pintura extrínseca tem por função aumentar o croma de uma restauração, ou seja, torná-la mais saturada (McPhee, 1985). Observa-se que em todos os grupos as amostras com pintura extrínseca estão mais saturadas do que as apenas glazeadas. 


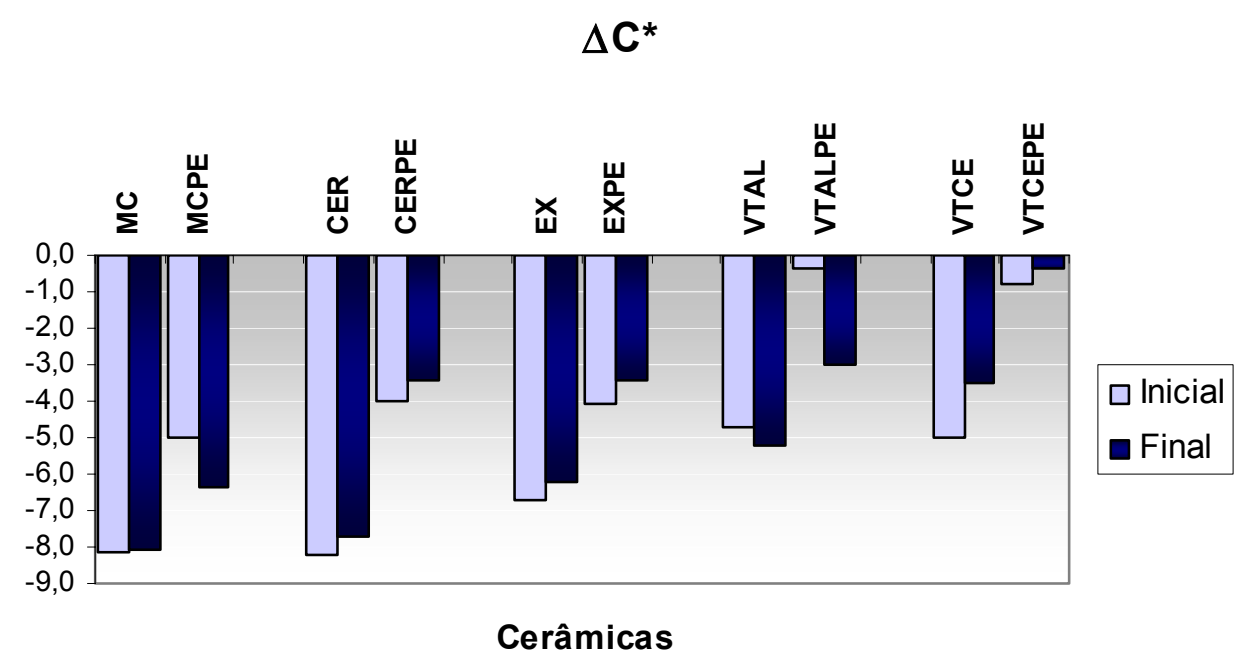

Gráfico 10: Média de $\Delta C^{*}$ inicial e final das cerâmicas testadas.

Os dados contidos na tabela 15 foram avaliados estatisticamente, aplicando-se o teste $t$ de Student para dados vinculados com $p<0,05$ (tabela 16).

Tabela 16: Análise estatística (teste t de Student) dos valores de $\Delta \mathrm{C}^{*}$ com fator de variação envelhecimento artificial (dados vinculados) para $p<0,05$.

\begin{tabular}{|c|c|c|c|c|}
\hline & & \multicolumn{3}{|c|}{ Teste $t$ de Student } \\
\hline & & $\neq$ (médias) & $t$ & $p$ \\
\hline \multicolumn{5}{|c|}{ Cerâmicas } \\
\hline Grupo 1 & $\begin{array}{c}\mathrm{MC} \\
\mathrm{MCPE}\end{array}$ & $\begin{array}{l}-0,4 \\
1,34\end{array}$ & $\begin{array}{c}-0,33 \\
2,45\end{array}$ & $\begin{array}{l}0,75 \\
0.05\end{array}$ \\
\hline \multirow{2}{*}{ Grupo 2} & CER & $-0,44$ & $-2,87$ & 0,03 \\
\hline & CERPE & $-0,6$ & $-1,57$ & 0,17 \\
\hline \multirow{2}{*}{ Grupo 3} & EX & $-0,47$ & $-3,47$ & 0,01 \\
\hline & EXPE & $-0,69$ & $-3,7$ & 0,01 \\
\hline \multirow{2}{*}{ Grupo 4} & VTAL & 0,49 & 0,58 & 0,58 \\
\hline & VTALPE & 2,61 & 1,67 & 0,15 \\
\hline \multirow{2}{*}{ Grupo 5} & VTCE & $-1,53$ & $-2,86$ & 0,03 \\
\hline & VTCEPE & $-0,43$ & $-0,48$ & 0,65 \\
\hline
\end{tabular}


A tabela 16 mostra que o fator envelhecimento artificial foi significante para os grupos 3 e 5 e para a cerâmica CER.

Neste caso, não se conseguiu relacionar em todos os grupos, a pintura extrínseca com uma menor variação quanto ao envelhecimento artificial. Isto foi possível apenas no grupo 2 e 5 . Nos outros grupos (1, 3 e 4), a significância das cerâmicas com pintura extrínseca foi igual ou maior do que as apenas glazeadas, ou seja, elas variaram mais do que as apenas glazeadas. 


\subsubsection{Resultados de $\Delta h^{*}$.}

A coordenada $\mathrm{h}^{*}$ é representante da tonalidade ou matiz de uma cor. $\mathrm{O}$ ângulo formado pela diferença de tonalidade entre duas cores é chamado $\Delta \mathrm{h}^{*}$. Um valor positivo indica a direção anti-horária e um valor negativo indica a direção horária (Figura 33).

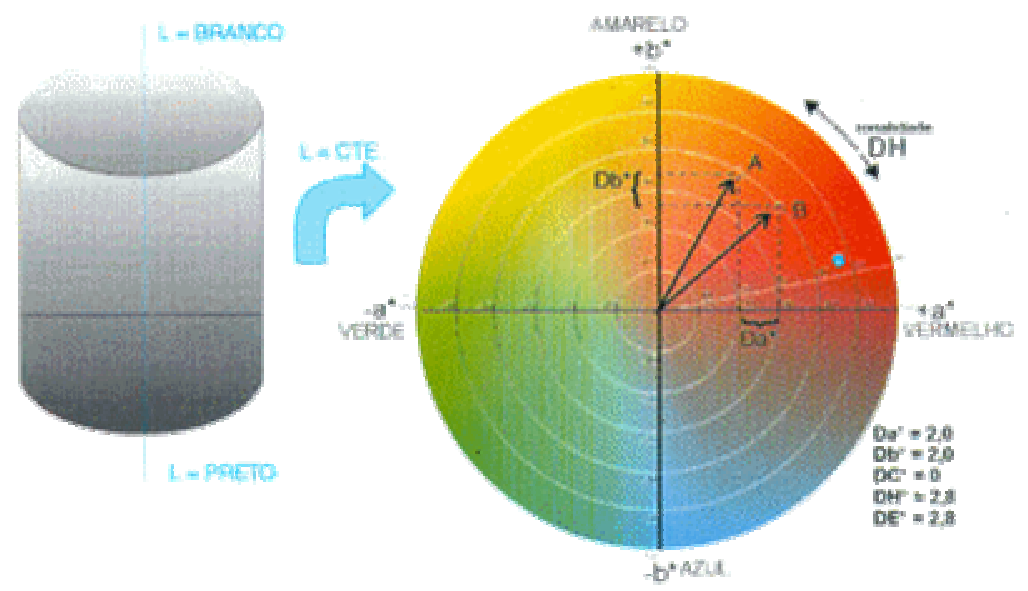

Figura 33: Representação gráfica do sistema CIELab e CIELCh . (Disponível em: <http://www.cromexbrancolor.com.br> Acesso em 07/01/2007).

Os valores de $\Delta \mathrm{h}^{*}$ foram calculados pelo aparelho utilizando a seguinte fórmula:

$$
\Delta h^{*}{ }_{\text {inicial }}=h^{*}{ }_{\text {inicial amostra }}-h^{*} \text { padrão B3 e } \Delta h^{*} \text { final }=h^{*} \text { final amostra }-h^{*} \text { padrão B3. }
$$

Os valores médios e desvios-padrão dos $\Delta h^{*}$ iniciais e finais dos 5 sistemas cerâmicos glazeados e pintados extrinsecamente estão demonstrados na tabela 17 , sendo os valores originais apresentados no apêndice F. 
Tabela 17: Valores médios e desvios-padrão dos $\Delta \mathrm{h}^{*}$ dos 5 sistemas cerâmicos glazeados e com pintura extrínseca antes (inicial) e depois (final) do envelhecimento artificial acelerado.

\begin{tabular}{|c|c|c|c|}
\hline & & \multicolumn{2}{|c|}{ Envelhecimento artificial } \\
\hline & & Inicial & Final \\
\hline \multicolumn{2}{|c|}{ Cerâmicas } & & \\
\hline \multirow{2}{*}{ Grupo 1} & MC & $1,57 \pm 1,51$ & $2,07 \pm 1,23$ \\
\hline & MCPE & $0,10 \pm 1,00$ & $0,86 \pm 0,75$ \\
\hline \multirow{2}{*}{ Grupo 2} & CER & $3,50 \pm 1,61$ & $3,06 \pm 1,66$ \\
\hline & CERPE & $-0,11 \pm 0,22$ & $-0,21 \pm 0,28$ \\
\hline \multirow{2}{*}{ Grupo 3} & EX & $-1,94 \pm 0,45$ & $-1,77 \pm 0,54$ \\
\hline & EXPE & $-2,94 \pm 0,28$ & $-2,94 \pm 0,29$ \\
\hline \multirow{2}{*}{ Grupo 4} & VTAL & $-0,43 \pm 1,44$ & $-0,19 \pm 1,73$ \\
\hline & VTALPE & $-3,74 \pm 0,93$ & $-2,19 \pm 0,57$ \\
\hline \multirow{2}{*}{ Grupo 5} & VTCE & $-0,86 \pm 0,41$ & $0,70 \pm 1,34$ \\
\hline & VTCEPE & $-2,31 \pm 0,50$ & $-1,19 \pm 0,41$ \\
\hline
\end{tabular}

Através da tabela 17 observa-se que os valores médios de $\Delta \mathrm{h}^{*}$ variam tanto na direção horária (valores negativos), quanto na direção anti-horária (valores positivos).

Situando a cor B3 padrão na figura 33 , sua localização seria no quadrante superior esquerdo, pois a cor B3 é predominantemente amarela. Desta forma, os grupos 3,4 e 5 e a cerâmica CERPE tiveram um $\Delta \mathrm{h}^{*}$ inicial negativo em relação ao padrão, ou seja, a cor da amostra estava posicionada mais para o vermelho em relação ao padrão.

Já o grupo 1 e a cerâmica CER obtiveram valores de $\Delta \mathrm{h}^{*}$ positivo indicando uma mudança na direção anti-horária, ou mais para o verde. Isto se deve provavelmente à presença de um substrato metálico no grupo $1 \mathrm{e}$ 
também a uma característica da cerâmica de recobrimento (Ceramco), o que foi apontado no estudo da coordenada $a^{*}$ medida pelo aparelho Color Guide.

As médias finais de $\Delta h^{*}$ do grupo 1 orientaram-se ainda mais no sentido anti-horário, ou para o verde. Isto devido ao envelhecimento artificial agir como um meio oxidante da subestrutura metálica presente neste grupo. O mesmo não ocorreu com a cerâmica CER, que caminhou em sentido horário quando comparada com o $\Delta \mathrm{h}^{*}$ inicial, portanto tornou-se mais avermelhada ou menos verde.

As outras médias após o envelhecimento, quando comparadas às médias iniciais tenderam para o sentido anti-horário, ou seja, elas se tornaram mais próximo do zero, provando que eles se aproximaram da cor padrão amarela e tornaram-se menos vermelhos (Gráfico 11).

$\Delta \mathbf{h}^{*}$

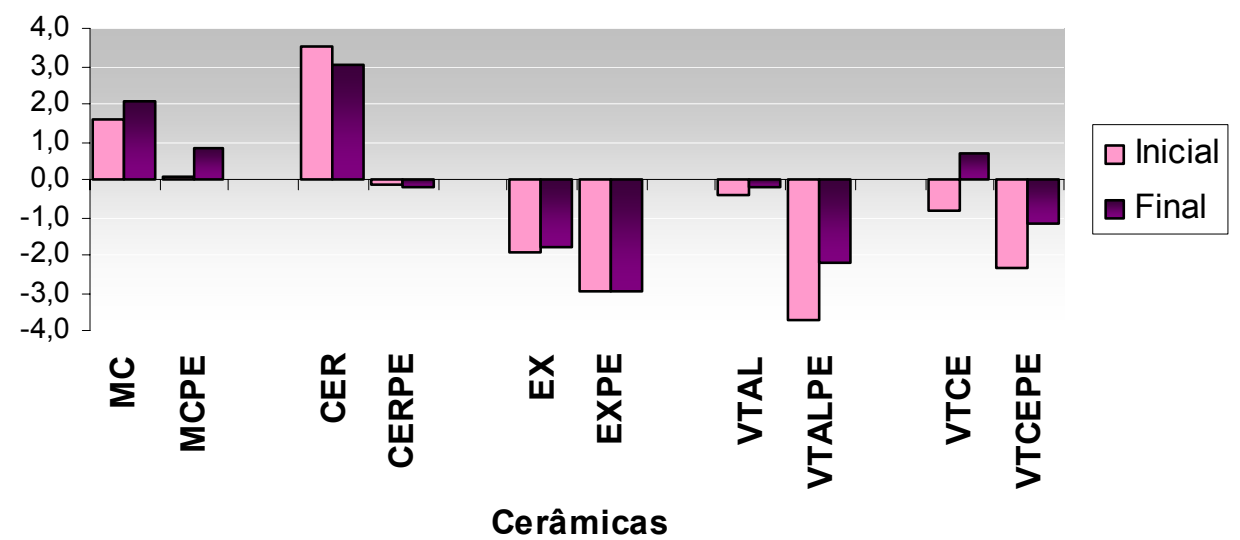

Gráfico 11: Média de $\Delta \mathrm{h}^{*}$ inicial e final das cerâmicas testadas. 
Os dados contidos na tabela 17 foram avaliados estatisticamente, aplicando-se o teste $t$ de Student para dados vinculados com $p<0,05$ (tabela 18).

Tabela 18: Análise estatística (teste $t$ de Student) dos valores de $\Delta \mathrm{h}^{*}$ com fator de variação envelhecimento artificial (dados vinculados) para $p<0,05$.

\begin{tabular}{|c|c|c|c|c|}
\hline & & \multicolumn{3}{|c|}{ Teste $t$ de Student } \\
\hline & & $\notin$ (médias) & $\mathrm{t}$ & $\mathrm{p}$ \\
\hline \multicolumn{5}{|c|}{ Cerâmicas } \\
\hline \multirow{2}{*}{ Grupo 1} & $\mathrm{MC}$ & $-0,5$ & $-1,63$ & 0,15 \\
\hline & MCPE & $-0,76$ & $-1,45$ & 0,20 \\
\hline \multirow{2}{*}{ Grupo 2} & CER & 0,44 & 2,65 & 0,04 \\
\hline & CERPE & 0,1 & 1,22 & 0,27 \\
\hline \multirow{2}{*}{ Grupo 3} & EX & $-0,17$ & $-2,20$ & 0,07 \\
\hline & EXPE & 0 & 1 & 0 \\
\hline \multirow{2}{*}{ Grupo 4} & VTAL & $-0,24$ & $-0,37$ & 0,72 \\
\hline & VTALPE & $-1,56$ & $-3,55$ & 0,01 \\
\hline \multirow{2}{*}{ Grupo 5} & VTCE & $-1,56$ & $-3,07$ & 0,02 \\
\hline & VTCEPE & $-1,13$ & $-6,02$ & 0,0009 \\
\hline
\end{tabular}

A tabela 18 mostra que o fator envelhecimento artificial influenciou estatisticamente o grupo 5 e as cerâmicas CER, EX e VTALPE.

Nos grupos 1, 2 e 3 as cerâmicas com pintura extrínseca sofreram menos influência do envelhecimento artificial. Já nos grupos 4 e 5 as cerâmicas com pintura extrínseca sofreram mais influência do envelhecimento.

Observa-se pelos níveis de significância que a cerâmica que mais sofreu os efeitos do envelhecimento artificial quanto ao $\Delta \mathrm{h}^{*}$ foi a VTCEPE e o grupo que menos sofreu foi o grupo 1 (MC e MCPE). 
5.2.4. Resultados de $\Delta \mathrm{E}^{*}$.

O $\Delta \mathrm{E}^{*}$ representa a mudança total de cor de uma amostra quando comparada com um padrão ou quando comparada com ela mesma após ser submetida a algum tratamento. $\mathrm{O}$ aparelho Easyshade forneceu neste estudo dois valores de $\Delta \mathrm{E}^{*}$ que foram calculados pela seguinte fórmula:

$$
\begin{aligned}
& \Delta E^{*}{ }_{\text {inicial }}=\left[\left(\Delta L^{*}{ }_{\text {inicial }}\right)^{2}+\left(\Delta C^{*}{ }_{\text {inicial }}\right)^{2}+\left(\Delta h^{*}{ }_{\text {inicial }}\right)^{2}\right]^{1 / 2} \\
& \Delta E^{*}{ }_{\text {final }}=\left[\left(\Delta L^{*}{ }_{\text {final }}\right)^{2}+\left(\Delta C^{*}{ }_{\text {final }}\right)^{2}+\left(\Delta h^{*}{ }_{\text {final }}\right)^{2}\right]^{1 / 2}
\end{aligned}
$$

Desta forma obtiveram-se dois valores de $\Delta \mathrm{E}^{*}$, um antes do envelhecimento e outro depois do envelhecimento.

Os valores médios e desvios-padrão dos $\Delta \mathrm{E}^{*}$ iniciais e finais dos 5 sistemas cerâmicos glazeados e pintados extrinsecamente estão demonstrados na tabela 19, sendo os valores originais apresentados no apêndice $F$. 
Tabela 19: Valores médios e desvios-padrão dos $\Delta \mathrm{E}^{*}$ dos 5 sistemas cerâmicos glazeados e com pintura extrínseca antes (inicial) e depois (final) do envelhecimento artificial acelerado.

\begin{tabular}{|c|c|c|c|}
\hline & & \multicolumn{2}{|c|}{ Envelhecimento artificial } \\
\hline & & Inicial & Final \\
\hline \multicolumn{2}{|c|}{ Cerâmicas } & & \\
\hline \multirow{2}{*}{ Grupo 1} & MC & $9,99 \pm 2,28$ & $9,54 \pm 2,21$ \\
\hline & MCPE & $7,34 \pm 0,60$ & $7,53 \pm 0,36$ \\
\hline \multirow{2}{*}{ Grupo 2} & CER & $9,56 \pm 1,62$ & $8,91 \pm 1,69$ \\
\hline & CERPE & $5,00 \pm 0,67$ & $4,47 \pm 0,99$ \\
\hline \multirow{2}{*}{ Grupo 3} & EX & $7,33 \pm 0,85$ & $6,89 \pm 0,92$ \\
\hline & EXPE & $5,06 \pm 0,41$ & $4,49 \pm 0,60$ \\
\hline \multirow{2}{*}{ Grupo 4} & VTAL & $9,80 \pm 0,56$ & $7,80 \pm 0,79$ \\
\hline & VTALPE & $7,89 \pm 1,54$ & $4,96 \pm 0,62$ \\
\hline \multirow{2}{*}{ Grupo 5} & VTCE & $8,49 \pm 0,85$ & $5,01 \pm 0,75$ \\
\hline & VTCEPE & $5,90 \pm 1,62$ & $3,76 \pm 0,87$ \\
\hline
\end{tabular}

$\mathrm{Na}$ tabela 19 observa-se que os valores de $\Delta \mathrm{E}^{*}$ tanto antes quanto depois de envelhecimento são acima de 3,0 para todos os grupos cerâmicos, ou seja, nenhuma cerâmica, mesmo com pintura extrínseca, foi capaz de reproduzir a cor escolhida B3 de maneira clinicamente aceitável. Todas ficaram mais claras e menos saturadas do que a cor padrão. Isto significa que predizer a cor de uma restauração cerâmica é uma tarefa complexa, já que envolve vários fatores tais como, presença de subestrutura metálica ou opaca, a marca da cerâmica, o lote de cerâmica, o forno, a espessura e o número de vezes que ela foi glazeada (WEE et al., 2002).

Apenas selecionar a cor e aplicá-la conforme instruções do fabricante não são garantia de se alcançar à cor desejada. Muitos técnicos lançam mão de alguns artifícios para se obter um bom resultado estético, entre eles o de misturar dois ou mais pós cerâmicos de cores e translucidez diferentes. 
$\mathrm{Na}$ tabela 19 nota-se também que os valores de $\Delta \mathrm{E}^{*}$ diminuíram para todas as cerâmicas com o envelhecimento artificial, com exceção da cerâmica MCPE. Isto significa que o envelhecimento artificial aproximou a cor das amostras da cor padrão.

As cerâmicas com pintura extrínseca obtiveram valores de $\Delta \mathrm{E}^{\star}$ menores do que as apenas glazeadas e após o envelhecimento artificial, a cerâmica que obteve o menor $\Delta \mathrm{E}^{\star}$ foi a VTCEPE (Gráfico 12).

$\Delta \mathrm{E}^{*}$

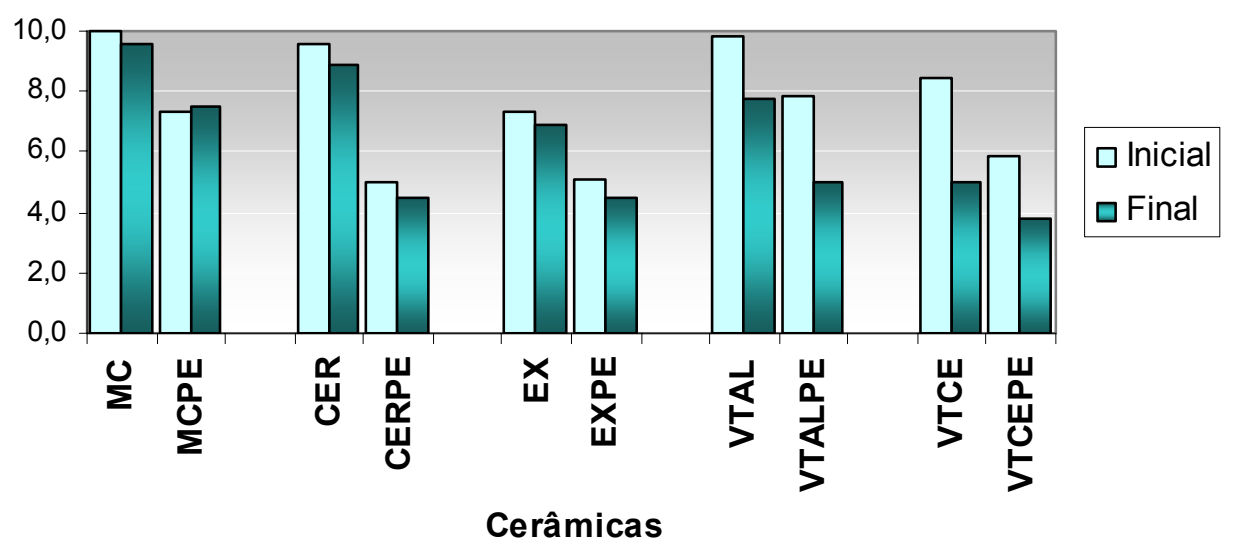

Gráfico 12: Média de $\Delta \mathrm{E}^{*}$ inicial e final das cerâmicas testadas.

Os dados contidos na tabela 19 foram avaliados estatisticamente, aplicando-se $o$ teste $t$ de Student para dados vinculados com $p<0,05$ (tabela 21). 
Tabela 20: Análise estatística (teste $t$ de Student) dos valores de $\Delta \mathrm{E}^{*}$ com fator de variação envelhecimento artificial (dados vinculados) para $p<0,05$.

\begin{tabular}{|c|c|c|c|c|}
\hline & & \multicolumn{3}{|c|}{ Teste $t$ de Student } \\
\hline & & $\neq$ (médias) & $\mathrm{t}$ & $\mathrm{p}$ \\
\hline \multicolumn{5}{|c|}{ Cerâmicas } \\
\hline \multirow{2}{*}{ Grupo 1} & MC & 0,44 & 4,24 & 0,005 \\
\hline & MCPE & $-0,19$ & $-0,65$ & 0,54 \\
\hline \multirow{2}{*}{ Grupo 2} & CER & 0,64 & 2,54 & 0,04 \\
\hline & CERPE & 0,53 & 1,84 & 0,12 \\
\hline \multirow{2}{*}{ Grupo 3} & EX & 0,44 & 5,27 & 0,002 \\
\hline & EXPE & 0,57 & 3,09 & 0,2 \\
\hline \multirow{2}{*}{ Grupo 4} & VTAL & 2 & 5,54 & 0,001 \\
\hline & VTALPE & 2,93 & 5,21 & 0,002 \\
\hline \multirow[t]{2}{*}{ Grupo 5} & VTCE & 3,47 & 26,62 & 0,00000 \\
\hline & VTCEPE & 2,14 & 5,86 & 0,001 \\
\hline
\end{tabular}

Nesta análise observa-se que os grupos 4 e 5 e as cerâmicas MC, CER e EX sofreram mudanças de cor com o envelhecimento artificial. Pelo nível de significância percebe-se que o grupo 5 foi o que mais sofreu alterações de cor com o envelhecimento artificial, assim como relatado anteriormente pelo aparelho Color Guide. Porém, diferentemente do que no outro aparelho, neste as cerâmicas MC, CER, EX e VTAL foram consideradas ineficazes quanto à estabilidade de cor.

È importante salientar que comparações entre dados de diferentes espectrofotômetros não são válidas quando a geometria óptica destes aparelhos é diferente, como é o caso deste estudo, portanto limitou-se a estudar separadamente os dados obtidos pelos aparelhos utilizados.

Desde a década de 80 existe uma discussão sobre como utilizar os avanços da tecnologia óptica para expandir o uso de espectrofotômetros e colorímetros, e aplica-los no dia a dia como um auxiliar para o cirurgiãodentista (SEGHI et al, 1989 a). 
Nos anos 90 os estudos se intensificaram e alguns aparelhos foram desenvolvidos para a área odontológica. O espectrofotômetro Easyshade foi introduzido no mercado com esta finalidade.

Segundo Seghi et al. (1989 b), as informações mais válidas obtidas pelos espectrofotômetros são aquelas facilmente interpretadas. Neste estudo percebeu-se que a identificação de uma restauração como insatisfatória em termos de cor, quando comparada com a cor padrão, foi facilmente detectável; porém a análise correta das três dimensões da cor e suas alterações, que eram expressas tanto numericamente como graficamente, exigiam do operador um conhecimento maior de cor e da metodologia utilizada pelo aparelho para medir esta diferença. 


\section{CONCLUSÕES}


De acordo com os resultados obtidos por meio da metodologia aplicada, conclui-se que:

1. O grupo 5 (VTCE e VTCEPE) foi o que mais sofreu os efeitos do envelhecimento artificial acelerado, tendo a cerâmica apenas glazeada VTCE um valor de $\Delta \mathrm{E}^{*}=3,32$, seguida da cerâmica com pintura extrínseca VTCEPE com um valor de $\Delta \mathrm{E}^{*}=2,68$. A cerâmica VTALPE também sofreu os efeitos do envelhecimento, porém apresentado um valor de $\Delta \mathrm{E}^{*}=0,78$. As outras cerâmicas não apresentaram significância estatística quanto ao envelhecimento artificial acelerado e todas apresentaram $\Delta \mathrm{E}^{*}<1$ com a utilização do espectrofotômetro Color Guide 45/0 (BYK-Gardner).

2. Com o espectrofotômetro Easyshade (Vita), as seguintes cerâmicas demonstraram alteração sob os efeitos do envelhecimento: MC, CER, EX, grupo 4 (VTAL e VTALPE) e grupo 5 (VTCE e VTCEPE), sendo a cerâmica VTCE a que apresentou a maior significância estatística.

3. As cerâmicas do grupo 2 (CER e CERPE) e 3 (EX e EXPE) obtiveram a menor porcentagem de opacidade. Quando submetidas ao envelhecimento artificial acelerado os grupos 2, 3 e 4 (VTAL e VTALPE) sofreram influência estatisticamente significante.

4. A pintura extrínseca diminui os efeitos do envelhecimento artificial acelerado sobre a opacidade.

5. Com o espectrofotômetro Color Guide $45 / 0$ a pintura extrínseca influenciou estatisticamente o grupo 4 (VTAL e VTALPE). Já nos outros grupos, as cerâmicas com pintura extrínseca tiveram um valor de $\Delta \mathrm{E}^{*}$ menor do que as apenas glazeadas. 
6. Com o espectrofotômetro Easyshade, todas as cerâmicas com pintura extrínseca sofreram menos os efeitos do envelhecimento artificial acelerado sobre a estabilidade de cor do que as apenas glazeadas. 
7. REFERÊNCIAS BIBLIOGRÁFICAS 
1. ADEXIM-COMEXIM. Equipamentos. Disponível em: <http://www.adeximcomexim.com.br >. Acesso em 10/01/2007.

2. ADOLFI, D. A Estética Natural. São Paulo, Santos Editora, 2002. 109 p.

3. AKER, D.A.; AKER, J.R.; SORENSEN, S.E. Toothbrush abrasion of colorcorrective porcelain stains applied to porcelain-fused-to-metal restorations. $\mathbf{J}$ Prosthet Dent, St. Louis, v. 44, n. 2, p. 161-163, 1980.

4. BARATH, V.S.; FABER, F.J.; WESTLAND, S.; NIEDERMEIER, W. Spectrophotometric analyses of all-ceramic materials and their interaction with luting agents and differents backgrounds. Adv Dent Res, n.17, p.55-60, 2003.

5. BARATIERI, L.N. Abordagem restauradora de dentes tratados endodonticamente. Pinos/núcleos e restaurações unitárias. In: BARATIERI, L.N.; MONTEIRO JÚNIOR, S.; ANDRADA, M.A.C.; VIEIRA, L.C.C.; RITTER, A.V.; CARDOSO, A.C. Odontologia Restauradora - Fundamentos e Possibilidades. São Paulo, Santos Editora, 2001. p. 619-672.

6. BELSUZARRI, A.L.O. Efeito das superfícies cerâmicas no desgaste dos dentes antagonistas. Tese de doutorado apresentada à Faculdade de Odontologia da Universidade de São Paulo. São Paulo, 2004. 95p.

7. BOTTINO, M. A.; FARIA, R.; BUSO, L. Sistema In-Ceram na atualidade. In: DIB, L. L.; SADDY, M. S. Atualização Clínica Em Odontologia: Estética/Prótese. São Paulo, Artes Médicas Editora, 2006. p. 411-446.

8. BRUNI, L. F.; CRUZ, A.A.V. Sentido cromático: tipos de defeitos e testes de avaliação clínica. Arq. Bras. Oftalmol, São Paulo, v. 69, n. 5, set/out. 2006.

9. BRECKER, S.C. Porcelain baked to gold. A new medium in prosthodontics. J Prosthet Dent, St. Louis, v. 6, n. 6, p. 801-810, 1956.

10. BYK-GARDNER. Color perception, light sourece, color systems and color instrumental. Disponível em: <http://www.byk-gardner.com/color.php> Acesso em: 20/01/2007. 
11. CHAIN, M. C.; RODRIGUES, C.C.; ANDRIANI, O. Estética: Dominando os desejos e controlando as expectativas. In: CARDOSO, R.J.A.; GONÇALVES, E.A.N. Estética. São Paulo: Artes Médicas Editora, 2002. p. 43-77.

12. CHO, M.S.; LEE, Y.K.; LIM, B.S.; LIM, Y.J. Changes in optical properties of enamel porcelain after repeated external staining. J Prosthet Dent, St. Louis, v. 95, n. 6, p. 437-443, 2006.

13. CLARK, E. B. Requeriments of the jacket crown. J Am Dent Assoc, Chicago, v. 26, n. 3, p. 355-363, 1939.

14. Comission Internacionale de I"Eclairage - Technical Report. CIE 15.2. Colorimetry. Áustria, Central Bureau of the CIE, 1986. p. 1-74.

15. CRISPIN, B.J.; HEWLETT, E.; SEGHI, R. Relative color stability of ceramic stains subjected to glazing temperatures. J Prosth Dent, St. Louis, v. 66, n. 1, p. 20-23, 1991.

16. CRUZ, A.J. A matéria de que é feita a cor. Os pigmentos utilizados em pintura e a sua identificação e caracterização. Comunicação realizada durante o " $1{ }^{\circ}$ Encontro de Conservação e Restauro - Tecnologias", Instituto Politécnico de Tomar, 2000.

17. DOUGLAS, R.D.; BREWER, J.D. Variability of color reproduction by commercial laboratories. J Prosth Dent, St. Louis, v. 90, n. 4, p.339-346, 2003.

18. DOZIC, A.; KLEVERLAAN, C.J.; MEEGDES, M.; VAN DER ZEL, J.; FEILZER, A.J. The influence of porcelain layer thickness on the final shade of ceramic restorations. J Prosth Dent, St. Louis, v. 90, n. 6, p.563-570, 2003.

19. ERTAN, A.A.; SAIIIN, E. Colour stability of low fusing porcelains: an in vitro study. J Oral Rehabilit, v. 32, p. 358-361, 2005.

20. ESQUIVEL, J. F.; CHAI, J.; WOSNIAK, W. Color stability of low-fusing porcelains for titanium. Int J of Prosthodont, Lombard, v. 8, n. 5, p. 479485, 1995. 
21. FELCHER, F. R. Dental Porcelains. J Am Dent Assoc, Chicago,v. 19,p. 1021-1026, 1932.

22. GOVEIA, J. C. Estudo colorimétrico da translucidez de materiais restauradores odontológicos. Dissertação de mestrado, apresentada à Faculdade de Odontologia da universidade de São Paulo. São Paulo, 2004. $110 p$.

23. HASSEL, A.J.; GROSSMANN, A.C.; SCHMITTER, M.; BALKE, Z.; BUZELLO, A.M. Interexaminer reliability in clinical measurement of $L^{*} C^{*} h^{\star}$ values of anterior teeth using a spectrophotometer. . Int J of Prosthodont, Lombard, v. 20, n. 1, p. 79-84, 2007.

24. HEFFERNAN, M.J.; AQUILINO, S.A.; DIAZ-ARNOLD, A.M.; HASELTON, D.R.; STANFORD, C.M.; VARGAS, M.A. Relative translucency of six allceramic systems. Part I: Core materials. J Prosth Dent, St. Louis, v. 88, n. 1, p.4-9, 2002 (a).

25. HEFFERNAN, M.J.; AQUILINO, S.A.; DIAZ-ARNOLD, A.M.; HASELTON, D.R.; STANFORD, C.M.; VARGAS, M.A. Relative translucency of six allceramic systems. Part II: Core and venner materials. J Prosth Dent, St. Louis, v. 88, n. 1, p.10-15, 2002 (b).

26. HEgenbARTH, E. A. Sistema Prático de Seleção de Cores em Cerâmica. São Paulo. Quintessence Editora, 1992. 109p.

27. HEYDECKE, G. ZHANG, F.; RAZZOOG, M.E. In vitro stability of doublelayer veneers after accelerated aging. J Prosthet Dent, St. Louis, v. 85, n. 6, p. 551-557, 2001.

28. HODSON, J.T. Phase composition for crown and inlay porcelains. J Dent Res, Chicago, v. 38, p. 483-489, May/June, 1959.

29. JJL TECHNOLOGIES, LLC. Vita Easyshade: The principles of use of a spectrophotometer and its application in the measurement of dental shades, 2003. 21p.

30. JOHNSTON, W.M.; KAO, E.C. Assessment of appearance match by visual observation and critical colorimetry. J Dent Res, Chicago, v. 68, p. 819-822, 1989. 
31. JONES, D. W. Ceramics in dentistry. Dent Tech, London, v. 7, n. 24, p. 6468, 1971.

32. KELLY, J.R. Dental ceramics: current thinking and trends. Dent Clin North Am, Philadelphia, v. 48, n. 2, p. 513-530, 2004.

33. KOMMA, O. Hydrotermal Dental Ceramic Systems. Technical Report. Rosbach, Germany. Ducera Dental Co. p. 44, 1993.

34. KOURTIS, S.G.; TRIPODAKIS, A.P.; DOUKOUDAKIS, A.A. Spectrophotometric evaluation of the optical influence of different metal alloys and porcelains in the metal-ceramic complex. J Prosthet Dent, St. Louis, v. 92, n. 5, p. 477-485, 2004.

35. LAND, C.H. Porcelain dental art. The Dental Cosmos, Philadelphia, v. 45, n. 6, p.437-444, May, 1903.

36. LAND, E. H. The retinex theory of color vision. Scientific American, v. 237, n. 6, p. 39-62, 1977.

37. LOPES, A.; BOM, A.L.; MONTEIRO, C.; BARBOSA, D. Glossário sobre cor e colorimetria. Departamento de consultoria da ITG. Disponível em: <http://www.itgcom.com/cor_colorimetria.html > Acesso em 19/10/2006.

38. LUND, P.S.; PIOTROWSKI, T.J. Color changes of porcelain surface colorants resulting from firing. Int J Prosthodont, Lombard, v. 5, n. 1, p. 2227, 1992.

39. MAGNE, P.; BELSER, U. Estética oral natural. In: .Restaurações Adesivas de Porcelana na Dentição Anterior: Uma Abordagem Biomimética. São Paulo, Quintessence Editora. 2003. p. 57-96.

40. MALLMAN, A. Metalocerâmica ou cerâmica pura? Jornal Angelus, Londrina, n. 02, ano 2, 2007.

41. Mc LEAN, J.M. Dental materials developments in the U.K.: a personal view. J Dent Res, Chicago, v. 75, n. 11, p. 1816-1819, Nov., 1996. 
42. Mc PHEE, E.R. Extrinsic coloration of ceramometal restorations. Dent Clin North Am, Philadelphia, v. 29, n. 4, p. 645-666, 1985.

43. MENDES, V. Seleção de cor. Princípios básicos para o sucesso em reabilitação oral. Disponível em: <http://www.dentalgaucho.com.br/htmls/biblio30.html > Acesso em $13 / 01 / 2007$.

44. MENDES, W.B.; BONFANTE, G.; BONFANTE, E.A.; CONSANI, S. Tendências atuais em prótese fixa. In: DIB, L. L.; SADDY, M. S. Atualização Clínica Em Odontologia: Estética/Prótese. São Paulo, Artes Médicas Editora, 2006. p.387-409.

45. MIYASHITA, E.; MESQUITA, A.M.M.; VASCONCELOS, D.K. Seleção de cor. In: DIB, L. L.; SADDY, M. S. Atualização Clínica Em Odontologia: Estética/Prótese. São Paulo, Artes Médicas Editora, 2006. p.510-526.

46. MOLLON, J.D. Specifying, generating and measuring colours. In: CARPENTER, R.H.S.; ROBSON, J.G. Vision Research: A Practical Guide to Laboratory Methods. New York: Oxford University Press. 1998. p. 106128.

47. MORALES, A. R. A Cor em Três Dimensões. Disponível em: $<$ http://www.cromexbrancolor.com.br/portugues/biblioteca/artigos/princip3.ht $m>$ Acesso em 20/10/2006.

48. MULLA, F.A.; WEINER, S. Effects of temperature on color stability of porcelain stains. J Prosthet Dent, St. Louis, v. 65, n. 4, p. 507-512, 1991.

49. ODMAN, P.; ANDERSSON, B. Procera Allceram crowns followed for 5 to 10.5 years: a prospective clinical study. Int J Prosthodont, Lombard, v. 14, n. 6, p. 504-509, 2001.

50. O' KEEFE, K.L.; POWERS, J.M.; NOIE, F. Effect of dissolution on color of extrinsic porcelain colorants. Int J Prosthodont, Lombard, v. 6, n.6, p. 558563, nov/dez, 1993.

51. O' KUBO, S.R.; KANAWATI, A.; RICHARDS, M.W.; CHILDRESS, S. Evaluation of visual and instrumental shade matching. J Prosthet Dent, St. Louis, v. 80, n. 6, p. 642-648, 1998. 
52. PAUL, S.J.; PETER, A.; RODONI, L.; PIETROBON, N. Convencional visual vs spectrophotometric shade taking for porcelain-fused-to-metal crowns: A clinical comparison. Int J Perio Rest Dent, v. 24, n. 3, p. 223-231, 2004.

53. PHILLIPS, R. W. Propriedades físicas dos materiais dentários. In: Materiais Dentários de Skinner. Rio de Janeiro: Ed. Interamericana. 1984. p. 20-44.

54. PORTO, L.R.S. Avaliação "in vitro" do desajuste marginal de facetas laminadas de porcelana empregando diferentes términos de preparo e sistemas cerâmicos. Dissertação de mestrado apresentada à Faculdade de Odontologia de Ribeirão Preto - Universidade de São Paulo, Ribeirão Preto, 2003.

55. RAZZOOG, M.; LANG, B.R.; RUSSEL, M.M.; MAY, K.B. A comparison of the color stability of convencional and titanium dental porcelain. $\mathbf{J}$ Prosthet Dent, St. Louis, v. 72, n. 5, p. 453-456, 1994.

56. REIS, A.C. Envelhecimento artificial acelerado de resinas compostos análise da superfície e estudo da alteração de cor por meio de colorímetro espectrofotométrico. Tese de doutorado, apresentada à Faculdade de Odontologia de Ribeirão Preto - Universidade de São Paulo, Ribeirão Preto, 2003.

57. REIS, R.; BASTOS, R.L. Pintura e caracterização extrínseca de restaurações cerâmicas: materiais, métodos, limitações e problemas atuais. R Bras Odont, v. 53, n. 4, p. 29-32, jul/ago, 1996.

58. SALESKI, C.G. Color, light and shade matching. J Prosth Dent, St. Louis, v. 27, n. 3, p.263-268, 1972.

59. SCHANDA, J. CIE colorimetry and color display. 2005. Disponível em: <http://www.knt.vein.hu> . Acesso em 14/12/2006.

60. SCHULZE, K.A.; MARSHALL, S.J.; GANSKY, S.A.; MARSHALL, G.W. Color stability and hardness in dental composites after accelerated aging. Dental Materials, v. 19, p. 612-619, 2003.

61. SEGHI, R.R.; JOHNSTON, W.M.; O'BRIEN, W.J. Performance assessment of colorimetric devices on dental porcelains. J Dent Res, Chicago, v. 68, n. 12, p. 1755-1759, 1989 (a). 
62. SEGHI, R.R.; HEWLETT, E.R.; KIM, J.Visual and instrumental colorimetric assessments of small color differences on translucent dental porcelain. $\mathbf{J}$ Dent Res, Chicago, v. 68, n. 12, p. 1760-1764, 1989 (b).

63. SHILLINGBURG JR., H.T.; HOBO, S.; WHITSETT, L.D.; JACOBI, R.; BRACKETT, S.E. Restaurações de cerâmica. In: SHILLINGBURG JR., H.T.; HOBO, S.; WHITSETT, L.D.; JACOBI, R.; BRACKETT, S.E. Fundamentos de Prótese Fixa. São Paulo: Quintessence Editora, 1998.p.353-371.

64. SHOKRY, T.E.; SHEN, C.; ELHOSARY, M.M.; ELKHODARY, A.M. Effect of core and venner thicknesses on the color parameters of two all-ceramic systems. J Prosth Dent, St. Louis, v. 95, n. 2, p. 124-129, 2006.

65. SPROULL, R.C. A history of porcelain in dentistry. Bull Hist Dent, Chicago, v. 26, n. 1, p. 3-10, Apr. 1978.

66. SPROULL, R.C. Color matching in dentistry. Part I. The three-dimensional nature of color. J Prosth Dent, St. Louis, v. 29, n. 4, p. 416-424, 1973.

67. TIDEHAG, P.; GUNNE, J. A 2 year clinical follow-up study of IPS Empress ceramic inlays. Int J of Prosthodont, Lombard, v. 8, n. 5, p. 456-460, 1995.

68. VICHI, A.; FERRARI, M.; DAVIDSON, C.L. Color opacity variations in three different resin-based composite products after water aging. Dental Materials, v. 20, p. 530-534, 2004.

69. VINES, R. F; SEMMELMAN, J. O. Densification of Dental Porcelain. J Dent Res, Chicago, v. 36, n. 6, p. 950-956, Dec. 1957.

70. WEE, A.G.; MONAGHAN, P.; JOHNSTON, W.M. Variation in color between intended matched shade and fabricated shade of dental porcelain, J Prosth Dent, St. Louis, v. 87, n. 6, p. 657-666, 2002.

71. WERNER, J.S. Aging through the eyes of Monet. In: BACKHAUS, W.G.K.; KLIEGL, R; WERNER, J.S. Color Vision: Perspectives From Different Disciplines. Berlin, 1998. p. 3-41.

72. YAMAN, P.; QAZI, S.R.; DENNISON, J.B.; RAZZOOG, M.E. Effect of adding opaque porcelain on the final coloro $f$ porcelain laminates. J Prosth Dent, St. Louis, v. 77, n. 2, p. 136-140, 1997. 


\section{APÊNDICES}


APÊNDICE A: Valores de opacidade (\%) dos corpos de prova cerâmicos antes (inicial) e depois (final) do envelhecimento artificial acelerado.

\begin{tabular}{|c|c|c|c|c|c|c|}
\hline & Glazeado & Inicial & Final & Pintado & Inicial & Final \\
\hline \multirow[t]{7}{*}{ Grupo 1} & MC 1 & 100,04 & 99,98 & MCPE 1 & 100,01 & 100,01 \\
\hline & MC 2 & 100 & 100,01 & MCPE 2 & 99,99 & 100 \\
\hline & MC 3 & 100 & 100 & MCPE 3 & 100,01 & 100 \\
\hline & MC 4 & 100 & 99,98 & MCPE 4 & 99,99 & 100 \\
\hline & MC 5 & 100,01 & 100 & MCPE 5 & 99,98 & 100,01 \\
\hline & MC 6 & 100,01 & 99,99 & MCPE 6 & 100,01 & 100 \\
\hline & MC 7 & 100,01 & 100,04 & MCPE 7 & 100 & 100 \\
\hline \multirow[t]{7}{*}{ Grupo 2} & CER 1 & 80,02 & 80,37 & CERPE 1 & 76,26 & 76,96 \\
\hline & CER 2 & 80,43 & 81,26 & CERPE 2 & 76,86 & 77,73 \\
\hline & CER 3 & 77,5 & 78,28 & CERPE 3 & 82,24 & 83,11 \\
\hline & CER 4 & 75,97 & 78,13 & CERPE 4 & 76,68 & 79,28 \\
\hline & CER 5 & 76,46 & 77,58 & CERPE 5 & 80,19 & 81,81 \\
\hline & CER 6 & 77,1 & 77,73 & CERPE 6 & 76,75 & 76,8 \\
\hline & CER 7 & 81,48 & 81,94 & CERPE 7 & 77,22 & 77,73 \\
\hline \multirow[t]{7}{*}{ Grupo 3} & EX 1 & 71,72 & 72,11 & EXPE 1 & 73,01 & 73,77 \\
\hline & EX 2 & 72,12 & 72,49 & EXPE 2 & 73,42 & 73,59 \\
\hline & EX 3 & 70,45 & 71,19 & EXPE 3 & 71,23 & 71,91 \\
\hline & EX 4 & 71,16 & 71,81 & EXPE 4 & 72,07 & 73,87 \\
\hline & EX 5 & 70,6 & 71,67 & EXPE 5 & 73,9 & 74,14 \\
\hline & EX 6 & 71,23 & 72,16 & EXPE 6 & 71,53 & 72,07 \\
\hline & EX 7 & 75,41 & 75,93 & EXPE 7 & 70,98 & 71,47 \\
\hline \multirow[t]{7}{*}{ Grupo 4} & VTAL 1 & 99,26 & 99,97 & VTALPE1 & 99,93 & 100,01 \\
\hline & VTAL 2 & 99,74 & 100 & VTALPE2 & 99,98 & 100 \\
\hline & VTAL 3 & 99,73 & 99,99 & VTALPE3 & 100 & 100 \\
\hline & VTAL 4 & 99,78 & 99,96 & VTALPE4 & 99,99 & 100 \\
\hline & VTAL 5 & 99,44 & 100,03 & VTALPE5 & 99,99 & 100 \\
\hline & VTAL 6 & 99,36 & 100,01 & VTALPE6 & 99,92 & 100 \\
\hline & VTAL 7 & 99,02 & 99,99 & VTALPE7 & 99,95 & 100 \\
\hline \multirow[t]{7}{*}{ Grupo 5} & VTCE 1 & 99,88 & 99,96 & VTCEPE1 & 99,9 & 99,93 \\
\hline & VTCE 2 & 99,93 & 99,97 & VTCEPE2 & 99,86 & 99,98 \\
\hline & VTCE 3 & 99,97 & 100 & VTCEPE3 & 99,95 & 99,81 \\
\hline & VTCE 4 & 99,99 & 99,99 & VTCEPE4 & 99,95 & 99,99 \\
\hline & VTCE 5 & 99,97 & 99,97 & VTCEPE5 & 99,87 & 99,98 \\
\hline & VTCE 6 & 99,94 & 99,96 & VTCEPE6 & 99,98 & 100,06 \\
\hline & VTCE 7 & 100 & 100 & VTCEPE7 & 99,89 & 99,97 \\
\hline
\end{tabular}


APÊNDICE B: Valores da coordenada $L^{*}$ (aparelho BYK-Gardner) dos corpos de prova cerâmicos antes (inicial) e depois (final) do envelhecimento artificial acelerado.

\begin{tabular}{|c|c|c|c|c|c|c|c|c|}
\hline & Glazeado & L inicial & L Final & $\Delta \mathbf{L}$ & Pintado & L inicial & L Final & $\Delta \mathbf{L}$ \\
\hline \multirow[t]{7}{*}{ Grupo 1} & MC 1 & 66,79 & 66,51 & $-0,27$ & MCPE 1 & 67,95 & 67,52 & $-0,43$ \\
\hline & MC 2 & 68,49 & 68,28 & $-0,21$ & MCPE 2 & 68,12 & 67,69 & $-0,43$ \\
\hline & MC 3 & 70,22 & 69,69 & $-0,52$ & MCPE 3 & 66,58 & 66,12 & $-0,45$ \\
\hline & MC 4 & 69,55 & 69,22 & $-0,33$ & MCPE 4 & 68,07 & 67,25 & $-0,82$ \\
\hline & MC 5 & 70,28 & 69,85 & $-0,43$ & MCPE 5 & 66,67 & 66,34 & $-0,33$ \\
\hline & MC 6 & 70,56 & 70,04 & $-0,51$ & MCPE 6 & 68,94 & 68,62 & $-0,32$ \\
\hline & MC 7 & 68,64 & 68,15 & $-0,48$ & MCPE 7 & 67,12 & 66,79 & $-0,33$ \\
\hline \multirow[t]{7}{*}{ Grupo 2} & CER 1 & 71,30 & 70,77 & $-0,53$ & CERPE 1 & 69,17 & 69,09 & $-0,07$ \\
\hline & CER 2 & 72,43 & 71,65 & $-0,78$ & CERPE 2 & 69,20 & 68,74 & $-0,46$ \\
\hline & CER 3 & 71,27 & 70,63 & $-0,63$ & CERPE 3 & 69,07 & 68,98 & $-0,09$ \\
\hline & CER 4 & 71,69 & 71,33 & $-0,36$ & CERPE 4 & 69,00 & 68,76 & $-0,24$ \\
\hline & CER 5 & 71,96 & 71,67 & $-0,29$ & CERPE 5 & 69,20 & 68,89 & $-0,31$ \\
\hline & CER 6 & 71,73 & 71,27 & $-0,45$ & CERPE 6 & 69,20 & 68,84 & $-0,36$ \\
\hline & CER 7 & 71,65 & 71,08 & $-0,57$ & CERPE 7 & 69,30 & 68,98 & $-0,32$ \\
\hline \multirow[t]{7}{*}{ Grupo 3} & EX 1 & 70,32 & 70,09 & $-0,22$ & EXPE 1 & 68,51 & 68,18 & $-0,32$ \\
\hline & EX 2 & 69,93 & 69,53 & $-0,39$ & EXPE 2 & 68,64 & 68,43 & $-0,21$ \\
\hline & EX 3 & 69,93 & 69,66 & $-0,26$ & EXPE 3 & 68,48 & 68,09 & $-0,38$ \\
\hline & EX 4 & 70,70 & 70,06 & $-0,64$ & EXPE 4 & 68,39 & 67,95 & $-0,44$ \\
\hline & EX 5 & 70,60 & 69,9 & $-0,69$ & EXPE 5 & 68,46 & 68,04 & $-0,42$ \\
\hline & EX 6 & 70,55 & 70,19 & $-0,36$ & EXPE 6 & 68,56 & 68,02 & $-0,54$ \\
\hline & EX 7 & 69,02 & 68,45 & $-0,57$ & EXPE 7 & 68,52 & 68,35 & $-0,17$ \\
\hline \multirow[t]{7}{*}{ Grupo 4} & VTAL 1 & 71,48 & 71,07 & $-0,41$ & VTALPE1 & 70,71 & 69,91 & $-0,79$ \\
\hline & VTAL 2 & 71,99 & 71,45 & $-0,54$ & VTALPE2 & 69,03 & 68,51 & $-0,52$ \\
\hline & VTAL 3 & 70,91 & 70,05 & $-0,85$ & VTALPE3 & 70,32 & 69,49 & $-0,83$ \\
\hline & VTAL 4 & 71,57 & 71,18 & $-0,39$ & VTALPE4 & 69,40 & 68,61 & $-0,79$ \\
\hline & VTAL 5 & 71,70 & 71,29 & $-0,41$ & VTALPE5 & 69,54 & 68,82 & $-0,72$ \\
\hline & VTAL 6 & 72,07 & 71,75 & $-0,32$ & VTALPE6 & 69,89 & 69,21 & $-0,68$ \\
\hline & VTAL 7 & 71,60 & 70,96 & $-0,64$ & VTALPE7 & 70,09 & 69,57 & $-0,52$ \\
\hline \multirow[t]{7}{*}{ Grupo 5} & VTCE 1 & 69,29 & 67,87 & $-1,42$ & VTCEPE1 & 68,72 & 67,4 & $-1,31$ \\
\hline & VTCE 2 & 69,42 & 68,17 & $-1,25$ & VTCEPE2 & 67,58 & 66,25 & $-1,32$ \\
\hline & VTCE 3 & 68,70 & 67,38 & $-1,31$ & VTCEPE3 & 68,19 & 66,93 & $-1,25$ \\
\hline & VTCE 4 & 69,30 & 67,86 & $-1,44$ & VTCEPE4 & 68,41 & 67,25 & $-1,16$ \\
\hline & VTCE 5 & 69,34 & 68,13 & $-1,21$ & VTCEPE5 & 67,86 & 66,48 & $-1,38$ \\
\hline & VTCE 6 & 69,39 & 68,05 & $-1,34$ & VTCEPE6 & 68,33 & 66,98 & $-1,35$ \\
\hline & VTCE 7 & 68,58 & 67,25 & $-1,33$ & VTCEPE7 & 68,59 & 67,11 & $-1,48$ \\
\hline
\end{tabular}


APÊNDICE C: Valores da coordenada $a^{*}$ (aparelho BYK-Gardner) dos corpos de prova cerâmicos antes (inicial) e depois (final) do envelhecimento artificial acelerado.

\begin{tabular}{|c|c|c|c|c|c|c|c|c|}
\hline & Glazeado & $a^{*}$ inicial & $a^{*}$ final & $\Delta \mathbf{a}^{*}$ & Pintado & $a^{*}$ inicial & $a^{*}$ final & $\Delta \mathbf{a}^{*}$ \\
\hline \multirow[t]{7}{*}{ Grupo 1} & MC 1 & 2,92 & 2,71 & $-0,21$ & MCPE 1 & 3,11 & 3,05 & $-0,05$ \\
\hline & MC 2 & 2,51 & 2,52 & 0,01 & MCPE 2 & 3,35 & 3,3 & $-0,05$ \\
\hline & MC 3 & 3,18 & 3,1 & $-0,07$ & MCPE 3 & 3,06 & 2,94 & $-0,11$ \\
\hline & MC 4 & 2,13 & 2,09 & $-0,03$ & MCPE 4 & 3,18 & 3,14 & $-0,04$ \\
\hline & MC 5 & 2,23 & 2,09 & $-0,13$ & MCPE 5 & 3,07 & 2,89 & $-0,18$ \\
\hline & MC 6 & 2,80 & 2,74 & $-0,06$ & MCPE 6 & 3,06 & 2,93 & $-0,13$ \\
\hline & MC 7 & 2,68 & 2,61 & $-0,07$ & MCPE 7 & 3,32 & 3,3 & $-0,02$ \\
\hline \multirow[t]{7}{*}{ Grupo 2} & CER 1 & 2,91 & 3,43 & 0,52 & CERPE 1 & 4,54 & 4,73 & 0,19 \\
\hline & CER 2 & 2,38 & 2,64 & 0,26 & CERPE 2 & 4,53 & 4,78 & 0,25 \\
\hline & CER 3 & 2,67 & 2,92 & 0,24 & CERPE 3 & 4,01 & 4,13 & 0,12 \\
\hline & CER 4 & 1,68 & 1,95 & 0,27 & CERPE 4 & 4,39 & 4,6 & 0,21 \\
\hline & CER 5 & 2,34 & 2,4 & 0,05 & CERPE 5 & 3,93 & 4,21 & 0,28 \\
\hline & CER 6 & 2,65 & 2,99 & 0,33 & CERPE 6 & 4,52 & 4,86 & 0,34 \\
\hline & CER 7 & 2,58 & 2,87 & 0,28 & CERPE 7 & 4,28 & 4,37 & 0,09 \\
\hline \multirow[t]{7}{*}{ Grupo 3} & EX 1 & 3,76 & 3,96 & 0,19 & EXPE 1 & 5,02 & 5,17 & 0,15 \\
\hline & EX 2 & 3,85 & 3,96 & 0,11 & EXPE 2 & 4,95 & 5,19 & 0,24 \\
\hline & EX 3 & 3,63 & 3,81 & 0,17 & EXPE 3 & 5,28 & 5,37 & 0,09 \\
\hline & EX 4 & 3,66 & 3,9 & 0,23 & EXPE 4 & 5,00 & 5,28 & 0,28 \\
\hline & EX 5 & 3,66 & 3,81 & 0,15 & EXPE 5 & 4,83 & 5,1 & 0,27 \\
\hline & EX 6 & 3,69 & 3,82 & 0,13 & EXPE 6 & 4,90 & 5,09 & 0,19 \\
\hline & EX 7 & 4,04 & 4,23 & 0,18 & EXPE 7 & 5,12 & 5,35 & 0,23 \\
\hline \multirow[t]{7}{*}{ Grupo 4} & VTAL 1 & 3,92 & 3,97 & 0,05 & VTALPE1 & 5,25 & 5,35 & 0,09 \\
\hline & VTAL 2 & 3,74 & 3,72 & $-0,01$ & VTALPE2 & 5,29 & 5,37 & 0,08 \\
\hline & VTAL 3 & 3,49 & 3,45 & $-0,03$ & VTALPE3 & 5,39 & 5,59 & 0,20 \\
\hline & VTAL 4 & 3,97 & 3,99 & 0,02 & VTALPE4 & 5,40 & 5,58 & 0,18 \\
\hline & VTAL 5 & 3,62 & 3,6 & $-0,02$ & VTALPE5 & 5,30 & 5,44 & 0,14 \\
\hline & VTAL 6 & 3,70 & 3,69 & $-0,01$ & VTALPE6 & 5,34 & 5,39 & 0,05 \\
\hline & VTAL 7 & 3,72 & 3,73 & 0,01 & VTALPE7 & 5,27 & 5,45 & 0,18 \\
\hline \multirow[t]{7}{*}{ Grupo 5} & VTCE 1 & 3,47 & 3,59 & 0,12 & VTCEPE1 & 4,40 & 4,54 & 0,13 \\
\hline & VTCE 2 & 2,88 & 2,94 & 0,06 & VTCEPE2 & 5,10 & 5,41 & 0,31 \\
\hline & VTCE 3 & 3,21 & 3,29 & 0,08 & VTCEPE3 & 4,43 & 4,75 & 0,31 \\
\hline & VTCE 4 & 3,26 & 3,29 & 0,03 & VTCEPE4 & 4,63 & 4,98 & 0,35 \\
\hline & VTCE 5 & 3,43 & 3,53 & 0,10 & VTCEPE5 & 5,02 & 5,34 & 0,32 \\
\hline & VTCE 6 & 3,22 & 3,32 & 0,10 & VTCEPE6 & 4,27 & 4,58 & 0,31 \\
\hline & VTCE 7 & 3,36 & 3,47 & 0,11 & VTCEPE7 & 3,52 & 3,67 & 0,15 \\
\hline
\end{tabular}


APÊNDICE D: Valores da coordenada $b^{*}$ (aparelho BYK-Gardner) dos corpos de prova cerâmicos antes (inicial) e depois (final) do envelhecimento artificial acelerado.

\begin{tabular}{|c|c|c|c|c|c|c|c|c|}
\hline \multirow{2}{*}{ Grupo 1} & \multirow{2}{*}{$\begin{array}{l}\text { Glazeado } \\
\text { MC } 1\end{array}$} & \multicolumn{2}{|c|}{$b^{*}$ inicial $b^{*}$ final } & \multirow{2}{*}{$\begin{array}{l}\Delta \mathbf{b}^{*} \\
-0,48\end{array}$} & \multirow{2}{*}{$\begin{array}{l}\text { Pintado } \\
\text { MCPE } 1\end{array}$} & \multicolumn{2}{|c|}{$b^{*}$ inicial $b^{*}$ final } & \multirow{2}{*}{$\begin{array}{l}\Delta \mathbf{b}^{*} \\
-0,07\end{array}$} \\
\hline & & 17,44 & 16,95 & & & 16,23 & 16,16 & \\
\hline & MC 2 & 14,90 & 14,59 & $-0,3$ & MCPE 2 & 16,38 & 16,35 & $-0,02$ \\
\hline & MC 3 & 17,23 & 17,22 & 0 & MCPE 3 & 15,87 & 15,62 & $-0,25$ \\
\hline & MC 4 & 10,84 & 10,64 & $-0,19$ & MCPE 4 & 16,39 & 16,22 & $-0,17$ \\
\hline & MC 5 & 13,14 & 13 & $-0,14$ & MCPE 5 & 15,89 & 15,72 & $-0,17$ \\
\hline & MC 6 & 11,39 & 11,4 & 0 & MCPE 6 & 16,08 & 15,99 & $-0,09$ \\
\hline & MC 7 & 12,71 & 12,71 & 0 & MCPE 7 & 16,05 & 16,04 & $-0,01$ \\
\hline \multirow[t]{7}{*}{ Grupo 2} & CER 1 & 18,78 & 18,93 & 0,14 & CERPE 1 & 24,63 & 24,78 & 0,15 \\
\hline & CER 2 & 17,99 & 18,04 & 0,05 & CERPE 2 & 25,81 & 25,38 & $-0,43$ \\
\hline & CER 3 & 19,14 & 18,72 & $-0,42$ & CERPE 3 & 21,86 & 21,56 & $-0,29$ \\
\hline & CER 4 & 16,53 & 16,21 & $-0,32$ & CERPE 4 & 24,25 & 24,07 & $-0,18$ \\
\hline & CER 5 & 19,15 & 18,87 & $-0,28$ & CERPE 5 & 24,02 & 23,86 & $-0,16$ \\
\hline & CER 6 & 20,26 & 20,08 & $-0,17$ & CERPE 6 & 25,39 & 25,49 & 0,10 \\
\hline & CER 7 & 17,93 & 17,44 & $-0,49$ & CERPE 7 & 23,40 & 23,07 & $-0,33$ \\
\hline \multirow[t]{7}{*}{ Grupo 3} & EX 1 & 21,30 & 21,72 & 0,42 & EXPE 1 & 24,09 & 24,13 & 0,04 \\
\hline & EX 2 & 21,47 & 21,53 & 0,06 & EXPE 2 & 24,17 & 24,26 & 0,09 \\
\hline & EX 3 & 18,66 & 18,93 & 0,27 & EXPE 3 & 24,54 & 24,42 & $-0,11$ \\
\hline & EX 4 & 21,28 & 21,32 & 0,03 & EXPE 4 & 24,14 & 24,3 & 0,16 \\
\hline & EX 5 & 20,09 & 20,03 & $-0,05$ & EXPE 5 & 24,14 & 24,24 & 0,10 \\
\hline & EX 6 & 20,17 & 20,29 & 0,12 & EXPE 6 & 24,28 & 24,26 & $-0,02$ \\
\hline & EX 7 & 19,15 & 19,16 & 0 & EXPE 7 & 24,07 & 24,18 & 0,11 \\
\hline \multirow[t]{7}{*}{ Grupo 4} & VTAL 1 & 19,20 & 18,77 & $-0,43$ & VTALPE1 & 22,05 & 21,56 & $-0,48$ \\
\hline & VTAL 2 & 16,46 & 16,31 & $-0,14$ & VTALPE2 & 22,75 & 22,86 & 0,11 \\
\hline & VTAL 3 & 16,74 & 16,36 & $-0,38$ & VTALPE3 & 22,91 & 22,59 & $-0,31$ \\
\hline & VTAL 4 & 16,70 & 15,89 & $-0,81$ & VTALPE4 & 22,34 & 22,23 & $-0,11$ \\
\hline & VTAL 5 & 17,48 & 17,28 & $-0,20$ & VTALPE5 & 22,19 & 22,44 & 0,25 \\
\hline & VTAL 6 & 18,40 & 18,26 & $-0,14$ & VTALPE6 & 22,91 & 22,52 & $-0,39$ \\
\hline & VTAL 7 & 18,51 & 18,25 & $-0,26$ & VTALPE7 & 23,49 & 22,93 & $-0,56$ \\
\hline \multirow[t]{7}{*}{ Grupo 5} & VTCE 1 & 17,00 & 20,16 & 3,16 & VTCEPE1 & 20,70 & 23,13 & 2,43 \\
\hline & VTCE 2 & 16,86 & 20 & 3,14 & VTCEPE2 & 24,12 & 26,1 & 1,97 \\
\hline & VTCE 3 & 16,48 & 19,6 & 3,12 & VTCEPE3 & 21,88 & 24,16 & 2,27 \\
\hline & VTCE 4 & 16,98 & 19,7 & 2,72 & VTCEPE4 & 21,44 & 24,08 & 2,64 \\
\hline & VTCE 5 & 17,20 & 19,85 & 2,65 & VTCEPE5 & 22,17 & 24,36 & 2,19 \\
\hline & VTCE 6 & 16,66 & 19,57 & 2,91 & VTCEPE6 & 22,93 & 25,47 & 2,54 \\
\hline & VTCE 7 & 16,71 & 20,3 & 3,59 & VTCEPE7 & 23,10 & 25,23 & 2,13 \\
\hline
\end{tabular}


APÊNDICE E: Valores de $\Delta \mathrm{E}^{*}$ dos corpos de prova cerâmicos (aparelho BYKGardner).

\begin{tabular}{|c|c|c|c|c|}
\hline & Glazeado & $\Delta \mathrm{E}^{*}$ & Pintado & $\Delta \mathrm{E}^{*}$ \\
\hline \multirow{7}{*}{ Grupo 1} & MC 1 & 0,58 & MCPE 1 & 0,43 \\
\hline & MC 2 & 0,36 & MCPE 2 & 0,43 \\
\hline & MC 3 & 0,52 & MCPE 3 & 0,52 \\
\hline & MC 4 & 0,38 & MCPE 4 & 0,83 \\
\hline & MC 5 & 0,47 & MCPE 5 & 0,41 \\
\hline & MC 6 & 0,51 & MCPE 6 & 0,35 \\
\hline & MC 7 & 0,48 & MCPE 7 & 0,33 \\
\hline \multirow[t]{7}{*}{ Grupo 2} & CER 1 & 0,75 & CERPE 1 & 0,25 \\
\hline & CER 2 & 0,82 & CERPE 2 & 0,67 \\
\hline & CER 3 & 0,79 & CERPE 3 & 0,32 \\
\hline & CER 4 & 0,55 & CERPE 4 & 0,36 \\
\hline & CER 5 & 0,4 & CERPE 5 & 0,44 \\
\hline & CER 6 & 0,58 & CERPE 6 & 0,5 \\
\hline & CER 7 & 0,8 & CERPE 7 & 0,46 \\
\hline \multirow[t]{7}{*}{ Grupo 3} & EX 1 & 0,51 & EXPE 1 & 0,35 \\
\hline & EX 2 & 0,4 & EXPE 2 & 0,33 \\
\hline & EX 3 & 0,41 & EXPE 3 & 0,4 \\
\hline & EX 4 & 0,68 & EXPE 4 & 0,54 \\
\hline & EX 5 & 0,7 & EXPE 5 & 0,5 \\
\hline & EX 6 & 0,4 & EXPE 6 & 0,57 \\
\hline & EX 7 & 0,59 & EXPE 7 & 0,3 \\
\hline \multirow[t]{7}{*}{ Grupo 4} & VTAL 1 & 0,59 & VTALPE1 & 0,92 \\
\hline & VTAL 2 & 0,55 & VTALPE2 & 0,53 \\
\hline & VTAL 3 & 0,93 & VTALPE3 & 0,9 \\
\hline & VTAL 4 & 0,89 & VTALPE4 & 0,81 \\
\hline & VTAL 5 & 0,45 & VTALPE5 & 0,77 \\
\hline & VTAL 6 & 0,34 & VTALPE6 & 0,78 \\
\hline & VTAL 7 & 0,69 & VTALPE7 & 0,78 \\
\hline \multirow[t]{7}{*}{ Grupo 5} & VTCE 1 & 3,46 & VTCEPE1 & 2,76 \\
\hline & VTCE 2 & 3,38 & VTCEPE2 & 2,39 \\
\hline & VTCE 3 & 3,38 & VTCEPE3 & 2,6 \\
\hline & VTCE 4 & 3,07 & VTCEPE4 & 2,9 \\
\hline & VTCE 5 & 2,9 & VTCEPE5 & 2,6 \\
\hline & VTCE 6 & 3,2 & VTCEPE6 & 2,89 \\
\hline & VTCE 7 & 3,83 & VTCEPE7 & 2,59 \\
\hline
\end{tabular}


APENNDICE F: Valores de $\Delta \mathrm{L}^{*}, \Delta \mathrm{C}^{*}, \Delta \mathrm{h}^{*}$ e $\Delta \mathrm{E}^{*}$ (aparelho Easyshade) dos corpos de prova cerâmicos antes (inicial) e depois (final) do envelhecimento artificial acelerado.

\begin{tabular}{|c|c|c|c|c|c|c|c|c|c|c|c|c|c|c|c|c|}
\hline \multicolumn{9}{|c|}{ Amostras Glazeadas } & \multicolumn{8}{|c|}{ Amostras Pintadas } \\
\hline & \multicolumn{2}{|l|}{$\Delta \mathrm{L}^{*}$} & \multicolumn{2}{|c|}{$\Delta \mathrm{C}^{*}$} & \multicolumn{2}{|c|}{$\Delta \mathrm{h}^{*}$} & \multicolumn{2}{|l|}{$\Delta \mathrm{E}^{*}$} & \multicolumn{2}{|l|}{$\Delta \mathrm{L}^{*}$} & \multicolumn{2}{|c|}{$\Delta \mathrm{C}^{*}$} & \multicolumn{2}{|c|}{$\Delta \mathrm{h}^{*}$} & \multicolumn{2}{|l|}{$\Delta \mathrm{E}^{*}$} \\
\hline & inicial & Final & Inicial & Final & Inicial & Final & Inicial & Final & inicial & Final & Inicial & Final & Inicial & Final & Inicial & Final \\
\hline \multirow[t]{7}{*}{ Grupo 1} & 3,1 & 2,8 & $-6,4$ & $-6,1$ & 2,8 & 1,6 & 7,2 & 6,6 & 5 & 4,5 & $-5,7$ & $-6,3$ & 0,1 & 1 & 7,6 & 7,7 \\
\hline & 5,8 & 5,3 & $-7,2$ & $-7,3$ & 2,9 & 3,4 & 9,3 & 9,1 & 5,8 & 4,3 & $-5,7$ & $-5,5$ & 0,3 & $-0,1$ & 8 & 7 \\
\hline & 5,8 & 5,2 & $-4,1$ & $-4,6$ & 0 & 0,6 & 7,1 & 6,8 & 5,5 & 2,8 & $-2,6$ & $-6,9$ & $-1,3$ & 1,8 & 6,2 & 7,4 \\
\hline & 6,4 & 5,6 & -11 & $-10,6$ & 2,6 & 3,1 & 12,7 & 12 & 5,1 & 4,5 & $-4,9$ & $-6,8$ & 0,5 & $-0,2$ & 7 & 8,1 \\
\hline & 6,3 & 5,3 & $-8,5$ & $-8,3$ & 2,8 & 3,5 & 10,6 & 9,9 & 5,4 & 3,8 & $-5,1$ & $-6,2$ & 1,1 & 1,2 & 7,5 & 7,3 \\
\hline & 6,6 & 5,9 & $-10,7$ & $-10,4$ & $-0,2$ & 0,9 & 12,6 & 12 & 4,8 & 4,2 & $-5,5$ & $-6,1$ & $-1,2$ & 0,9 & 7,3 & 7,4 \\
\hline & 5,5 & 4,8 & $-8,9$ & $-9,2$ & 0,1 & 1,4 & 10,4 & 10,4 & 5,5 & 4,1 & $-5,4$ & $-6,5$ & 1,2 & 1,4 & 7,8 & 7,8 \\
\hline \multirow[t]{7}{*}{ Grupo 2} & 4,2 & 3,8 & $-7,2$ & $-6,5$ & 2,4 & 1,3 & 8,4 & 7,6 & 2,6 & 2,8 & $-3,7$ & $-2,8$ & $-0,2$ & $-0,5$ & 4,5 & 3,9 \\
\hline & 4,3 & 4 & $-8,2$ & $-8,1$ & 3,2 & 3,2 & 9,3 & 9,1 & 3,4 & 3,1 & $-2,7$ & $-2,3$ & 0 & $-0,4$ & 4,3 & 3,9 \\
\hline & 3,7 & 3,5 & $-7,4$ & $-7,6$ & 2,7 & 2,9 & 8,3 & 8,4 & 1,6 & 1,4 & $-5,3$ & $-5,2$ & 0,2 & 0 & 5,5 & 5,4 \\
\hline & 3,7 & 3,4 & $-12,5$ & $-11,8$ & 7 & 6,4 & 13,1 & 12,4 & 3,5 & 3,1 & $-4,8$ & $-5,4$ & 0,1 & 0,3 & 5,9 & 6,2 \\
\hline & 5,2 & 5 & $-7,7$ & $-7,4$ & 3,8 & 3,5 & 9,4 & 9 & 2,8 & 3 & $-3,5$ & $-2,1$ & $-0,4$ & $-0,3$ & 4,5 & 3,6 \\
\hline & 5 & 5 & $-6,1$ & $-5,1$ & 2,7 & 2 & 9,2 & 7,2 & 3,4 & 3,1 & $-3,1$ & $-3,4$ & $-0,2$ & $-0,2$ & 4,6 & 4,6 \\
\hline & 4,1 & 3,9 & $-8,2$ & $-7,7$ & 2,7 & 2,1 & 9,2 & 8,7 & 2,6 & 2,4 & $-5,1$ & $-2,8$ & $-0,3$ & $-0,4$ & 5,7 & 3,7 \\
\hline \multirow[t]{7}{*}{ Grupo 3} & 3,4 & 3,5 & $-5,4$ & $-4,6$ & $-1,5$ & $-1,3$ & 6,3 & 5,8 & 1,9 & 2 & $-4,2$ & -4 & -3 & $-2,8$ & 4,7 & 4,6 \\
\hline & 2,8 & 3,1 & $-5,6$ & -5 & $-1,6$ & $-1,4$ & 6,3 & 5,9 & 1,8 & 2 & -4 & $-3,3$ & $-2,6$ & $-2,8$ & 4,4 & 3,9 \\
\hline & 1,9 & 2 & $-8,4$ & $-7,9$ & $-2,5$ & $-2,3$ & 8,7 & 8,2 & 2 & 1,7 & $-4,4$ & $-2,8$ & -3 & $-3,6$ & 4,9 & 3,5 \\
\hline & 3,3 & 3,3 & $-6,3$ & $-5,5$ & $-1,8$ & $-1,7$ & 7,1 & 6,4 & 2,4 & 2,1 & $-3,8$ & $-3,1$ & $-3,4$ & $-2,8$ & 5,6 & 4,6 \\
\hline & 3,6 & 3,6 & $-6,7$ & $-6,9$ & $-1,5$ & $-1,3$ & 7,6 & 7,2 & 1,9 & 2 & $-4,1$ & -4 & $-2,9$ & $-2,9$ & 5,3 & 5,3 \\
\hline & 3,1 & 3,3 & $-7,2$ & -7 & $-2,2$ & $-1,7$ & 7,8 & 7,8 & 1,7 & 2,1 & $-3,9$ & $-3,2$ & $-3,1$ & $-2,8$ & 5,2 & 4,7 \\
\hline & 1,8 & 1,6 & $-7,3$ & $-6,7$ & $-2,5$ & $-2,7$ & 7,5 & 6,9 & 1,9 & 1,8 & $-4,2$ & $-3,4$ & $-2,6$ & $-2,9$ & 5,3 & 4,8 \\
\hline \multirow[t]{7}{*}{ Grupo 4} & 8,3 & 6,5 & $-3,5$ & $-4,8$ & 0,1 & 0,8 & 9 & 8,1 & 6,8 & 4,8 & $-1,6$ & $-2,3$ & $-3,3$ & $-2,5$ & 7,1 & 5,4 \\
\hline & 9,5 & 5,8 & $-0,5$ & $-5,5$ & $-1,7$ & 0,8 & 9,6 & 8 & 5,2 & 3,3 & 0,2 & $-1,7$ & $-3,5$ & $-2,5$ & 5,3 & 3,8 \\
\hline & 7,8 & 5,4 & $-6,6$ & $-7,4$ & 0,9 & 2 & 10,2 & 9,2 & 7,3 & 3,3 & 5,3 & $-3,2$ & $-5,5$ & $-2,2$ & 9,3 & 4,6 \\
\hline & 8,5 & 5,1 & $-5,8$ & $-4,5$ & -2 & $-0,3$ & 10,5 & 6,8 & 4,2 & 3,5 & 4,9 & $-3,5$ & $-4,5$ & -2 & 7,7 & 5,3 \\
\hline & 7,8 & 5,6 & $-6,1$ & -5 & 0,8 & $-1,6$ & 9,9 & 7,6 & 6,7 & 4 & $-3,1$ & $-2,9$ & $-3,1$ & $-1,9$ & 8 & 5,2 \\
\hline & 8,1 & 5,4 & $-5,9$ & $-4,0$ & $-2,1$ & $-3,2$ & 10,2 & 7,9 & 8,8 & 2,1 & -5 & $-3,2$ & $-2,9$ & -3 & 10,1 & 4,8 \\
\hline & 7,9 & 5,4 & $-4,8$ & $-4,5$ & 1 & 0,2 & 9,2 & 7 & 6,1 & 3,9 & $-3,3$ & $-4,1$ & $-3,4$ & $-1,2$ & 7,7 & 5,6 \\
\hline \multirow[t]{7}{*}{ Grupo 5} & 5,4 & 3,7 & $-6,5$ & $-3,8$ & $-0,8$ & $-0,1$ & 8,4 & 5,3 & 7,9 & 4,6 & $-1,5$ & $-1,2$ & $-2,3$ & -1 & 8,1 & 4,8 \\
\hline & 8,6 & 4,6 & $-2,1$ & $-3,2$ & $-0,7$ & 2,3 & 8,8 & 5,6 & 3,8 & 2,3 & 0,9 & 2,8 & $-2,8$ & $-2,1$ & 4 & 3 \\
\hline & 5 & 3,5 & -6 & $-2,7$ & $-0,7$ & $-0,4$ & 7,8 & 4,4 & 5,1 & 3,4 & -2 & $-0,2$ & $-1,7$ & $-1,1$ & 5,5 & 3,5 \\
\hline & 6,5 & 2,1 & $-4,8$ & $-3,6$ & $-1,2$ & $-0,8$ & 8,1 & 4,2 & 4,3 & 2,4 & $-1,3$ & $-0,1$ & -2 & -1 & 4,9 & 2,6 \\
\hline & 8,1 & 4,5 & $-6,1$ & $-4,1$ & $-0,9$ & $-0,1$ & 10,1 & 6,1 & 5,2 & 3,1 & $-0,9$ & $-3,1$ & $-1,9$ & $-0,9$ & 5,6 & 4,4 \\
\hline & 5,9 & 2,3 & $-4,5$ & $-2,9$ & $-1,5$ & 2,1 & 7,5 & 4,2 & 4,2 & 2,4 & 1,3 & -2 & $-2,4$ & $-1,2$ & 5 & 3,3 \\
\hline & 7,1 & 2,9 & $-5,1$ & $-4,1$ & $-0,2$ & 1,9 & 8,7 & 5,3 & 7,4 & 4,5 & $-2,1$ & 1,2 & $-3,1$ & -1 & 8,2 & 4,7 \\
\hline
\end{tabular}

